\begin{tabular}{|c|c|c|}
\hline Beitr. Ent. & Keltern & ISSN $0005-805 \mathrm{X}$ \\
\hline $\mathbf{5 4}(2004) 2$ & S. $267-331$ & 20.12 .2004 \\
\hline
\end{tabular}

\title{
The fauna of sciarid flies from the Dominican Republic
}

\section{(Diptera, Sciaridae)}

With 45 figures

Werner Mohrig, Frank Röschmann and Bjoern Rulik

\begin{abstract}
Summary
This report is the first comprehensive study on sciarids within the Caribbean fauna, which includes 50 species belonging to 11 genera, 44 of them new to science. Forty five species were collected in the Dominican Republic, five in Puerto Rico. The species belong to the following genera: Leptosciarella (2), Pseudosciara (4, two of them previously known), Chaetosciara (1), Cratyna (1), Hyperlasion (2, one of them previously known), Pseudolycoriella (13), Bradysia (16, one of them previously known), Scatopsciara (5), Corynoptera (2), Keilbachia (1) and Epidapus (3, one of them previously known).

Assessing the Caribbean fauna is handicapped by lack of information on sciarids from neighboring mainland's, especially Florida and South America. Nevertheless, due to thorough knowledge of the sciarid fauna of the Palaearctic Region and partial knowledge of that of the Nearctic Region and Central America, we can say that Caribbean sciarids show great similarities to Holarctic faunistic elements. This is particularly true for Leptosciarella, Chaetosciara, Keilbachia, Scatopsciara, most species of Bradysia, Corynoptera and Epidapus, and at least partly also for Pseudolycoriella. The only endemic Neotropical genus is Pseudosciara with four described species, and the two species of the Bradysia pararufescens group.
\end{abstract}

\section{Zusammenfassung}

Die vorliegende Publikation ist die erste vergleichende Studic über die Trauermücken der Karibik. Sie umfaßt 50 Arten aus 11 Gattungen, von denen 44 Arten Neubeschreibungen darstellen. 45 Arten wurden in der Dominikanischen Republik nachgewiesen, 5 Arten in Puerto Rico. Die Arten gehören zu folgenden Gattungen: Leptosciarella (2), Pseudosciara (4, davon 2 beschrieben), Chatosciara (1), Cratyna (1), Hyperlasion (2, eine davon beschrieben), Pseudolycoriella (13), Bradysia (16, eine davon beschrieben ), Scatopsciara (5), Corynoptera (2), Keilbachia (1) und Epidapus (3, eine davon beschrieben).

Die Bewertung der faunistischen Ergebnisse ist erschwert durch fehlende Informationen über die Sciaridenfauna benachbarter Gebiete wie Florida und nördliches Südamerika. Aus gesicherten Kenntnissen über die Sciaridenfauna der Paläarktischen Region und (mit Abstrichen) aus Nord- und Mittelamerika kann geschlußfolgert werden, daß die karibische Fauna mehrheitlich größere Ahnlichkeit zur Holarktis als zur Neotropis besitzt. Das gilt besonders für die Gattungen Leptosciarella, Chaetosciara, Keilbachia, Scatopsciara, die meisten Arten von Bradysia, Corynoptera und Epidapus, teilweise auch für Pseudolycoriella. Die einzige endemische Gattung für Süd- und Mittelamerika ist Pseudosciara mit 4 Arten sowie 2 Arten der Bradysia pararufenscens-Gruppe, die ebenfalls nur in Mittel-und Südamerika verbreitet scheint.

\section{Key words}

Sciaridae, Dominican Republic, Puerto Rico, new species, taxonomy, Leptosciarella, Pseudosciara, Cratyna, Chaetosciara, Pseudolycoriella, Bradysia, Scatopsciara, Corynoptera, Keilbachia, Epidapus 


\section{Introduction}

The Sciarids were collected by V. Almanzar in 1991, D. Grimaldi \& J. Stark 1991 1992 from the Dominican Republic using either Malaise traps or sweep net. Small samples from Puerto Rico were collected using light trapping by Y. Canals in 1996. The sciarid flies were preserved in $70 \%$ ethanol. For preparation on microscopic slides they were dehydrated in $96 \%$ ethanol and treated with creosote for at least 10 minutes. The genitalia were separated carefully and body and genitalia were embedded subsequently under two different coverglasses in Canada Balsam.

The morphologic terminology (Fig. 1) and nomenclature corresponds with that of SöLI (1997) and Menzel \& Mohrig (1997, 2000).

The type material and other specimens were preserved in the American Museum of Natural History (AMNH), New York City, and in the collection of MoHrig, Poseritz (CWMP), Germany.

\section{Locations}

1. Hispaniola (Dominican Republic): Pedernales Prov., $27 \mathrm{~km} \mathrm{~N} \mathrm{Pedernales,} \mathrm{rd.} \mathrm{to} \mathrm{Los} \mathrm{Arroyos,} \mathrm{Oct.} \mathrm{1992,}$ leg. D. Grimaldi \& J. Stark.

2. Hispaniola (Dominican Republic): Pedernales Prov., $40 \mathrm{~km} \mathrm{~N}$ Caba Rojo, 2,300 ft., dry forest, Aug. 1991, leg. D. Grimaldi \& J. Stark.

3. Hispaniola (Dominican Republic): Pedernales Prov, $20 \mathrm{~km}$ NE Pedernales, Las Abejas $1.500 \mathrm{~m}$, in broadleaf cloud forest, Oct./Nov. 1992, leg. D. Grimaldi \& J. Stark.

4. Hispaniola (Dominican Republic): La Romana, sea level, forest along coastal inlet, Sept. 1992, leg. D. Grimaldi \& J. Stark.

5. Hispaniola (Dominican Republic): La Vega Prov., $12 \mathrm{~km} \mathrm{~S} \mathrm{Constanza,} \mathrm{rd.} \mathrm{to} \mathrm{San} \mathrm{José} \mathrm{de} \mathrm{Ocoa,} \mathrm{5.000} \mathrm{ft.,}$ Jul. 1991, leg. D. Grimaldi \& J. Stark.

6. Hispaniola (Dominican Republic): Duarte Prov, $13 \mathrm{~km}$ N San Francisco de Macoris, $800 \mathrm{ft}$. , Malaise trap in cloud forest, Apr./Aug. 1991, leg. V. Almanzar

7. Hispaniola (Dominican Republic): Monte Plata, 9 km N Bayaguana, 300 ft., Aug. 1991, leg. D. Grimaldi $\&$ J. Stark.

8. Hispaniola (Dominican Republic): La Altagracia Prov., Boca de Yuma, sea level, Net, Mangroves along a river, Nov. 1992, leg. D. Grimaldi \& J. Stark.

9. Hispaniola (Dominican Republic): La Vega Prov, $10-14 \mathrm{~km}$ SW Jarabacoa on road to Monebão, swept over and by streams, Jul. 1991, leg. D. Grimaldi \& J. Stark.

10. Hispaniola (Dominican Republic): La Vega Prov., $21 \mathrm{~km}$ W Bonão, 3.400 ft., Aug. 1991, leg. D. Grimaldi \& J. Stark.

11. Hispaniola (Dominican Republic): Barahona Prov., just S La Cienaga, 100 ft., Aug. 1991, near stream, leg. D. Grimaldi \& J. Stark.

12. Hispaniola (Dominican Republic): Paravia Prov., $30 \mathrm{~km}$ N San José de Ocoa, 3.000 ft., Jul. 1991, near stream, leg. D. Grimaldi \& J. Stark. 
13. Hispaniola (Dominican Republic): Sakedo Prov., $8 \mathrm{~km} \mathrm{~N}$ Tenares, $800 \mathrm{ft}$., swept in gully, Aug. 1991, leg. D. Grimaldi \& J. Stark.

14. Puerto Rico, Guanica, $17.97^{\circ} \mathrm{N} 66.86^{\circ} \mathrm{W}$, Guanica State Forest, Jul. 1996, light trap, leg. Y. Canals.

Systematics

\section{Genus Leptosciarella Tиомікоккі, 1960}

On the basis of the Holarctic species, Leptosciarella can be interpreted as an independent genus with five subgenera (Mohrig \& Menzel 1997, Mohrig 2003). The monophyly is based on an autapomorphic character: the apical tooth on the gonostyles is shaped like a hawk beak. The occurrence of spine-like bristles (subgenus Hirtipennia) or short awl-like spines above the apical tooth (subgenus Leptosciarella s. str.) is without doubt more recently developed. In amber fossil species of Leptosciarella we find only short bristles above the tooth (Mohrig \& Röschmann 1994, Röschmann \& Mohrig 1995a). The development of the typical awl-like spines is only seen in Leptosciarella tertiaria (Meunier, 1904). In recent species such spines are absent only in the Mediterranean sciarid Leptosciarella mediterranea (MOHRIg \& KaUschike, 1994). This species is also unique in the shape of the flagellomeres, which have bottle-like necks, typical of the genus Sciara and the Leptosciarella subgenera Hirtipennia in the Palaearctic region and Protosciarella in Central America. In all other recent species of Leptosciarella the flagellomeres have conical necks with sharp corners on the basal part of the flagellomeres. Further Diagnosis are the mostly setose postpronotum, macrotrichia on the posterior wing veins in most species and an indistinct patch of bristles at the inner apex of the fore tibia.

The genus Leptosciarella is species rich and widespread within the Palaearctic Region. Some species are known from the USA, Canada and Central America (Mohrig 2003).

\section{Leptosciarella (Leptosciarella) nudinervosa MOHRIG \& RösCHMANN spec. nov.}

(Fig. 2)

Diagnosis: This new species is a typical Leptosciarella for the Holarctic species. It is characterised by the absence of macrotrichia on the posterior wing veins, the bare postpronotum and the short palpi.

Description: $\sigma^{\top}$. Head: Eye bridge 4 facets wide; antennae short, unicolour brown, flagellomere 4 about $2.0 \times$ longer than wide, with a distinct conical neck, setae dense and shorter than the diameter of the basal part of flagellomere; palpi short, 2-3-segmented, basal segment with 2-3 bristles and a patch of sensillae.

Thorax: Brown, mesonotum with rather short, fine setae, some stronger lateral and 4 stronger scutellar setae; postpronotum bare; antepronotum and prethoracic episternum with sparse, fine setae; wings smoky; $\mathrm{R}_{1}$ long, $=4 / 5 \mathrm{R} ; \mathrm{R}_{5}$ without ventral macrotrichia; $\mathrm{C}=2 / 3 \mathrm{w} ; \mathrm{y}=\mathrm{x}$, without macrotrichia; posterior veins without macrotrichia; halteres short and darkened; legs brownish; fore tibiae at the inner apex with a large indistinct patch of bristles; spurs of mid and hind tibiae long and subequal; claws untoothed. 
Abdomen: Brown, tergal and sternal sclerites with sparse, rather short setae; genitalia ventrally with sparse, short setae, inner ventral margin of gonocoxites with moderately long setae; gonostyles narrowed, apically shaped like a forehead, with a spine on the apex shaped like a hawkbeak and short awl-like spines above it; tegmen broad, aedeagus rather short. Body length: $2.8 \mathrm{~mm}$. 9 : unknown.

Locus typicus: Hispaniola (Dominican Republic): Duarte Prov., 13 km N San Francisco de Macoris.

Holotype: $1 \sigma^{\pi}$, alt. $800 \mathrm{ft} .$, Malaise trap in cloud forest, Jul. 1991, leg. V. Almanzar.

Paratypes: 4 ơ $\sigma^{x}$, same data as holotype.

Depository: Holotype and 1 paratype in AMNH, 3 paratypes in CWMP.

\section{Leptosciarella (Protosciarella) ampullocera MoHRIG \& RösCHMANN spec. nov.} (Fig. 3)

Diagnosis: This new species is characterized by the lack of short awl-like spines above the apical tooth of gonostyles and the bottle-like shape of flagellomeres, in combination with a lack of macrotrichia on the posterior wing veins. It belongs to the subgenus Protosciarella and appears related to the fossil species Leptosciarella botuli in Baltic amber (Mohrig \& Röschmann 1994).

Description: $\sigma^{\star}$. Head: Eye bridge 4 facets wide; antennae rather long, uniform brown, scapus ochreous, flagellomeres with bottle-like necks (Sciara-like); flagellomere 4 about $3.0 \mathrm{x}$ longer than wide, setae dense, erect and as long as the diameter of the basal part of flagellomere; palpi 3-segmented, basal segment with 3-4 bristles and a patch of short sensillae. Segment III long and narrow.

Thorax: Ochreous-brown; mesonotum laterally paler, with rather central setae, some stronger lateral and 4 stronger scutellar setae; lower half of katepisternum and coxae yellow; upper part of katepisternum and antemesothoracic epimeron darkened; postpronotum with one bristle; antepronotum and prethoracic episternum with sparse, fine setae; postthoracic episternum with one or two bristles; wings smoky; $R_{1}=2 / 3 R_{5} R_{5}$ without ventral macrotrichia; $C=2 / 3 \mathrm{w} ; \mathrm{y}=\mathrm{x}$, without macrotrichia; CuA-stem short; posterior veins without macrotrichia; halteres short and darkened; coxae elongate and narrow; legs long, femora and tibiae yellow, tarsi darkened; fore tibiae at the inner apex with a large indistinct patch of bristles; spurs of mid and hind tibiae long and subequal; claws with a flat subapical tooth.

Abdomen: Brown, tergal and sternal sclerites with rather long setae; genitalia ventrally with sparse, short setae, inner ventral margin of gonocoxites with sparse, short setae; gonostyles long and narrow, apically shaped like a forehead, with a spine on the apex shaped like a hawkbeak and short bristles above (without short awl-like spines); tegmen higher than wide, with fine teeth; aedeagus rather long. Body length: $3 \mathrm{~mm}$. 9 : unknown.

Locus typicus: Hispaniola (Dominican Republic): Pedernales Prov., $20 \mathrm{~km} \mathrm{NE} \mathrm{Peder-}$ nales, Las Abejas.

Holotype: 1 s, alt. $1.500 \mathrm{~m}$, broadleaf cloud forest, 1. Oct. 1992, leg. Grimaldi \& Stark. 
Paratype: 1 o, same data as holotype, but 26.-27. Nov. 1992.

Depository: Holotype in AMNH, paratype in CWMP.

\section{Genus Pseudosciara SCHINER, 1868}

The taxonomic history of this taxon has experienced many errors, which were clarified by Amorim (1992). Although the type species is lost, it is most likely that it is a Pseudosciara as from LANE (1959b). LANE included 23 Neotropical species in his key; AMorim (1992) gave 27 species in his Catalogue of Sciaridae of the Americas south of the United States. We have seen only some type species of PetTey and WILLISTON and it seems to be clear that there are many identical species and that a revision is necessary.

Species of this genus are characterized by macrotrichia on the posterior wing veins together with a long CuA-stem, virtually as long as half the distance between the base of $\mathrm{R}_{5}$ and the end of $\mathrm{CuA}$. The patch of bristles at the inner apex of the fore tibiae is large and semicircular; claws are untoothed; palpi are three-segmented and elongate; with the basal segment having some setae and without a deepened sensory pit; postpronotum is bare and the gonostyle rather uniform with 5 strong spines apically and a spine near the middle of the inner side, frequently inserted on a protuberance that sometimes forms a distinct thumb-like lobe. Most of the known species are of medium size and richly contrasted in yellow and black.

\section{Pseudosciara aitheni LANE, 1959}

(Fig. 4a, c)

Literature: LANe, 1959b. Rev. Bras. Biol. 19: 290, Fig. 1 and 2.

We identified our specimens with Pseudosciara aitkeni LANE as described from Trinidad. This species is of medium size and predominantly yellow. It is characterized by the thumb-like lobe with single curved spine near the base of the inner side of the gonostyles. The gonostyles are mostly dark, in contrast to the yellow gonocoxites and the base of the hypopygium. The differences from the new species Pseudosciara longicera are shown in the descriptions.

Material examined:

Dominican Republic: Duarte Prov., $13 \mathrm{~km} N$ San Francisco de Macoris: $20^{\circ} 0^{\circ}$ Apr. 1991; $40^{*} \sigma^{*}$, May/June 1991; $15 \sigma^{*} \sigma^{*}$, Jul. 1991; $40^{*} o^{*}$, Aug. 1991, all leg. Almanzar; $17 \sigma^{\star}$, Pedernales Prov., Las Abejas, 26.-27. Nov. 1992; 10 , La Vega Prov., $21 \mathrm{~km}$ W Bonão, 2. Aug. 1991; 1 0, Sakedo Prov., 8 km N Tenares, 7. Aug. 1991, all leg. Grimaldi \& Stark.

\section{Pseudosciara cariba LANE, 1959}

Literature: LANE 1959b. Rev. Bras. Biol. 19: 291-292, Fig. 6 and 7.

We identified our specimens with Pseudosciara cariba LANE as described from Trinidad. This species is characterised by the strong spine below the middle of the inner side that is 
without any basal protuberance. The gonostyles are darkened as in Pseudosciara aitkeni. The first abdominal sternite is yellow, the $4^{\text {th }}$ with larger yellow basal and apical bands.

Material examined:

Dominican Republic: 1 o, La Vega Prov., $12 \mathrm{~km} S$ Constanza, 29. Jul. 1991, leg. Grimaldi \& Stark; $20^{\star} 0^{*}$, May/June 1991; $30^{\star}$, Jul. 1991, Duarte Prov., 13 km N San Francisco de Macoris leg. Almanzar.

\section{Pseudosciara longicera MoHrig \& RöschmanN spec. nov.}

(Fig. 5)

Diagnosis: This new species is very similar to Pseudosciara aitkeni LANE, especially in the colour and the nearly identical shape of gonostyles. It differs chiefly from this species by the long flagellomeres, which elongate to the apex of antennae. Also, the apices of tibiae and the tarsi are darker, $y$ is shorter, the CuA-stem and $C$ longer and the body size larger than in Pseudosciara aitkeni. Confusion with other described species can not be excluded until a final revision of this genus, but based on the existing descriptions it is unlikely.

Description: 0 . Head: Eye bridge 3 facets wide; antennae long, Hagellomeres narrow and elongate to the apex, basal segments and first flagellomere yellow, the other flagellomeres uniform brown, necks paler with a darkened apex, flagellomere 4 about $4 \mathrm{x}$ longer than wide, with a distinct neck, setae dense and longer than diameter of the basal part of flagellomere. Palpi long, three-segmented, basal segment with 3-4 bristles and a patch of sensillae.

Thorax: Yellow, mesonotum darkened dorsally; with rather long, brown setae, a lateral row and 4 stronger scutellar setae; postpronotum bare; antepronotum and prethoracic episternum with sparse, fine setae; wings brownish; $R_{1}$ long, $=3 / 4 R_{5} R_{5}$ with ventral and dorsal macrotrichia along whole length; $C=2 / 3 w ; y=1 / 2 x$, both with macrotrichia; $\mathrm{M}$-stem with macrotrichia along whole length, $\mathrm{M}$-fork = $\mathrm{M}$-stem, narrow; CuA-stem very long, longer than $\mathrm{CuA}$, all posterior veins with macrotrichia; halteres short, with yellow stem and darkened heads; legs yellow, tarsi darkened; fore tibiae with some spinelike bristles among the ground setae, inner apex with a large indistinct patch of bristles, forming an arched row of bristles apically and with indistinct bristles up to the strong semicircular border; spurs of mid and hind tibiae long and subequal; claws untoothed.

Abdomen: Tergal and sternal sclerites dense and with rather long setae; tergites dark with yellow base, sternite 1-5 yellow, the others darkened; hypopygium brownish, gonostyles somewhat darker; gonocoxite with moderately long setae at the inner ventral margin; gonostyles narrowed at apex, with a strong apical tooth, 4 shorter spines and a thumblike lobe with a single curved spine near base of inner side; tegmen rounded, with a large area of fine teeth; aedeagus rather long. Body length: $4 \mathrm{~mm}$. o : unknown.

Locus typicus: Hispaniola (Dominican Republic): Pedernales Prov., 20 km NE Pedernales, Las Abejas.

Holotype: 1 क, alt. $1.500 \mathrm{~m}$, broadleaf cloud forest, 26.-27. Nov. 1992, leg. Grimaldi \& Stark.

Paratype: $1 \sigma^{\star}$, same data as holotype.

Depository: Holotype in AMNH, paratype in CWMP. 
Pseudosciara fragistyla MoHRig \& Röschmann spec. nov.

(Fig. 6)

Diagnosis: This unique new species undoubtedly belongs to Pseudosciara by all Diagnosis with exception of the very simple gonostyles. The absence of any spine or lobe at the inner side of gonostyles can be seen as a plesiomorphic characteristic and therefore as an indicator for a more primary position of this species in the special phylogeny of Pseudosciara.

Description: of. Head: Dark, palpi and the basal segments of antennae yellow; eye bridge 3 facets wide; antennae long, flagellomeres not elongate to apex, basal segments yellow, other flagellomeres uniform brown, necks brownish with a darkened apex, flagellomere 4 about $3 \mathrm{x}$ longer than wide, with a distinct neck, setae dense and longer than the diameter of the basal part of flagellomere; palpi three-segmented, basal segment short, clublike, with 3-4 bristles and a patch of sensillae.

Thorax: Yellow-brown contrasted, mesonotum brown, only prescutum yellow; with rather long and brown setae, a stronger lateral row and 4 stronger scutellar setae; scutellum brownish; postpronotum bare; antepronotum and prethoracic episternum with sparse, fine setae, yellow; pleural sclerite, katepisternum and mediotergite brown, metanotum and postthoracic episternum yellow; wings brownish; $R_{1}$ long, $=2 / 3 \mathrm{R} ; \mathrm{R}_{5}$ with ventral and dorsal macrotrichia along whole length; $C$ somewhat longer $1 / 2 \mathrm{w} ; \mathrm{y}$ shorter $\mathrm{x}$, both with macrotrichia; $M$-fork = M-stem, narrow; CuA-stem elongated, somewhat shorter than $\mathrm{CuA}_{2}$; all posterior veins with macrotrichia; halteres short, with yellow stem and darkened heads; legs yellow, hind coxae with a brown spot apically, tarsi darkened; fore tibiae with some spine-like bristles among the ground setae, inner apex with a large indistinct patch of bristles, forming an arched row of bristles apically with indistinct bristles up to the strong semicircular border; spurs of mid and hind tibiae long and subequal; claws untoothed.

Abdomen: Tergal and sternal sclerites dense and with rather long setae; first tergite chiefly yellow, all other tergites dark with yellow base, sternite 1-5 yellow, the others darkened; hypopygium brownish, gonostyles somewhat darker; gonocoxite ochreous, with sparse and moderately short setae at the inner ventral margin; gonostyles long and narrow, with a strong apical tooth and 4 shorter spines, without any lobe or spine near base of inner side of the gonostyles; tegmen rounded, with a large area of fine teeth; aedeagus rather long. Body length: $3 \mathrm{~mm}$. $\%$ : unknown.

Locus typicus: Hispaniola (Dominican Republic): La Romana, sea level.

Holotype: $1 \sigma^{\star}$, forest along coastal inlet, 30. Sept. 1992, leg. Grimaldi \& Stark.

Paratypes: $10^{\circ}$, sama date as holotype; $20^{\circ}$, La Altagracia Prov., Boca de Yuma, 29. Nov. 1992; 1 o , La Vega Prov., 10 - 14 km SW Jarabacoa on road to Monebao, 29. Jul. 1991; $2 \sigma^{\star}$, Paravia Prov.; $30 \mathrm{~km}$ N San José de Ocoa, 30. Jul. 1991, all leg. Grimaldi \& Stark; $1 \%$, Duarte Prov., $13 \mathrm{~km}$ N San Francisco de Macoris, Apr. 1991, leg. Almanzar.

Depository: Holotype and 4 paratypes in AMNH, 3 paratypes in CWMP.

\section{Genus Chaetosciara FrEY, 1942}

Only three distinct Eastern Palaearctic species (Menzel \& Mohrig 1998), two species from Papua New Guinea (MoHrig 1999) and one species from Honduras (MoHrig 
2003), are known in this genus. The taxonomic position of other species mentioned (AMORIN 1992, two species from the Neotropic Region; STEFFAN 1972, five species from the Indomalayan Region) is not clear, because of the lack of a revision unlike those of the Palaearctic species.

The genus is characterised by a distinct lobe at the ventral base of the hypopygium, very short and thick flagellomeres with a distinct barred surface structure in most species, three-segmented palpi with three or more bristles, a large indistinct bristle patch at the apex of the fore tibiae, bare postpronotum, four or more scutellar bristles, a lack of macrotrichia on the posterior wing veins and untoothed tarsal claws. Most species consistently have three spines at the apex of the gonostyles.

\section{Chaetosciara gilva Mohrig \& Röschmann spec. nov.}

(Fig. 7)

Diagnosis: This new species is a typical Chaetosciara. It is well characterised by the shape of gonostyles and the basal lobe of the base of hypopygium with short setae. It represents the feature of Holarctic species of this genus.

Description: $\sigma$. Head: Eye bridge 4 facets wide; antennae short, uniform brown, necks pale, flagellomeres thick; flagellomere 4 about $1.2 \mathrm{x}$ longer than wide, with a distinct neck, with rather dense setae and shorter than half of the diameter of the basal part of flagellomere; palpi three-segmented, basal segment with 5-6 bristles and a patch of sensillae.

Thorax: Yellow-brown; mesonotum with rather short, fine setae, 4 stronger scutellar setae; postpronotum bare; antepronotum and prethoracic episternum with sparse setae; wings smoky; $\mathrm{R}_{1}=3 / 4 \mathrm{R} ; \mathrm{R}_{5}$ with dorsal and ventral macrotrichia only apically; $\mathrm{C}=2 / 3 \mathrm{w} ; \mathrm{y}=\mathrm{x}$, with $2-3$ macrotrichia; posterior veins without macrotrichia; halteres short and darkened; legs brownish; fore tibiae at the inner apex with a large indistinct bristle-patch; spurs of mid and hind tibiaesubequal; claws untoothed.

Abdomen: Tergal and sternal sclerites rather short and finely setose; basal lobe of hypopygium with short setae, with moderately long setae at the inner ventral margin of gonocoxites; gonostyles strong, with 3 short spines; tegmen rounded, aedeagus very short. Body length: $3.5 \mathrm{~mm}$. ㅇ: unknown.

Locus typicus: Hispaniola (Dominican Republic): Duarte Prov., $13 \mathrm{~km} \mathrm{~N} \mathrm{San} \mathrm{Francisco}$ de Macoris.

Holotype: $1 \sigma^{*}$, alt. $800 \mathrm{ft}$., Malaise trap in cloud forest, July 1991, leg. V. Almanzar.

Paratypes: $7 \sigma^{\star} \sigma^{*}$, same data as holotype; $1 \sigma^{\circ}$, same data, May/June 1991; $1 \sigma^{*}$, Pedernales Prov., Las Abejas, 26.-27. Nov. 1992, leg. Grimaldi \& Stark.

Depository: Holotype and 4 paratypes in AMNH, 5 paratypes in CWMP.

\section{Genus Cratyna WinnerTz, 1867}

The features characterising this genus are heterogenous up to now. Only the Palaearctic species belonging to the subgenus Spathobdella FREY, 1948 [type species Cr. nobilis (WINNERTZ, 1867)] are well known and clearly defined. Cratyna s. str., too, with spe- 
cies related to the typical $C r$. atra WINNERTz $[=P$. pictiventris (KIEFFER)], including the species of Decembrina Frey sensu TuOMnKoski (1960, p. 31), the Cratyna species of Central America (Momrig 2003) and perhaps also the Neotropical species of Plastosciara described by LANE (1960) are more or less well defined. Further studies in other zoogeographic regions are needed before proposing an adequate definition of the limits of this and related genera.

About 40 Palaearctic species are known in the genus. Fourteen species are known from Papua New Guinea (Mohrig 1999). Only two species are known from the Nearctic Region (Poole \& Gentili 1996). StefFan (1969) mentioned three species from Micronesia, but two of his Scythropochroa species seem to belong to Cratyna. The genus Pseudozygoneura Steffan, 1969 is synonym to Cratyna (Mohrig 1999: 181-182). The genus is also known from tertiary amber (MoHrig \& RösCHMANN 1994, RöschmanN \& Mohrig 1995b).

\section{Cratyna (Cratyna) fumoalata MoHRIG \& RösCHMANN spec. nov.}

(Fig. 8)

Diagnosis: This new species is well characterised by the shape of gonostyles and macrotrichia on the $y$ part of $\mathrm{R}_{5}$. The species corresponds to species of the Holarctic subgenus Decembrina. The tooth-like spine pairs and their arrangement presume a closer relationship to Neotropic species near Cr. curarosi (LANE, 1960).

Description: 0 . Head: Eye bridge 3 facets wide; antennae short, uniform brown, flagellomeres thick; flagellomere 4 about 1.5 x longer than wide, with a distinct neck, setae dense and shorter than the diameter of the basal part of flagellomere; palpi two-segmented, basal segment with 2-3 bristles and a patch of sensillae.

Thorax: Brown, with light spots at prescutum and mediotergite; mesonotum with rather short, fine setae, some stronger lateral and scutellar setae. Postpronotum setose; antepronotum and prethoracic episternum with sparse setae; wings smoky; $R_{1}=2 / 3 R ; R_{5}$ in distal half with dorsal and ventral macrotrichia; $C=2 / 3 w ; y=2 x$, with macrotrichia; posterior veins weak and without macrotrichia; halteres short and darkened; legs brownish; fore tibiae at the inner apex with a small indistinct patch of bristles; spurs of mid and hind tibiae subequal; claws untoothed.

Abdomen: Tergal and sternal sclerites with dense, rather long setae; hypopygium with short and strong gonocoxites, with moderately long setae at inner ventral margin; gonostyles ovoid, with 4 hyaline spines in two pairs on the apex and subapically; tegmen rounded, with a short tongue-like structure; aedeagus very short. Body length: $3 \mathrm{~mm}$. ㅇ: unknown.

Locus typicus: Hispaniola (Dominican Republic): Duarte Prov., $13 \mathrm{~km} \mathrm{~N} \mathrm{San} \mathrm{Francisco}$ de Macoris.

Holotype: $1 \sigma^{\circ}$, alt. $800 \mathrm{ft}$., Malaise trap in cloud forest, Jul. 1991, leg. V. Almanzar.

Paratypes: 22 ot, same data as holotype.

Other material: $1 \%$, same data as holotype.

Depository: Holotype and 11 paratypes in AMNH, 11 paratypes in CWMP. 


\section{Genus Hyperlasion SсHмIT, 1919}

The genus included small species with reduced palpi, short legs with very short tibial spurs, and short halteres. The species are very similar to small species of the genus Cratyna with the exception of short tibial spurs and an extended head capsule in some species.

\section{Hyperlasion multisetus MoHrig \& Röschmann spec. nov.}

(Fig. 9)

Diagnosis: The new species is characterised by one-segmented palpi, two to three very fine hyaline spines among several subequal bristles at the apex of gonostyles, a very weak $\mathrm{M}$-stem and strong CuA-veins and macrotrichia on $\mathrm{x}$ and $\mathrm{y}$.

Description: 0 . Head: Somewhat egg-shaped with a larger posterior vertex; eye bridge narrow, 2 facets wide, antennae rather long; necks $1 / 3$ of the basal part; flagellomere 4 about $2 \times$ longer than wide; setae of flagellomeres sparse and bristle-like, longer than the diameter of the basal part; palpi rounded, one-segmented; sensillae at the apex.

Thorax: Brown, mesonotum with short and sparse setae, some stronger lateral and 2 stronger scutellar setae; postpronotum bare; antepronotum and prethoracic episternum with sparse, fine setae; wings brownish, dense with macrotrichia; $R_{1}=3 / 4 R ; R_{5}$ rather straight and wide, with ventral and dorsal macrotrichia along whole length; $C=3 / 4 \mathrm{w}$; $\mathrm{y}=\mathrm{x}$, with macrotrichia; M-stem short and rather broad; CuA-stem short; posterior veins weak and without macrotrichia; halteres elongated, darkened; coxae somewhat elongated; legs of normal size; apex of fore tibia without a distinct patch of bristles, only with some longer setae; spurs of mid and hind tibiae short, fine and subequal, tarsal claws untoothed.

Abdomen: Brown, tergal and sternal setae sparse and moderately long; genitalia ventrally with short setae, the inner margin of gonocoxites with rather long setae; gonocoxites short and rather strong; gonostyles long, without an apical tooth, with only a few hyaline fine spines among longer spine-like bristles; tegmen rather small, apically rounded, laterallyangled; aedeagus very short. Body length: $1.5 \mathrm{~mm}$.. : unknown.

Locus typicus: Hispaniola (Dominican Republic): Duarte Prov., 13 km N San Francisco de Macoris.

Holotype: $1 \sigma^{*}$, alt. $800 \mathrm{ft}$., Malaise trap in cloud forest, Jul. 1991, leg. V. Almanzar.

Paratypes: $7 \sigma^{\star} \sigma^{\star}$, same data as holotype, $1 \sigma^{\star}$, Pedernales Prov., Las Abejas, 26.-27. Nov. 1992, leg. Grimaldi \& Stark.

Depository: holotype and 3 paratypes in AMNH, 5 paratypes in CWMP.

\section{Hyperlasion wasmanni SCHMITZ, 1919}

Literature: Menzel \& Mohrig 2000. Stud. Dipt., Suppl. 6: 346-347; Mohrig 2003. Beitr. Ent. 53: 2728, fig. 19.

This small species is characterised by one-segmented palpi, rather short coxae and legs with very short and fine tibial spurs. Gonostyles apically rounded, with 5-6 subapi- 
cal spines; tegmen small. The palpi are without a sensory pit in specimens from the Dominican Republic. The species is possibly distributed cosmopolitan.

Material:

7 б $\sigma^{*}$. Hispaniola (Dominican Republic): Duarte Prov., $13 \mathrm{~km} \mathrm{~N} \mathrm{San} \mathrm{Francisco} \mathrm{de}$ Macoris, alt. $800 \mathrm{ft}$., Malaise trap in cloud forest, Jul. 1991, leg. V. Almanzar; 1 o , La Vega Prov., $21 \mathrm{~km}$ W Bonão, 2. Aug. 1991, leg. D. Grimaldi \& J. Stark.

Depository: 4 specimens in AMNH, 3 in CWMP.

\section{Genus Pseudolycoriella MENZEL \& MOHRIG, 1998}

The genus was established for species of the Palaearctic Lycoriella bruckii group (MENzEL \& Mohrig 1998). The main characteristic is a long subapical whip-lash seta on the gonostyles (rarely two or more). This characteristic is combined with toothed tarsal claws in most species, 4 scutellar setae, bare postpronotum, lack of macrotrichia on the posterior wing veins, rough surface of the flagellomeres with distinct white insertion points of short sensoriae among the setae, three-segmented palpi with a long and narrow basal segment with more than one bristle, short halteres and subequal spurs on the mid and hind tibiae. The bristle patch at the apex of the fore tibiae is mostly with semicircular margin, in some species more comb-like.

The genus is well known from the Palaearctic region. Recent studies of the sciarid fauna of New Zealand (Mohrig \& Jaschhor 1999), Central America (Mohrig 2003) and Cuba (Menzel 1997) and unpublished material of New Caledonia, Papua-New Guinea, Zimbabwe and Brazil show the worldwide distribution as well as a high number of undescribed species. It seems that the origin of the genus is located in the Southern hemisphere.

\section{Pseudolycoriella torva Momrig \& RULiK spec. nov.}

(Fig. 10)

Diagnosis: This large and dark species is a typical Pseudolycoriella. Is is characterised by the shape of gonostyles, the short and thick flagellomeres and the somewhat elongated mouth parts.

Description: $\sigma$. Head: Higher than wide, clypeus and labrum distinctly elongate; eye bridge 3 facets wide; antennae uniform brown; flagellomere 4 about $2 x$ as long as wide, with distinct neck, surface not rough, setae shorter than the half diameter of basal part of Alagellomere; palpi three-segmented; basal segment with $4-5$ bristles and a patch of short sensillae; third segment narrow and elongate.

Thorax: Dark brown; central parts of mesonotum darkened; mesonotum with moderately short setae, 2-3 stronger lateral setae; scutellum with 4 strong posterior setae; postpronotum bare, antepronotum and prethoracic episternum with sparse setae; wings dark brown, all veins darkened; $R_{1}=3 / 4 R ; R_{5}$ with only dorsal macrotrichia; $C=3 / 4 \mathrm{w}$; $y$ shorter $\mathrm{x}$, bare; $\mathrm{CuA}$-stem rather long; branches of $\mathrm{M}$ and $\mathrm{Cu}$ without macrotrichia. Halteres short with darkened heads; legs dark brown; fore tibiae at the inner apex without a distinct patch of bristles, only with some stronger bristles among the ground setae; spurs of mid and hind tibiae subequal brownish and longer than the diameter of apex; claws weakly toothed. 
Abdomen: Tergal and sternal setae dense and moderately long; genitalia ventrally and the inner ventral margin of gonocoxites with sparse, short setae; gonostyles curved, with two strong subequal spines apically and a longer whip-lash seta; tegmen broader than high and with a semicircular structure apically; aedeagus rather short, with large basal part. Body length: $4 \mathrm{~mm}$. 9 : unknown.

Locus typicus: Hispaniola (Dominican Republic): Pedernales Prov., $20 \mathrm{~km}$ NE Pedernales, Las Abejas.

Holotype: $10^{\star}$, alt. $1.500 \mathrm{~m}$, broadleaf cloud forest, 26.-27. Nov. 1992, leg. Grimaldi \& Stark.

Paratypes: $10^{\star}$, same data as holotype.

Depository: Holotype in AMNH, paratype in CWMP.

\section{Pseudolycoriella bicornis (MENZEL, 1997)}

The species is very similar to $P_{S}$. torva, but clearly smaller. It can be distinguish by the flattened and smooth ventral part at the distal half of gonostyles.

\section{Material:}

Hispaniola (Dominican Republic): Paravia Prov., $30 \mathrm{~km}$ N San José de Ocoa, $3 \sigma^{\star} \sigma^{*}$, alt. $3000 \mathrm{ft} ., 30$. Jul. 1991, near stream, leg. Grimaldi \& Stark; $3 \sigma^{\star}$, Duarte Prov., San Francisco de Macoris, July 1991, leg. V. Almanzar.

Puerto Rico: $10^{*}$, Guanica, $17^{\circ} 97^{\prime} \mathrm{N} 66^{\circ} 86^{\prime} \mathrm{W}$, Guanica State Forest, 25.7.96, light trap, leg. Canals.

\section{Pseudolycoriella pulla MoHrig \& Rulik spec. nov.}

(Fig. 11)

Diagnosis: This new species is a typical Pseudolycoriella with connections to Ps. barbata. It is characterised through the shape of gonostyles.

Description: 0 . Head: Ovoid, clypeus and labrum elongated; eye bridge 3 facets wide; flagellomeres uniform brown, basal segments somewhat paler, necks rather long, uniform colour; flagellomere 4 about $2 \mathrm{x}$ as long as wide, smooth, setae as long as the basal part of flagellomere; palpi three-segmented; basal segment narrow with 3-4 bristles and a patch of short sensillae.

Thorax: Brown; mesonotum somewhat darker, with moderately long dorsocentral setae, some stronger lateral setae scutellum with 4 strong posterior setae; postpronotum bare, antepronotum and prethoracic episternum with sparse and rather short setae; wings brownish, all veins darkened; $R_{1}=1 / 2 R ; R_{5}$ with only dorsal macrotrichia; $C=2 / 3 \mathrm{w}$; $\mathrm{y}=\mathrm{x}$, bare; CuA-stem $=\mathrm{x}$; branches of $\mathrm{M}$ and $\mathrm{Cu}$ without macrotrichia; halteres short with darkened heads; legs brownish; fore tibiae at the inner apex with an indistinct row of bristles, without semicircular margin; spurs of mid and hind tibiae subequal brownish and longer than the diameter of apex; claws weakly toothed.

Abdomen: Brown, with sparse, moderately long setae; base of hypopygium with sparse setae, the inner ventral margin of gonocoxites with rather dense and long setae; gonostyles 
short and strongly curved,widely rounded apically, with dense setae, with two strong subequal spines and a long whiplash seta; tegmen widely rounded and without a semicircular structure apically; aedeagus rather long. Body length: $2.8 \mathrm{~mm}$. $q$ : unknown.

Locus typicus: Hispaniola (Dominican Republic): La Vega Prov., $12 \mathrm{~km}$ S Constanza, rd. to San Jose de Ocoa.

Holotype: 1 o , alt. 5.000 ft., 29. Jul. 1991, leg. Grimaldi \& Stark.

Paratypes: $11 \sigma^{\star}$, same data as in holotype.

Depository: Holotype and 5 paratypes in AMNH, 6 paratypes in CWMP.

\section{Pseudolycoriella barbata MoHRIG \& RULIK spec. nov.}

(Fig. 12)

Diagnosis: This large species is a typical Psendolycoriella. It is well characterised by the compact, inwardly curved gonostyles with two short apical spines, a long whip-lash seta and by the dense and lobe-like setae at the base of the hypopygium.

Description: $\sigma^{*}$. Head: Rounded; eye bridge 3 facets wide; antennae uniform brown, necks paler; flagellomere 4 about $2 \mathrm{x}$ as long as wide, with distinct neck, surface not rough, setae shorter than the half diameter of basal part of flagellomere; palpi three-segmented; basal segment with 5-6 bristles and a patch of short sensillae.

Thorax: Brown; mesonotum with moderately fine, short dorsocentral setae, some stronger lateral setae; scutellum with 4 strong posterior setae; postpronotum bare, antepronotum and prethoracic episternum with sparse, fine setae; wings brownish, all veins darkened; $R_{1}$ long, $=3 / 4 \mathrm{R} ; \mathrm{R}_{5}$ with only dorsal macrotrichia; $\mathrm{C}=3 / 4 \mathrm{w} ; \mathrm{y}=\mathrm{x}$, bare; branches of $\mathrm{M}$ and $\mathrm{Cu}$ without macrotrichia. Halteres short with darkened heads; legs brown; fore tibiae at the inner apex without a distinct patch of bristles, only with some stronger bristles among the ground setae; spurs of mid and hind tibiae subequal, brownish and longer than the diameter of apex; claws untoothed.

Abdomen: Tergal and sternal setae dense and moderately long; base of hypopygium lobelike with dense setae, inner ventral margin of gonocoxites normally with short setae; gonostyles strong, curved apically, with two short strong subequal spines and a longer whip-lash seta; tegmen as wide as high and with a weak semicircular structure apically; aedeagus rather long, with large basal part. Body length: $4.5 \mathrm{~mm}$. 9 : unknown.

Locus typicus: Hispaniola (Dominican Republic): Duarte Prov., $13 \mathrm{~km}$ N San Francisco de Macoris.

Holotype: $1 \sigma$, alt. $800 \mathrm{ft} .$, Malaise trap in cloud forest, July 1991, leg. V. Almanzar.

Paratypes: $16 \sigma^{\circ} \sigma^{\star}$, same data as holotype, $1 \sigma^{*}$, La Vega Prov., $12 \mathrm{~km} \mathrm{~S} \mathrm{Constanza,} \mathrm{rd.} \mathrm{to}$ San Jose de Ocoa, 29. July 1991 leg. Grimaldi \& Stark.

Other material: 10 , Duarte Prov., $13 \mathrm{~km}$ N San Francisco de Macoris; 1 o, Apr. 1991; $2 \sigma^{*}$, May/June 1991; $166 \sigma^{*}$, Jul. 1991 (164 of them unprepared preserved in alcohol); $2 \sigma^{*}$, Aug. 1991, all leg. V. Almanzar.

Depository: Holotype and 8 paratypes in AMNH, 9 paratypes in CWMP. 


\section{Pseudolycoriella aculeacera MoHRIG \& RULIK spec. nov.}

(Fig. 13)

Diagnosis: This large, dark species is similar to Ps. ovistyla. It differs by the dark colour, the shape of gonostyles and the short, wide flagellomeres.

Description: 0 . Head: Rounded; eye bridge 2-3 facets wide; antennae brown, flagellomeres wide, basal segments somewhat honey-coloured; flagellomere 4 about $1.8 \mathrm{x}$ as long as wide with distinct neck, surface slightly rough, setae dense and as long as the half diameter of basal part of flagellomere; palpi three-segmented; basal segment with 3-4 bristles and a patch of short sensillae.

Thorax: Dark brown; central part of mesonotum darkened; mesonotum with short dorsocentral setae, 2-3 stronger lateral setae; scutellum with 4 strong posterior setae; postpronotum bare, antepronotum and prothoracic epimeron sparsely setose; wings browned, posterior veins distinct; $R_{1}=1 / 2 R ; R_{5}$ only with dorsal macrotrichia; $C=1 / 2 \mathrm{w} ; \mathrm{y}=\mathrm{x}$, bare; $\mathrm{CuA}$-stem rather long, =x; branches of $\mathrm{M}$ and $\mathrm{Cu}$ without macrotrichia. Halteres short with darkened heads; legs yellowish-brown; fore tibiae at the inner apex with a distinct patch of bristles with semicircular margin; spurs of mid and hind tibiae subequal, brownish and longer than the diameter of apex. Claws strongly toothed.

Abdomen: Tergal and sternal setae short; genitalia ventrally and inner ventral margin of gonocoxites with sparse and short setae; gonostyles widely rounded, apex with dense setae, with 6-8 subequal spines among the equal-length setae and a longer whip-lash seta; tegmen wider than high, without an internal structure apically; aedeagus rather short, basal part rather small. Body length: 3,2 mm. \&: Eye bridge 2-3 facets wide, antennae short, flagellomeres brown, pedicel ochreous, flagellomere 4 as long as wide, setae very short, some setae stout, bristle-like, necks very short, all other Diagnosis as in male.

Locus typicus: Puerto Rico, Guanica, $17^{\circ} 97^{\prime} \mathrm{N} 66^{\circ} 86^{\prime} \mathrm{W}$, Guanica State Forest.

Holotype: $1 \sigma^{\star}, 15-21.7 .1996$, Malaise trap, leg. Y. Canals.

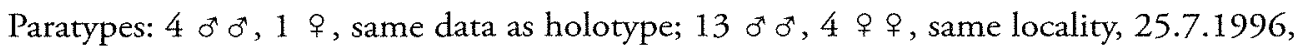
caught in light trap, all leg. Canals.

Other material: $7 \sigma^{*}$, same data as holotype; all leg. Canals.

Depository: Holotype and 19 paratypes in CWMP, 3 paratypes $\left(20^{\circ}, 1 \%\right)$ in AMNH.

\section{Pseudolycoriella ovistyla MoHRIG \& RULIK spec. nov.}

(Fig. 14)

Diagnosis: This species is very well characterised by colour and the palisade-like bristles at the base of the hypopygium. It belongs to Pseudolycoriella near Ps. aculeacera.

Description: $\sigma^{\star}$. Head: Rounded; eye bridge 2-3 facets wide; antennae short, bicolored; basal segments and first flagellomere yellow or yellow-brownish, flagellomeres brown with pale necks, flagellomere 4 about $1.2 \mathrm{x}$ as long as wide, with distinct neck, surface rough, setae dense and as long as the diameter of basal part of flagellomere; palpi threesegmented; basal segment with 2-3 bristles and a patch of short sensillae.

Thorax: Brown, with yellow parts on the katepisternum, pronotum, antepronotum, prethoracic episternum and the base of wings; mesonotum brown, setose with 2-3 stronger 
lateral setae; scutellum with 4 stronger posterior setae; postpronotum bare, antepronotum and prothoracic episternum with sparse setae; wings pale; $R_{1}=1 / 2 R_{5} R_{5}$ only with dorsal macrotrichia; $\mathrm{C}=$ somewhat longer $1 / 2 \mathrm{w} ; \mathrm{y}=\mathrm{x}$, bare; branches of $\mathrm{M}$ and $\mathrm{Cu}$ without macrotrichia. Halteres short with darkened heads; legs yellowish, tarsi darkened; fore tibiae at the inner apex with a indistinct row of bristles (without semicircular margin); spurs of mid and hind tibiae subequal and longer than the diameter of apex. Claws toothed.

Abdomen: Tergal and sternal setae brown and rather short; base of hypopygium ventrally with palisade-like row of dark, spine-like bristles, inner ventral margin of gonocoxites with short setae; gonostyles widely rounded, apex with dense setae, with 6-8 weak, hyaline, subequal spines behind the longer whip-lash seta; tegmen wider than high, without an internal structure apically; aedeagus short, basal part rather large. Body length: $2 \mathrm{~mm}$. i : Alagellomeres very short; flagellomere 4 as long as wide; clypeus and labrum somewhat longer than in male; colour and wing venation as in male.

Locus typicus: Puerto Rico, Guanica, $17.97^{\circ} \mathrm{N}, 66.86^{\circ} \mathrm{W}$, Guanica State Forest.

Holotype: $1 \sigma^{\pi}, 25.7 .1996$, light trap, leg. Y. Canals.

Paratypes: $40^{\star}, 2$ q 9 , same data as holotype; $8 \sigma^{*}, 1$ 우, same locality, 15 21.7.1996.

Depository: Holotype and 14 paratypes in CWMP, 1 paratype in AMNH.

\section{Pseudolycoriella subovistyla MoHRIG \& RULiK spec. nov.}

(Fig. 15)

Diagnosis: This new species is very similar to Pseudosciara ovistyla in colour and wing venation. It differs by stronger subapical spines inserted in front of the whip-lash seta, absence of palisade-like row of bristles on the base of hypopygium and shorter setae of flagellomeres.

Description: $\sigma$. Head: Rounded; eye bridge 3-4 facets wide; antennae short, bicoloured; basal segments and first flagellomere yellow or yellow-brownish, flagellomeres brown, flagellomere 4 about $1.2 \mathrm{x}$ as long as wide, with distinct neck, surface slightly rough, setae dense and shorter than the diameter of basal part of flagellomere; palpi three-segmented; basal segment with 2-3 bristles and a patch of short sensillae.

Thorax: Brown, with yellow parts on the katepisternum, pronotum, antepronotum, prethoracic episternum and the base of wings; mesonotum brown, setose, with 2-3 stronger lateral setae; scutellum with 4 stronger posterior setae; postpronotum bare, antepronotum and prothoracal episternum sparsely setose; wings pale; $R_{1}=1 / 3 R ; R_{5}$ with only dorsal macrotrichia; $C=$ or somewhat longer $1 / 2 \mathrm{w} ; \mathrm{y}=\mathrm{x}$, bare; branches of $\mathrm{M}$ and $\mathrm{Cu}$ without macrotrichia. Halteres short with darkened heads; legs yellowish, tarsi darkened; fore tibiae at the inner apex without a distinct patch of bristles, only some bristles somewhat stronger than the ground setae; spurs of mid and hind tibiae subequal and longer than the diameter of apex. Claws very weakly toothed.

Abdomen: Tergal and sternal setae brown and rather short; base of hypopygium ventrally without distinct bristles, the inner ventral margin of gonocoxites with short setae; gonostyles widely rounded, apex with dense setae, with 6-8 weak hyaline subequal spines in front of 
and behind the short whip-lash seta; tegmen wider than high, without an internal structure apically; aedeagus short, basal part rather large. Body length: $2 \mathrm{~mm}$. क : unknown.

Locus typicus: Puerto Rico, Guanica, $17.97^{\circ} \mathrm{N} 66.86^{\circ} \mathrm{W}$, Guanica State Forest.

Holotype: 1 o , 25.7.1996, light trap, leg. Y. Canals.

Paratype: 10 , same data as holotype.

Depository: Holotype and paratype in CWMP.

Pseudolycoriella rotundostyla MOHRIG \& RULIK spec. nov.

(Fig. 16)

Diagnosis: This new species is very similar to Pseudosciara ovistyla and Pseudosciara subovistyla and belongs to the same species group (Pseudosciara ovistyla group). It differs by the short and strong subapical spines of the gonostyles.

Description: $0^{*}$. Head: Rounded; eye bridge 3 facets wide; antennae short, bicoloured; basal segments and the first flagellomere yellow, other flagellomeres brown with pale necks, flagellomere 4 about $1.8 \mathrm{x}$ as long as wide, surface slightly rough, setae somewhat shorter than the diameter of basal part of flagellomere, with white insertion points of sensoria between; palpi three-segmented; basal segment narrow, with 3-4 bristles and a patch of short sensillae.

Thorax: Brown, with yellow-ochreous parts on the pleural sclerites and the base of wings; mesonotum laterally with an ochreous strip, with brown setae with 2-3 stronger lateral setae; scutellum with 4 stronger posterior setae; postpronotum bare, antepronotum and prothoracic episternum with rather long brown setae; wings pale; $R_{1}=2 / 3 R_{3} R_{5}$ distally with dorsal and few ventral macrotrichia; $C=$ somewhat longer $1 / 2 w ; y=x$, bare; branches of $\mathrm{M}$ and $\mathrm{Cu}$ distinct and without macrotrichia. Halteres short, yellow; legs yellowish, tarsi darkened; fore tibiae at inner apex with an indistinct row of dark bristles (without semicircular margin); spurs of mid and hind tibiae subequal and longer than the diameter of apex. Claws rather strongly toothed.

Abdomen: Tergal and sternal setae brown and rather long; base of hypopygium bare, inner ventral margin of gonocoxites with very short setae; gonostyles short, widely rounded, apex with dense setae, with 5 short, strong subequal spines behind and a short whip-lash seta; tegmen wider than high, without an internal structure apically; aedeagus rather short. Body length: $2 \mathrm{~mm}$. ㅇ: unknown.

Locus typicus: Hispaniola (Dominican Republic): Monte Plata, $9 \mathrm{~km} N$ Bayaguana.

Holotype: 1 o, alt. 300 ft., 8. Aug. 1991, leg. D. Grimaldi \& J. Stark.

Depository: Holotype in CWMP.

\section{Pseudolycoriella virgata MoHrig \& RuLrK spec. nov.}

(Fig. 17)

Diagnosis: This new species belongs to the Pseudosciara ovistyla group by the apically rounded gonostyles with 5 spines behind the apical setae (up to the middle of the inner side) and the more proximally inserted short whip lash seta. 
Description: $0^{*}$. Head: Roundish; eye bridge 3 facets wide; antennae brown, necks pale, basal segments somewhat paler; flagellomere 3 about $2.0 \mathrm{x}$ as long as wide, surface slightly rough, setae distinctly shorter than the diameter of basal part of flagellomere, with white insertion points of sensoria between; palpi three-segmented; basal segment narrow, with 3-4 bristles and a patch of short sensillae.

Thorax: Brown, with yellow-ochreous parts on the antepronotum, katepisternum and the base of wings; mesonotum laterally with wide ochreous strips and a smaller ochreous strip in the middle; with brown setae and stronger prescutellar lateral setae (2-3); scutellum with 4 stronger posterior setae; postpronotum bare, antepronotum and prothoracic episternum with sparse and fine setae; wings browned; $\mathrm{R} 1=2 / 3 \mathrm{R}$; $\mathrm{R} 5$ distally with dorsal and few ventral macrotrichia; $C=2 / 3 \mathrm{w} ; \mathrm{y}=\mathrm{x}$, bare; branches of $\mathrm{M}$ and $\mathrm{Cu}$ distinct and without macrotrichia; halteres short, with darkened heads; legs yellowish-brown, tarsi darkened; fore tibiae at the inner apex with an indistinct row of dark bristles with distinct semicircular margin; spurs of mid and hind tibiae subequal and longer than the diameter of apex. Claws rather strongly toothed.

Abdomen: Tergal and sternal setae brown and rather long, tergites brown, 1. and 2. sternites more yellowish; base of hypopygium bare, the inner ventral margin of gonocoxites with sparse and short setae; gonostyles longish, widely rounded and apically densely setose, with 5 long hyaline subequal spines and a short whip-lash seta behind the setae up to the middle of the inner side; tegmen wider than high, without an internal structure apically; aedeagus very short. Body length: $2.5 \mathrm{~mm}$. ㅇ: unknown.

Locus typicus: Hispaniola (Dominican Republic): Pedernales Prov.; $20 \mathrm{~km}$ NE Pedernales; Las Abejas.

Holotype: $1 \sigma^{\text {a }}$, alt. $1.500 \mathrm{~m}$; broadleaf cloud forest; 26.-27. Nov. 1992; leg. Grimaldi \& Stark.

Paratype: $1 \sigma^{\star}$, same data as holotype.

Depository: Holotype in the AMNH, paratype in the CWMP.

\section{Pseudolycoriella indocera MoHrig \& RULIK spec. nov.}

(Fig. 18)

Diagnosis: This new species is a typical Pseudolycoriella. It is similar to Ps. florentissima and Ps. fuscivenosa. It differs from the first one by the structure of tegmen, shorter flagellomeres and the simple bristle-patch of the foretibiae, from the second one by shorter gonostyles with longer subapical spines and a wider internal structure of the tegmen.

Description: 0 . Head: Roundish; eye bridge 3 facets wide; antennae short, basal segments yellow-ochreous, flagellomeres brown, flagellomere 4 about $1.2 \mathrm{x}$ as long as wide, with distinct neck, surface rough, setae bristle-like, shorter than the diameter of basal part of flagellomere, with setae-like sensoriae on light insertion points; palpi three-segmented; basal segment with 3-4 bristles and a patch of short sensillae.

Thorax: Brown, with lighter spots at pleural sclerites and lateral parts of mesonotum; mesonotum with sparse setae, with 2-3 stronger lateral setae; scutellum with 2 stronger posterior setae; postpronotum bare, antepronotum and prethoracic episternum with sparse, fine setae; wings brownish; $R_{1}=2 / 3 R ; R_{5}$ only with dorsal macrotrichia; $C=2 / 3 \mathrm{w}$; 
$y$ slightlyt shorter $\mathrm{x}$, bare; branches of $\mathrm{M}$ and $\mathrm{Cu}$ without macrotrichia. Halteres short with darkened heads; legs brownish, tarsi darkened; fore tibiae at the inner apex with 5 stronger bristles in an indistinct row; spurs of mid and hind tibiae subequal and longer than the diameter of apex. Claws very distinctly toothed.

Abdomen: Tergal and sternal setae brown and rather long; base of hypopygium ventrally without distinct bristles, the inner ventral margin of gonocoxites with short setae; gonostyles narrow, lightly curved, rounded apically and with dense setae, with 2 subapical, subequal spines and a slightly longer whip-lash seta; tegmen wider than high, with a semicircular structure apically; aedeagus rather short. Body length: $2.2 \mathrm{~mm}$. ㅇ: unknown.

Locus typicus: Hispaniola (Dominican Republic): Pedernales Prov., $20 \mathrm{~km}$ NE Pedernales, Las Abejas.

Holotype: $1 \mathrm{o}$, alt. $1.500 \mathrm{~m}$, broadleaf cloud forest, 26.-27. Nov. 1992, leg. Grimaldi \& Stark.

Paratypes: $220^{*} \sigma^{x}$, same data as holotype; $30^{*}$, same locality, 1. Oct. 1992.

\section{Other material:}

$40^{\star} 0^{\star}$, Pedernales Prov., rd. to Los Arroyos, 2. Oct. 1992; $100^{\star} 0^{\star}$, Pedernales Prov., Las Abejas, 1. Oct. 1992; $400^{\star} 0^{\star}, 26 .-27$. Nov. 1992; $1 \sigma^{\star}$, La Vega Prov., rd. to San Jose de Ocoa, 29. Jul. 1991; 4 đే , La Vega Prov., 21 km W Bonáo, 2. Aug. 1991, all leg. D. Grimaldi \& J. Stark; $40^{\star} \sigma^{\star}$, Duarte Prov., $13 \mathrm{~km}$ N San Francisco de Macoris, Jul. 1991, leg. V. Almanzar.

Depository: Holotype, 15 paratypes and all additional material in AMNH, 10 paratypes in CWMP.

\section{Pseudolycoriella fuscivenosa MoHRig \& RuLIK spec. nov.}

(Fig. 19)

Diagnosis: This new species is similar to $P_{s}$. indocera and $P_{S}$. florentissima. It differs from the former by the shape of gonostyles and the two subapical spines inserted on the ventral and dorsal side of the gonostyles, from the latter by the simple, row-like patch of bristles at the apex of fore tibia, shorter flagellomeres and paler basal segments of antennae.

Description: 0 . Head: Roundish, clypeus and labrum slightly elongated; eye bridge 4 facets wide; antennae short, basal segments yellow-ochreous, flagellomeres brown, flagellomere 4 about $1.2 \mathrm{x}$ as long as wide, with distinct neck, surface rough, setae shorter than half the diameter of basal part of flagellomere, with setae-like sensoriae in distinct rows on light insertion points; palpi three-segmented; basal segment with 2-3 bristles and a patch of short sensillae.

Thorax: Brown, mesonotum with sparse setae, with 2-3 stronger lateral setae; scutellum with 4 stronger posterior setae; postpronotum bare, antepronotum and prethoracic episternum with sparse, fine setae; wings pale-brownish; $R_{1}=2 / 3 R_{5} ; R_{5}$ with only dorsal macrotrichia; $C=2 / 3 \mathrm{w} ; \mathrm{y}=\mathrm{x}$, bare; branches of $\mathrm{M}$ and $\mathrm{Cu}$ without macrotrichia. Halteres short with darkened heads; legs yellowish, tarsi darkened; fore tibiae at the inner apex with stronger bristles in an indistinct row; spurs of mid and hind tibiae subequal and longer than the diameter of apex. Claws distinctly toothed. 
Abdomen: Tergal and sternal setae brown, sparse and rather long; base of hypopygium ventrally without distinct bristles, inner ventral margin of gonocoxites with short setae; gonostyles narrow, rounded apically with dense setae, with 2 subapical spines (one ventrally, the second more dorsally) and a long whip-lash seta; tegmen wider than high, with a small semicircular structure apically; aedeagus rather short. Body length: $2.6 \mathrm{~mm}$. क : unknown. Locus typicus: Hispaniola (Dominican Republic): Pedernales Prov., $20 \mathrm{~km}$ NE Pedernales, Las Abejas.

Holotype: $1 \sigma^{\star}$, alt. $1.500 \mathrm{~m}$, broadleaf cloud forest, 26.-27. Nov. 1992, leg. Grimaldi \& Stark.

Paratypes: $7 \sigma^{\star}$, same data as holotype; $2 \sigma^{*}$, Duarte Prov., $13 \mathrm{~km} \mathrm{~N} \mathrm{San} \mathrm{Francisco} \mathrm{de}$ Macoris, Jul. 1991, leg. V. Almanzar.

\section{Other material:}

$10 \sigma^{\star}$, same data as holotype; $7 \sigma^{\star}$, Duarte Prov., $13 \mathrm{~km}$ N San Francisco de Macoris, Jul. 1991, leg. Almanzar; $2 \sigma^{\star}$, La Vega Prov., $12 \mathrm{~km} S$ Constanza, rd. to San Jose de Ocoa, 29. Jul. 1991; 5 o $0^{\star}$, Monte Plata, 9 km N Bayaguana, 8. Aug. 1991; 3 o ơ, La Vega Prov., 21 km W Bonão, 2. Aug. 1991; 1 đ*, Barahona Prov., La Cienaga, 3. Aug. 1991; 2 ơ ơ Paravia Prov., $30 \mathrm{~km}$ N San José de Ocoa, 30. Jul. 1991, all leg. Grimaldi \& Stark.

Depository: Holotype and 5 paratypes in AMNH, 4 paratypes in CWMP.

\section{Pseudolycoriella florentissima MoHRIG \& RULIK spec. nov.}

(Fig. 20)

Diagnosis: This contrast rich species is similar to Ps. indocera and Ps. fuscivenosa. It differs from both by the bristle-patch with semicircular margin at inner apex of the fore tibiae, longer flagellomeres and rather flat thorax.

Description: 0 . Head: Roundish, mouth parts slightly elongated; eye bridge 2-3 facets wide; antennae uniform brown, flagellomere 4 about twice as long as wide, with distinct neck, surface rather smooth, setae dense and shorter than the diameter of basal part of flagellomere, without distinct sensoria; palpi three-segmented; basal segment with 2-3 bristles and a patch of short sensillae.

Thorax: Dark brown, base of wings up to the sides of scutellum yellowish; mesonotum with sparse, short setae, with 2-3 stronger lateral setae; scutellum with 2 stronger posterior setae; postpronotum bare, antepronotum and prethoracic episternum with sparse, fine setae; katepisternum rather flat; wings pale; $R_{1}$ short $=1 / 2 R_{5} ; R_{5}$ with only dorsal macrotrichia; $C=3 / 4 \mathrm{w} ; \mathrm{y}=\mathrm{x}$, bare; branches of $\mathrm{M}$ and $\mathrm{Cu}$ without macrotrichia. Halteres short with darkened heads; legs yellowish, tarsi darkened; fore tibiae at the inner apex with patch of bristles with strong semicircular margin; spurs of mid and hind tibiae subequal and longer than the diameter of apex. Claws distinctly toothed.

Abdomen: Tergal and sternal setae brown and sparse; base of hypopygium ventrally without distinct bristles, inner ventral margin of gonocoxites with rather short setae; gonostyles narrow, rounded apically and with dense setae, with 3 subapical spines and a long whip-lash seta; tegmen higher than wide; aedeagus rather short. Body length: $2.6 \mathrm{~mm}$. o: unknown. 
Locus typicus: Hispaniola (Dominican Republic): Pedernales Prov., $20 \mathrm{~km}$ NE Pedernales, Las Abejas.

Holotype: $1 \sigma^{*}$, alt. $1.500 \mathrm{~m}$, broadleaf cloud forest, 26.-27. Nov. 1992, leg. Grimaldi \& Stark.

Paratypes: $13 \sigma^{\star}$, same data as holotype.

Other material:

1 đ`, La Vega Prov., $12 \mathrm{~km}$ S Constanza, rd. to San Jose de Ocoa, 29. Jul. 1991, leg. Grimaldi \& Stark.

Depository: Holotype and 7 paratypes in AMNH, 6 paratypes in CWMP.

Pseudolycoriella curvimedia MoHRIG \& RULIK spec. nov.

(Fig. 21)

Diagnosis: This new species belongs to the genus Pseudolycoriella by the toothed claws, the narrow basal segment of palpi and the patch of bristles with semicircular margin on the tip of fore tibiae. The numerous strong spines at the tip of the gonostyles and the strongly curved $M_{1}$ are new Diagnosis of this genus. At present there are no affinities to any other of the known species.

Description: 0 . Head: Roundish, prefrons and clypeus with few long and curved setae; eye bridge 3 facets wide; antennae uniform brown, necks brown, flagellomere 4 about $2.2 \mathrm{x}$ as long as wide, surface rather smooth, setae shorter than the diameter of basal part of flagellomere; palpi three-segmented; basal segment narrow, with 2-3 bristles and a patch of short sensillae.

Thorax: Uniform brown; mesonotum with rather long setae, with 2-3 stronger lateral setae; scutellum with 4 stronger posterior setae; postpronotum bare, antepronotum and prethoracic episternum with rather long setae; wings pale; $R_{1}$ very short, $=1 / 4 R_{;} R_{5}$ only with dorsal macrotrichia; $C=2 / 3 \mathrm{w} ; y=1 / 2 \mathrm{x}$, bare; $M_{1}$ strongly curved, $M_{2}$ straight, in line with $\mathrm{M}$-stem; CuA-stem variable, mostly rather long; $\mathrm{CuA}$, strongly curved distally to the edge of wings; posterior veins without macrotrichia; halteres rather long, with a thin and yellow stem and darkened heads; legs yellowish-brown, tarsi darkened; fore tibiae at the inner apex with an indistinct row of bristles, with strong semicircular margin; spurs of mid and hind tibiae subequal and longer than the diameter of apex. Claws distinctly toothed.

Abdomen: Tergal and sternal setae brown and sparse; base of hypopygium and the inner ventral margin of gonocoxites indistinct and with rather long setae; gonostyles rather narrow, apex with 6-7 spines, two more dorsally, and two short whip-lash setae; tegmen higher than wide; aedeagus rather long and wide. Body length: $2.2 \mathrm{~mm}$. 울 unknown.

Locus typicus: Hispaniola (Dominican Republic): Pedernales Prov., $20 \mathrm{~km}$ NE Pedernales, Las Abejas.

Holotype: $1 \sigma^{*}$, alt. $1.500 \mathrm{~m}$, broadleaf cloud forest, 1. Oct. 1992, leg. Grimaldi $\&$ Stark. 
Paratypes: $1 \sigma^{*}$, same locality, 26.-27. Nov. 1992; $2 \sigma^{\star}$, La Vega Prov., Constanza, rd. to San Jose de Ocoa, 29. Jul. 1991; $20^{*}$, La Vega Prov., SW Jarabacoa on road to Monebao, 29. Jul. 1991, all leg. Grimaldi \& Stark.

Depository: Holotype and 2 paratypes in AMNH, 3 paratypes in CWMP.

\section{Genus Bradysia WINNERTZ, 1867}

We follow the concept of TuOMIKoski (1960), subdividing the genus in monophyletic species groups, suggesting that much more information from different zoogeographic regions is needed before subgenic taxa can be proposed. Bradysia is the largest genus of Sciaridae and is distributed world wide. The best known at present are approximately 215 species of the Palaearctic Region, subdivided in 16 species groups (MoHrig et al. 1989a, b; Menzel \& Mohrig 2000). The genus is also well represented within the Nearctic region (STEFfan 1966), in Micronesia (Steffan 1969) and in the Indomalayan islands (own material, unpublished).

The genus is well characterised by the very stable characteristic of a strong comb-like row of bristles at the tip of the fore tibiae, two subequal spurs of the mid and hind tibiae, mostly untoothed tarsal claws (only species of the Palaearctic Bradysia fungicola group show fine teethed claws), mostly 4 or more long scutellar bristles, 3-segmented palpi with at least 2 or more bristles on the basal segment, a bare posterior pronotum and without macrotrichia on the posterior wing veins. The shape of the gonostyles and the arrangement of spines and teeth are rather different. A lobe or a spine or bristle group at the ventral base of the hypopygium are present in some species groups. The head is normally round, in few species with slightly elongated mouth parts. The colour of body, head and antennae in Holarctic species is mostly brown, only the species of the Bradysia hilaris group (also some species of the $B$. fungicola group and the $B$. amoena group) constantly show flagellomeres with bicoloured necks and sometimes antennae with yellow basal segments.

\section{Bradysia turgida MoHrug \& RösCHMANn spec. nov.}

(Fig. 22)

Diagnosis: This new species is characterised by the wide comb of bristles at the apex of fore tibiae, the long gonostyles with a strong apical tooth and the macrotrichia on $\mathrm{x}$ and y. B. turgida is distinguished from the other species by the strong apical tooth. Its position within the $B$. hilaris group is not sure and based only on the bicoloured necks of the flagellomeres.

Description: $\sigma$. Head: Eye bridge 3 facets wide; antennae brown, basal segments yellowochreous, necks paler and weakly bicoloured, rather short; flagellomere 4 about $2.4 \mathrm{x}$ as long as wide, setae shorter than the diameter of basal part of flagellomere; palpi threesegmented, long; basal segment with $5-6$ bristles and a patch of short sensillae.

Thorax: Dark brown; mesonotum with moderately long, dorsocentral setae, some stronger lateral setae; scutellum with 4 strong posterior setae; postpronotum bare, antepronotum and prethoracic episternum with sparse but moderately long setae; wings brownish, $R_{1}$ long, = 3/4 $R ; R_{5}$ in distal half with ventral macrotrichia; $C=2 / 3 w ; y=x$, both with 
macrotrichia; posterior veins strong, without macrotrichia. Halteres short with darkened heads; legs yellowish-brown; tarsi darkened; fore tibiae at the inner apex with a very wide comb-like row of bristles, spurs of mid and hind tibiae subequal, brownish and longer than the diameter of apex. Claws untoothed.

Abdomen: Tergal and sternal setae dense and moderately long; base of hypopygium and the inner ventral margin of gonocoxites with short setae; gonostyles long and narrow, apex with a long tooth and 4 shorter spines; tegmen widely rounded, with a large area of teeth; aedeagus rather long. Body length: $3.2 \mathrm{~mm}$. : : unknown.

Locus typicus: Hispaniola (Dominican Republic): Pedernales Prov., $20 \mathrm{~km}$ NE Pedernales, Las Abejas.

Holotype: 1 o , alt. $1.500 \mathrm{~m}$, broadleaf cloud forest, 26.-27. Nov. 1992, leg. Grimaldi \& Stark.

Paratypes: $2 \sigma^{*}$, same data as holotype.

Depository: Holotype in AMNH, the paratypes in CWMP.

\section{Bradysia clara MoHrig \& Röschmann spec. nov.}

(Fig. 23)

Diagnosis: This unique yellow species is characterised by the colour and the shape of gonostyles with the short equal spines at the tip. It belongs to the $B$. hilaris group by the bicoloured necks of flagellomeres.

Description: $0^{\star}$. Head: Eye bridge 4 facets wide; antennae brown, basal segments slightly ochreous, necks paler and weakly bicoloured, rather short; flagellomere 4 about $2.5 \mathrm{x}$ as long as wide, setae dense and somewhat shorter than the diameter of basal part of flagellomere; palpi three-segmented, long; basal segment with 5-6 bristles and a patch of short sensillae.

Thorax: Yellow; mesonotum with dark brown setae, some stronger lateral setae; scutellum with 4 strong posterior setae; postpronotum bare, antepronotum and prethoracic episternum with sparse, fine setae; wings brownish, $R_{1}=3 / 4 R ; R_{5}$ with dorsal and ventral macrotrichia along the whole length; $C=2 / 3 \mathrm{w} ; \mathrm{y}=\mathrm{x}$, with macrotrichia; posterior veins without macrotrichia. Halteres short with darkened heads; legs yellowish; tarsi darkened; fore tibiae at the inner apex with a very wide comb-like row of bristles, spurs of mid and hind tibiae subequal, longer than the diameter of apex. Claws untoothed.

Abdomen: Tergites brown, sternites ochreous; base of hypopygium and the inner ventral margin of gonocoxites with short setae; gonostyles long and narrow, darkened in the apical half, apex with 6-7 short spines; tegmen widely rounded, with a large area of teeth; aedeagus rather long. Body length: $3.5 \mathrm{~mm}$. i : unknown.

Locus typicus: Hispaniola (Dominican Republic): Pedernales Prov., $20 \mathrm{~km}$ NE Pedernales, Las Abejas.

Holotype: $1 \sigma^{x}$, alt. $1.500 \mathrm{~m}$, broadleaf cloud forest, 26.-27. Nov. 1992, leg. Grimaldi \& Stark.

Paratypes: $2 \sigma^{\star} o^{*}$, same data as holotype, $1 \sigma^{*}$, same locality, 1 . Oct. 1992; $10^{*}$, La Vega Prov., rd. to San Jose de Ocoa, 29. Jul. 1991, all leg. D. Grimaldi \& J. Stark.

Depository: Holotype and one paratype in AMNH, 3 paratypes in CWMP. 


\section{Bradysia reticulata MoHRIg \& Röschmann spec. nov.}

(Fig. 24)

Diagnosis: This very pale species is characterised by the rough surface of flagellomeres with net-like lines between the insertion points of setae and sensoria, and the shape of gonostyles with 4 spines closely aligned at the apex. The species belongs to the $B$. hilaris group by the rough surface of flagellomeres.

Description: 0 . Head: Eye bridge 4 facets wide; antennae brown, basal segments yellowochreous, necks rather long, brownish and not distinctly bicoloured; flagellomere 4 about $2.2 \mathrm{x}$ as long as wide, setae somewhat shorter than the diameter of basal part of flagellomere, with white insertion points of short sensoria and a net structure between; surface rough; palpi three-segmented, basal segment with 1-2 bristles and a patch of short sensillae.

Thorax: Yellow-brown, with darker spots on the prethoracic episternum and the katepisternum; mesonotum brown and with moderately short setae, some lateral setae stronger; scutellum with 4 strong posterior setae; postpronotum bare, antepronotum and prethoracic episternum with sparse setae; wings pale, $R_{1}$ very short, shorter $1 / 2 R ; R_{5}$ with only dorsal macrotrichia; $C=2 / 3 \mathrm{w}$; $y$ shorter $\mathrm{x}$, without macrotrichia; posterior veins without macrotrichia. Halteres short with darkened heads; legs yellowish; tarsi darkened; fore tibiae at the inner apex with a comb-like row of bristles, spurs of mid and hind tibiae subequal, longer than the diameter of apex. Claws strong toothed.

Abdomen: Brown, with sparse setae; base of hypopygium and inner ventral margin of gonocoxites with sparse but rather long setae; gonostyles narrowed, curved, apex with 4 subequal spines; tegmen large, with rather coarse teeth; aedeagus very long. Body length: $2 \mathrm{~mm}$. : : unknown.

Locus typicus: Hispaniola (Dominican Republic): Pedernales Prov, $20 \mathrm{~km}$ NE Pedernales, Las Abejas.

Holotype: 1 \%, alt. $1.500 \mathrm{~m}$, broadleaf cloud forest, 26.-27. Nov. 1992, leg. Grimaldi \& Stark.

Paratypes: $6 \sigma^{\circ}$, same data as holotype; $1 \sigma^{\circ}$, same locality, 1. Oct. 1992.

Depository: Holotype and 3 paratypes in AMNH, 4 paratypes in CWMP.

\section{Bradysia spinea MoHrig \& Röschmann spec. nov.}

(Fig. 25)

Diagnosis: This new species belongs to the $B$. hilaris group by the bicoloured necks of flagellomeres. It is characterised by the shape of gonostyles and is similar $B$. subspinea (other differences see there).

Description: $\sigma$. Head: Eye bridge 3 facets wide; antennae uniform brown; necks rather short, brownish, weakly bicoloured; flagellomere 4 about $2.2 \mathrm{x}$ as long as wide, setae shorter than the diameter of basal part of flagellomere, surface not rough; palpi threesegmented, basal segment with 3-4 bristles and a patch of short sensillae.

Thorax: Ochreous, lower part of the katepisternum and three strips (lateral and central) of the mesonotum darkened; mesonotum with brown setae, some stronger lateral setae; scutellum with 4 strong, posterior setae; postpronotum bare, antepronotum and pretho- 
racic episternum with sparse setae; wings pale, anal area narrowed; $R_{1}=2 / 3 R$; $R_{5}$ with only dorsal macrotrichia; $\mathrm{C}=3 / 4 \mathrm{w} ; \mathrm{y}=\mathrm{x}$, without macrotrichia; posterior veins weak and without macrotrichia. Halteres short with darkened heads; legs yellowish-brown; tarsi darkened; fore tibiae at the inner apex with a comb-like row of bristles, spurs of mid and hind tibiae subequal, longer than the diameter of apex.

Abdomen: Brown, sparsely setose; base of hypopygium and inner ventral margin of gonocoxites sparsely setose; apex of gonostyles with 5 spines, one isolated dorsally, 4 subapical; tegmen rounded, with a rather large area of teeth; aedeagus rather long. Body length: $2.5 \mathrm{~mm}$. $\%$ : unknown.

Locus typicus: Hispaniola (Dominican Republic): Duarte Prov., $13 \mathrm{~km} \mathrm{~N}$ San Francisco de Macoris.

Holotype: $1 \sigma^{*}$, alt. $800 \mathrm{ft}$, Malaise trap in cloud forest, Jul. 1991, leg. V. Almanzar.

Depository: Holotypus in CWMP.

\section{Bradysia subspinea MoHRIG \& RöschmANN spec. nov.}

(Fig. 26)

Diagnosis: This new species belongs to the $B$. hilaris group by the bicoloured necks of flagellomeres. It is very similar to $B$. spinea. It differs in smaller size, darker colour and shorter gonostyles with more apical spines.

Description: 0 . Head: Eye bridge 3 facets wide; antennae uniform brown; necks rather short, brownish, weakly bicoloured; palpi three-segmented, basal segment with 3-4 bristles and a patch of short sensillae.

Thorax: Uniform ochreous-brown; mesonotum with dark setae, some stronger lateral setae; scutellum with 4 strong, posterior setae; postpronotum bare, antepronotum and prethoracic episternum with sparse setae; wings pale, $R_{1}$ slightly longer $1 / 2 R_{\text {; }} R_{5}$ with only dorsal macrotrichia; $\mathrm{C}=2 / 3 \mathrm{w} ; \mathrm{y}=\mathrm{x}$, without macrotrichia; posterior veins weak and without macrotrichia. Halteres short with darkened heads; legs somewhat paler than the thorax; tarsi darkened; fore tibiae at inner apex with a comb-like row of bristles, spurs of mid and hind tibiae subequal, longer than the diameter of apex. Claws untoothed.

Abdomen: Brown, sparsely setose; base of hypopygium and inner ventral margin of gonocoxites with sparse setae; gonostyles rather strong, apex with 7 spines, two of them more dorsally isolated, 5 more apical-subapical; tegmen rounded; aedeagus rather long. Body length: $1.9 \mathrm{~mm}$. ㅇ: unknown.

Locus typicus: Hispaniola (Dominican Republic): Barahona Prov., just S La Cienaga. Holotype: 1 o, alt. $100 \mathrm{ft}$, near stream, 3. Aug. 1991, leg. D. Grimaldi \& J. Stark. Depository: Holotypus in CWMP.

\section{Bradysia ciliocera MoHrig \& Röschmann spec. nov.}

(Fig. 27)

Diagnosis: This new species belongs to the $B$. hilaris group by the bicoloured necks of flagellomeres. It is characterised by the long setae of flagellomere and the shape of gonocoxites. 
Description: $0^{*}$. Head: Eye bridge 3-4 facets wide; antennae uniform brownish, with long, strong setae; necks rather long, pale, weakly bicoloured; flagellomere 4 about $2 \mathrm{x}$ as long as wide, flagellomeres with bristle-like setae, not dense and longer than the diameter of the basal part; palpi three-segmented, basal segment with 3-4 bristles and a patch of short sensillae.

Thorax: Uniform brown; mesonotum with short setae, some stronger lateral setae; scutellum with 4 stronger posterior setae; postpronotum bare, antepronotum and prethoracic episternum with sparse, fine setae; wings pale, $R_{1}=1 / 2 R ; R_{5}$ with only dorsal macrotrichia; $C=2 / 3$ w; $y=1 / 2 x$, without macrotrichia; posterior veins without macrotrichia. Halteres short with darkened heads; legs brownish; tarsi darkened; fore tibiae at the inner apex with a comb-like row of bristles, spurs of mid and hind tibiae subequal, longer than the diameter of apex. Claws untoothed.

Abdomen: Brown, sparse but with rather long setae; base of hypopygium and the inner ventral margin of gonocoxites with rather dense setae; gonostyles rather long, with 3 spines more subapically, one of them longer; tegmen wide, more or less rounded; adeagus rather short and strong. Body length: $2.2 \mathrm{~mm}$. 오 : unknown.

Locus typicus: Hispaniola (Dominican Republic): La Vega Prov., $12 \mathrm{~km} \mathrm{~S}$ Constanza, rd. to San Jose de Ocoa.

Holotype: 1 o , alt. 5.000 ft., 29. Jul. 1991, leg. D. Grimaldi \& J. Stark.

Depository: Holotypus in CWMP.

\section{Bradysia acerba MOHRIG \& RöschMANn spec. nov.}

(Fig. 28)

Diagnosis: This new species belongs to the $B$. amoena group by the deep sensory pit on the basal segment of palpi. The setae on some pleural sclerites are unusual. It differs from the following species by the long flagellar setae and the short gonostyles with several spines.

Description: 0 . Head: Eye bridge 3 facets wide, frons with $6-8$ setae; antennae uniform brown, with long, strong setae, necks rather long, uniform colour; flagellomere 4 about $2 \mathrm{x}$ longer than wide, setae of flagellomeres somewhat shorter than the diameter of the basal part; palpi three-segmented, basal segment with $3 / 4$ bristles and a deep pit of sensillae.

Thorax: Brown, with darkened spots on the mesonotum, the lower half of the katepisternum and mediotergite; mesonotum with rather long, brown setae, some stronger lateral setae; scutellum with 4 stronger posterior setae; postpronotum bare, antepronotum and prethoracic episternum with rather dense setae; antethoracic anepisternum with 6-7 fine setae, also the mediotergite with a setae patch; wings pale, $R_{1}$ somewhat shorter $1 / 2 R ; R_{5}$ with only dorsal macrotrichia; $C=2 / 3 \mathrm{w}$; $y$ somewhat shorter $\mathrm{x}$, both with macrotrichia; posterior veins strong and without macrotrichia; halteres short with darkened heads; legs yellow-ochreous; tarsi darkened; fore tibiae at inner apex with a comb-like row of bristles, spurs of mid and hind tibiae subequal, longer than diameter of apex. Claws untoothed. 
Abdomen: Brown, with brown setae; base of hypopygium and the inner ventral margin of gonocoxites with short setae; gonostyles rather short and strong, apically rounded, with 8-10 closely aligned spines; tegmen obtuse cone-shape; aedeagus rather short. Body length: $3 \mathrm{~mm}$. 9 : unknown.

Locus typicus: Hispaniola (Dominican Republic): Duarte Prov., 13 km N San Francisco de Macoris.

Holotype: $1 \sigma$, alt. $800 \mathrm{ft}$., Malaise trap in cloud forest, July 1991, leg. V. Almanzar.

Paratypes: $3 \sigma^{*}$, same data as holotype; $1 \sigma^{\star}$, same locality, Aug. 1991; 1 o, La Romana, coast forest, 30. Sept. 1992, leg. Grimaldi \& Stark.

\section{Other material:}

$20^{x}$, same data as holotype.

Depository: Holotypus and 2 paratypes in AMNH, 3 paratypes in CWMP.

\section{Bradysia obtusa Mohrig \& Röschmann spec. nov.}

(Fig. 29)

Diagnosis: This new species belongs to the $B$. amoena group by the deep sensory pit on the basal segment of palpi. It is similar to $B$. acerba by the setae on the antethoracic anepisternum and the mediotergite. It is distinguished by the dense setae of flagellomere and the shape of gonostyles.

Description: 0 . Head: Eye bridge 2-3 facets wide, antennae uniform brown, rather short with dense setae, necks rather long, uniform colour; flagellomere 4 about $2.2 \times$ longer than wide; palpi three-segmented, basal segment with 3-4 bristles and a deep pit of sensillae.

Thorax: Brown, mesonotum with short, fine setae, lateral setae only slightly longer; scutellum with 4 short and weak posterior setae; postpronotum bare, antepronotum and prethoracic episternum with sparse, fine setae; antethoracic anepisternum with 6-7 fine setae, also the mediotergite with a setae patch; wings pale, $\mathrm{R}_{1}$ somewhat shorter $1 / 2 \mathrm{R}$; $\mathrm{R}_{5}$ only with dorsal macrotrichia; $C$ slightly longer $1 / 2 \mathrm{w} ; \mathrm{y}=\mathrm{x}$, both with macrotrichia; posterior veins strong and without macrotrichia; halteres short with darkened heads; legs brownish; tarsi darkened; fore tibiae at the inner apex with a comb-like row of bristles, spurs of mid and hind tibiae subequal, longer than the diameter of apex. Claws untoothed.

Abdomen: Brown, with brown setae; base of hypopygium and the inner ventral margin of gonocoxites with short setae; gonostyles rather long and narrow, apex with 4 subequal spines; tegmen more obtuse cone-shape; aedeagus rather long. Body length: $2.5 \mathrm{~mm}$. 우 : unknown.

Locus typicus: Hispaniola (Dominican Republic): La Vega Prov., $12 \mathrm{~km} S$ Constanza, rd. to San Jose de Ocoa.

Holotype: $1 \sigma^{\star}$, alt. 5.000 ft., 29. Jul. 1991, leg. D. Grimaldi \& J. Stark.

Paratypes: $1 \varnothing$, same data as holotype.

Depository: Holotype in AMNH, paratype in CWMP. 


\section{Bradysia ocellaris (CомSTOCK, 1882)}

Literature: Comstock 1882. Ann. Rep. Dept. Agric., 1882: 202-204; plate 17, fig. 2-4.

The species is widely distributed within the Palaearctic and Nearctic Regions and in temperate climate is often connected with greenhouses where it is a plant pest. It has been described as Sciara tritici CoquIllett, 1895, Lycoria prothalliorum De Melerjere, 1946 and Bradysia rubicundula FREY, 1948. The recent distribution could be a result of spread by man.

\section{Material examined:}

Puerto Rico, Guanica, $17.97^{\circ} \mathrm{N} 66.86^{\circ} \mathrm{W}$, Guanica State Forest, $2 \sigma^{\circ} \sigma^{\star}, 25.7 .1996$, light trap, leg. Y. Canals.

\section{Bradysia crassicera MoHRIg \& RöschManN spec. nov.}

(Fig. 30)

Diagnosis: This new species belongs to the genus Bradysia by the comb-like row of bristles at the inner apex of fore tibiae. The strong apical tooth with shorter subapical spines is similar to some Holarctic species of the B. brunnipes group (species like $B$. subamoena and $B$. forcipulata).

Description: 0 . Head: Eye bridge 3 facets wide; antennae uniform brown, with short, rather ????tide setae, necks short, uniform colour; flagellomere 4 about $2 \times$ longer than wide, setae of flagellomeres shorter than the diameter of the basal part; palpi three-segmented, basal segment with $3 / 4$ bristles and a patch of sensillae.

Thorax: Brown, with ochreous spots on the lateral mesonotum and pleural sclerites, mesonotum with rather long, fine, brown setae, some stronger lateral setae; scutellum with 2 stronger posterior setae; postpronotum bare, antepronotum and prethoracic episternum with sparse, rather long setae; wings pale, $R_{1}=2 / 3 R_{2} R_{5}$ with only dorsal macrotrichia; $\mathrm{C}$ slightly longer $1 / 2 \mathrm{w} ; \mathrm{y}=\mathrm{x}$, bare; posterior veins strong and without macrotrichia; halteres short with darkened heads; legs yellow-brownish; tarsi darkened; fore tibiae at the inner apex with a comb-like row of bristles, spurs of mid and hind tibiae subequal, longer than the diameter of apex. Claws toothed.

Abdomen: Brown, with fine, brown setae; base of hypopygium and the inner ventral margin of gonocoxites with short setae; gonostyles with a strong apical spine tooth and 4 short subapical spines; tegmen rounded, with a large area of fine teeth; aedeagus rather short. Body length: $2.6 \mathrm{~mm}$. o : unknown.

Locus typicus: Hispaniola (Dominican Republic): Pedernales Prov., $20 \mathrm{~km}$ NE Pedernales, Las Abejas.

Holotype: $1 \sigma^{\star}$, alt. $1.500 \mathrm{~m}$, broadleaf cloud forest, 26.-27. Nov. 1992, leg. Grimaldi \& Stark.

Depository: Holotype in CWMP. 


\section{Bradysia pararufescens MoHRig \& Röschmann spec. nov.}

(Fig. 31)

Diagnosis: This new species undoubtedly belongs to the genus Bradysia. It has the basal lobe and the long convergent setae at the inner ventral margin of the gonocoxites together with nearly all Holarctic species of the well defined $B$. rufescens group. $B$. pararufescens is distinguished from these by the lack of an apical tooth and the rounded tegmen. One species from Costa Rica (Mohrig 2003) and a few species from Brazil (not published) are known which are very similar to the new species, so that we assume an endemic sister group to the Holarctic species.

Description: $\sigma^{*}$. Head: Eye bridge $2 / 3$ facets wide; antennae long, flagellomeres brown with long, strong setae, basal segments ochreous, necks rather short, weakly bicoloured; flagellomere 4 about $2.5 \times$ longer than wide, setac of flagellomeres somewhat longer than the diameter of the basal part; palpi three-segmented, basal segment with 1-3 bristles and a patch of short sensillae.

Thorax: Yellow with brownish spots on the pleural sclerites; mesonotum with brown setae, some stronger, lateral setae; scutellum with 2 stronger and 2 shorter posterior setae; postpronotum bare, antepronotum and prethoracic episternum with sparse, fine setose; wings pale, $R_{1}=2 / 3 R ; R_{5}$ with only dorsal macrotrichia; $C=2 / 3$ w; $y$ shorter $x$, with 1 2 macrotrichia; posterior veins without macrotrichia; halteres short with darkened heads; legs yellow-ochreous; tarsi darkened; fore tibiae at the inner apex with a comb-like row of bristles, spurs of mid and hind tibiae subequal, longer than the diameter of apex. Claws untoothed.

Abdomen: Brown, with rather long setae; base of hypopygium with a small and more membraneous lobe with 4 short setae, inner ventral margin of gonocoxites with long, overlapping setae in the basal half; gonostyles rather long, with 5 spines subapically, one isolated; tegmen rounded; aedeagus rather short. Body length: $2.2 \mathrm{~mm}$. ㅇ: unknown.

Locus typicus: Hispaniola (Dominican Republic): Duarte Prov., $13 \mathrm{~km}$ N San Francisco de Macoris.

Holotype: $1 \sigma^{\star}$, alt. $800 \mathrm{ft}$., Malaise trap in cloud forest, Jul. 1991, leg. V. Almanzar.

Paratypes: 5 o $\sigma^{*}$, same data as holotype.

Depository: Holotypus and 2 paratypes in AMNH, 3 paratypes in CWMP.

\section{Bradysia mellea MoHrig \& Röschmann spec. nov.}

(Fig. 32)

Diagnosis: This new species belongs undoubtedly to the genus Bradysia. It is very similar to $B$. pararufescens. It differs by the shorter basal lobe and the lack of long setae on the inner ventral margin of the gonocoxites.

Description: ${ }^{*}$. Head: Eye bridge 2/3 facets wide; antennac long, flagellomeres brown, with long, strong setae, basal segments ochreous, necks rather short, weakly bicoloured; flagellomere 4 about $2.4 \times$ longer than wide, setae of flagellomeres somewhat longer than the diameter of the basal part; palpi three-segmented, basal segment with $2-3$ bristles and a patch of short sensillae. 
Thorax: Ochreous; mesonotum with brown setae, some stronger lateral setae; scutellum with 4 stronger posterior setae; postpronotum bare, antepronotum and prethoracic episternum sparse and with rather short setae; wings pale, $\mathrm{R}_{1}=2 / 3 \mathrm{R} ; \mathrm{R}_{5}$ with only dorsal macrotrichia; $C=2 / 3 \mathrm{w} ; \mathrm{y}=\mathrm{x}$, with $2-3$ macrotrichia; posterior veins without macrotrichia; halteres short with darkened heads; legs yellowish; tarsi darkened; fore tibiae at inner apex with a comb-like row of bristles, spurs of mid and hind tibiae subequal, longer than the diameter of apex. Claws untoothed.

Abdomen: Brown, with brown setae; base of hypopygium with a short wide, more membraneous lobe with 4 setae, inner ventral margin of gonocoxites with short setae; gonostyles rather long, with 4 equal and closely aligned spines; tegmen rounded; aedeagus rather short; apical margin of the 9 th sternite narrowed in the middle. Body length: $2 \mathrm{~mm}$. o : unknown.

Locus typicus: Hispaniola (Dominican Republic): Pedernales Prov., $20 \mathrm{~km}$ NE Pedernales, Las Abejas.

Holotype: $1 \sigma^{\star}$, alt. $1.500 \mathrm{~m}$, broadleaf cloud forest, 26.-27. Nov. 1992, leg. Grimaldi \& Stark.

Depository: Holotypus in CWMP.

\section{Bradysia oculosa MoHrig \& Röschmann spec. nov.}

(Fig. 33)

Diagnosis: This new species is characterised by the elongated mouth part, the short and angular base of $R_{5}(x, y)$ and the rough flagellomeres. The shape of gonostyles with an apical tooth is similar to species near the Holarctic B. rufescens group.

Description: 0 . Head: Ovoid, clypeus and labrum elongated; eye bridge 3 facets wide: antennae uniform brown, necks short, uniform colour; flagellomere 4 about 2 x longer than wide, setae of flagellomeres shorter than the diameter of the basal part, surface rough, insertion points of sensory setae large and light; palpi three-segmented, basal segment with 3-4 bristles and a patch of sensillae.

Thorax: Brown, mesonotum with a dark central strip, with short, fine setae, some lateral and scutellar setae slightly longer; postpronotum bare, antepronotum and prethoracic episternum with sparse, fine setae; wings pale, anal area large, $R_{1}$ very short, about $1 / 4 \mathrm{R}$; $\mathrm{R}_{5}$ only with dorsal macrotrichia; $\mathrm{C}=2 / 3 \mathrm{w} ; \mathrm{y}$ short and strong squared off from $\mathrm{R}_{5} ; \mathrm{y}$ and $\mathrm{x}$ without macrotrichia; posterior veins without macrotrichia; halteres short with darkened heads; legs yellow-brownish; tarsi darkened; fore tibiae at inner apex with a comb-like row of bristles, spurs of mid and hind tibiae rather short and subequal. Claws untoothed.

Abdomen: Brown, with rather long setae; base of hypopygium and the inner ventral margin of gonocoxites with short setae; gonostyles short, apex with a short tooth and 4 longer subapical spines; tegmen rounded, with scale-like teeth; aedeagus rather strong. Body length: $1.6 \mathrm{~mm}$. 9 : unknown.

Locus typicus: Hispaniola (Dominican Republic): Pedernales Prov., $20 \mathrm{~km}$ NE Pedernales, Las Abejas. 
Holotype: $1 \sigma^{\star}$, alt. $1.500 \mathrm{~m}$, broadleaf cloud forest, 26.-27. Nov. 1992, leg. Grimaldi \& Stark.

Paratypes: $5 \sigma^{\circ}$, same data as holotype.

Depository: Holotype and 2 paratypes in AMNH, 3 paratypes in CWMP.

\section{Bradysia longioculosa MoHRig \& Röschmann spec. nov.}

(Fig. 34)

Diagnosis: This new species is characterised by the strongly toothed claws, the elongated mouth part, the membranous lobe at the base of the hypopygium, the distinctly pale wings with the angular anal area and very fine macrotrichia on the membranous area. It is similar to $B$. oculosa and also shows similarities to species of the $B$. rufescens group.

Description: 0 . Head: Ovoid, clypeus and labrum elongated; frons high, eye bridge 3 facets wide; antennae bicoloured brown, basal segments and the two first flagellomeres yellowbrownish, the other flagellomeres dark brown; necks uniform colour; flagellomere 4 about $2.2 \times$ longer than wide, setae of flagellomeres dense, fine and shorter than the diameter of the basal part; palpi three-segmented, basal segment with 3-4 bristles and a patch of sensillae.

Thorax: Dark brown, mesonotum, scutellum and mediotergite with a dark central strip; mesonotum with very short, fine setae, lateral and scutellar setae short; postpronotum bare, antepronotum and prethoracic episternum with sparse, fine setae; wings glass-clear, anal area large and angular, $R_{1}=1 / 2 R ; R_{5}$ with only dorsal macrotrichia; $C=2 / 3 \mathrm{w} ; \mathrm{y}$ shorter $\mathrm{x}$; bare; posterior veins very weak, without macrotrichia; halteres short with yellowish heads; legs yellow-brownish; tarsi darkened; fore tibiae at the inner apex with a comblike row of bristles, spurs of mid and hind tibiae subequal. Claws strongly toothed.

Abdomen: Dark brown, with brown setae; base of hypopygium with a membranous lobe without setae; the inner ventral margin of gonocoxites with short setae; gonostyles short, apex with short tooth and 3 somewhat longer subapical spines; tegmen higher than wide, rounded, with fine teeth; aedeagus rather short. Body length: $3 \mathrm{~mm}$. o : unknown.

Locus typicus: Hispaniola (Dominican Republic): Pedernales Prov., 20 km NE Pedernales, Las Abejas.

Holotype: $1 \delta^{x}$, alt. $1.500 \mathrm{~m}$, broadleaf cloud forest, 26.-27. Nov. 1992, leg. Grimaldi \& Stark.

Paratypes: $1{ }^{\star}$, Duarte Prov., San Francisco de Macoris, May/June 1991, leg. Almanzar. Depository: Holotype in AMNH, paratype in CWMP.

\section{Bradysia cauta Mohrig \& Röschmann spec. nov.}

(Fig. 35)

Diagnosis: This new species is characterised by the shape of gonostyles and the large anal area of wings. It is an Holarctic example of Bradysia species, but has no definite connections with any of the species groups known at present.

Description: $0^{*}$. Head: Eye bridge narrow, 2-3 facets wide; frons with few setae; antennae uniform brown, necks rather short, uniform colour; flagellomere 4 about 2 x lon- 
ger than wide, setae of flagellomeres shorter than the diameter of the basal part, surface smooth, palpi three-segmented, basal segment with 3-4 bristles and a patch of sensillae. Thorax: Dark brown, mesonotum with short, fine setae, some slightly longer lateral and scutellar setae; postpronotum bare, antepronotum and prethoracic episternum with sparse, fine, pale setae; wings pale, anal area large, $R_{1}$ longer $1 / 2 R ; R_{5}$ with only dorsal macrotrichia; $C=2 / 3 \mathrm{w}$; $y$ shorter $x$, with few macrotrichia; posterior veins without macrotrichia; halteres short with darkened heads; legs yellow-brownish; tarsi darkened; fore tibiae at the inner apex with a comb-like row of bristles, spurs of mid and hind tibiae subequal. Claws untoothed.

Abdomen: Brown, with brown setae; base of hypopygium and the inner ventral margin of gonocoxites with short setae; gonostyles apically with 6-7 spines, the lower two stronger; tegmen rounded, with fine teeth; aedeagus rather short. Body length: $2.5 \mathrm{~mm}$. $q$ : unknown.

Locus typicus: Hispaniola (Dominican Republic): Pedernales Prov., $20 \mathrm{~km}$ NE Pedernales, Las Abejas.

Holotype: $1 \sigma$, alt. $1.500 \mathrm{~m}$, broadleaf cloud forest, 26.-27. Nov. 1992, leg. Grimaldi \& Stark.

Paratypes: $16 \sigma^{\circ} \sigma^{*}$, same data as holotype, $20^{\circ} \sigma^{*}$, La Vega Prov., rd. to San Jose de Ocoa, 29. Jul. 1991; 1 \%, Pedernales Prov., 40 km N Caba Rojo, 1. Aug. 1991, all leg. Grimaldi \& Stark.

Depository: Holotype and 9 paratypes in AMNH, 10 paratypes in CWMP.

\section{Genus Scatopsciara EDWARDs, 1927}

The genus is distributed mainly within the Northern hemisphere. About 50 species from the Palaearctic Region (Menzel \& Mohrig 2000)and 7 species from the Nearctical Region (Poole \& Gentrl 1996) are known, as well as few non revised species from other zoogeographic regions. The genus is well characterised by the distinct reduction of the length or complete absence of one spur on the mid and/or the hind tibiae. This characteristic is combined with a small comb-like row of bristles at the apex of the fore tibiae (as in Bradysia, but smaller), a very short $\mathrm{R}_{1}$, rather wide and short flagellomeres, only two longer bristles on the posterior margin of the scutellum, untoothed tarsal claws and the lack of macrotrichia on posterior wing veins. The genus is divided in the two subgenera: Scatopsciara EDWARos, 1927 s. str. (gonostyle with a distinct apical tooth) and Xenoppygina Frey, 1948 (gonostyle with apical spines only; sometimes difficult to separate from Bradysia species).

\section{Scatopsciara (Scatopsciara) ventosa MoHRIG \& RöschmanN spec. nov.}

(Fig. 36)

Diagnosis: This new species is similar to some Holarctic species of the Scatopsciara atomaria group by the simple shape of the gonostyles with a long apical tooth and few hyaline subapical spines. The spurs of the mid and hind tibiae are rather long and distinctly unequal, $\mathrm{R}_{1}$ short. 
Description: $0^{\star}$. Head: Eye bridge 2-3 facets wide: antennae uniform brown, necks rather long, uniform colour; flagellomere 4 about $2 \times$ longer than wide, setae of flagellomeres sparse and as long as the diameter of the basal part; palpi three-segmented, basal segment with 1-3 bristles and a flat patch of sensillae.

Thorax: Brown, mesonotum with short, fine setae, some slightly longer lateral and scutellar setae; postpronotum bare, antepronotum and prethoracic episternum with sparse, fine setae; wings pale, anal area large, $R_{1}$ shorter $1 / 2 R ; R_{5}$ with only dorsal macrotrichia; $C=2 / 3 \mathrm{w} ; \mathrm{y}=1 / 2 \mathrm{x}$; bare; posterior veins without macrotrichia; halteres short with darkened heads; legs yellowish; tarsi darkened; fore tibiae at the inner apex with a comb-like row of bristles, spurs of mid and hind tibiae rather long and unequal. Claws untoothed.

Abdomen: Brown, with rather sparse setae; base of hypopygium and the inner ventral margin of gonocoxites with short setae; gonostyles with a long apical tooth and 2-3 slightly shorter hyaline subapical spines; tegmen rounded; aedeagus rather short. Body length: $1.8 \mathrm{~mm}$. ? : unknown.

Locus typicus: Hispaniola (Dominican Republic): La Vega Prov., $12 \mathrm{~km} \mathrm{~S} \mathrm{Constanza,}$ rd. to San Jose de Ocoa.

Holotype: 1 ơ, alt. 5.000 ft., 29. Jul. 1991, leg. D. Grimaldi \& J. Stark.

Paratypes: $31 \sigma^{*}$, same data as holotype; $1 \sigma^{*}$, Pedernales Prov., $40 \mathrm{~km} \mathrm{~N}$ Caba Rojo,

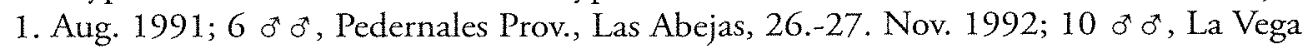
Prov., $21 \mathrm{~km}$ W Bonáo, 2. Aug. 1991, all leg. Grimaldi \& Stark.

Other material:

$10^{\star}$, same data as holotype; $2 \sigma^{\star}$, Pedernales Prov., Las Abejas, 26.-27. Nov. 1992, $10^{\star}$, La Vega Prov., $21 \mathrm{~km}$ W Bonão, 2. Aug. 1991, all leg. Grimaldi \& Stark.

Depository: Holotype and 30 paratypes in AMNH, 18 paratypes in CWMP.

\section{Scatopsciara (Xenopygina) caribiana MOHRIG \& RösCHMANN spec. nov.}

(Fig. 37)

Diagnosis: This new species belongs to the genus Scatopsciara by the unequal spurs of mid and hind tibiae. Within the genus it has similarities to some Palaearctic species around Sc. fritzi Mohrig \& Menzel, 1992. It is similar to the next species Sc. abiecta.

Description: 0 . Head: Eye bridge 3 facets wide; antennae uniform brown, necks rather long, uniform colour; flagellomere 4 about 2 x longer than wide, setae of flagellomeres sparse, bristle-like and longer than the diameter of the basal part; palpi three-segmented, basal segment with 3-4 bristles and a patch of sensillae.

Thorax: Brown, mesonotum with short, fine setae, some longer lateral setae, 2 longer scutellar setae; postpronotum bare, antepronotum and prethoracic episternum with sparse, fine setae; wings pale; $R_{1}$ short, $=1 / 2 R_{5} R_{5}$ with dorsal and ventral macrotrichia along whole length; $C$ slightly longer $1 / 2 \mathrm{w} ; \mathrm{y}=1 / 2 \mathrm{x}$; bare; posterior veins without macrotrichia; halteres short with darkened heads; legs brownish; tarsi darkened; fore tibiae at the inner apex with a rather wide comb-like row of bristles, spurs of mid and hind tibiae distinctly unequal. Claws untoothed. 
Abdomen: Brown, with rather sparse, short setae; base of hypopygium and the inner ventral margin of gonocoxites with short setae; gonostyles elongate and narrow, with 3 spines, one more subapically; tegmen rounded; aedeagus rather short. Body length: $2 \mathrm{~mm}$. ㅇ: unknown.

Locus typicus: Hispaniola (Dominican Republic): La Vega Prov., $21 \mathrm{~km} \mathrm{~W} \mathrm{Bonão.}$

Holotype: 1 o, alt. 3.400 ft., 2. Aug. 1991, leg. D. Grimaldi \& J. Stark.

Paratypes: $1 \sigma^{*}$, same data as holotype; $2 \sigma^{*}$, La Vega Prov., rd. to San Jose de Ocoa, 29. Jul. 1991; $1 \sigma^{*}$, Monte Plata, 9 km N Bayaguana, 8. Aug. 1991, $3 \sigma^{\star} \sigma^{\star}$, La Vega Prov., Jarabacoa on road to Monebao, 29. Jul. 1991; 1 o , Paravia Prov.; $30 \mathrm{~km} N$ San José de Ocoa, 30. Jul. 1991, all leg. D. Grimaldi \& J. Stark.

Depository: Holotype and 3 paratypes in AMNH, 5 paratypes in CWMP.

\section{Scatopsciara (Xenopygina) abiecta MoHrig \& RösCHMANn spec. nov.}

(Fig. 38)

Diagnosis: This new species belongs to the genus Scatopsciara by the unequal spurs of mid and hind tibiae. It is similar to Sc. caribiana and differs by the short flagellomeres, the lack of ventral macrotrichia on $\mathrm{R}_{5}$ and shorter gonostyles with three spines at the apex.

Description: $\sigma^{\star}$. Head: Eye bridge 3 facets wide; antennae uniform brown, flagellomeres short and rather wide, necks short, uniform colour; flagellomere 4 about $1.2 \times$ longer than wide, setae of flagellomeres shorter than the diameter of the basal part; palpi threesegmented, basal segment with 3-4 bristles and a flat patch of sensillae.

Thorax: Brown, mesonotum with short, brown setae, some lateral and 2 scutellar setae longer; postpronotum bare, antepronotum and prethoracic episternum with sparse, fine setae; wings pale, wide; $R_{1}$ very short, $=1 / 3 \mathrm{R} ; \mathrm{R}_{5}$ with only dorsal macrotrichia; $C=1 /$ $2 \mathrm{w} ; \mathrm{y}=\mathrm{x}$; bare; posterior veins weak and without macrotrichia; halteres short with darkened heads; legs brownish; tarsi darkened; fore tibiae at the inner apex with a comb-like row of bristles, one spur of mid tibiae very short; spurs of hind tibiae distinctly unequal. Claws untoothed.

Abdomen: Brown, with rather sparse, short setae; base of hypopygium and inner ventral margin of gonocoxites with short setae; gonostyles narrow, with 3 equal spines, and a patch of short spine-like bristles lower; tegmen obtuse cone-shape; aedeagus rather short. Body length: $1.2 \mathrm{~mm}$. 9 : unknown.

Locus typicus: Hispaniola (Dominican Republic): Paravia Prov., $30 \mathrm{~km} \mathrm{~N} \mathrm{San} \mathrm{José} \mathrm{de}$ Ocoa.

Holotype: 1 đ, alt. 3.000 ft., near stream, 30. Jul. 1991, leg. D. Grimaldi \& J. Stark.

Paratypes: $4 \sigma^{\star} \sigma^{*}$, same data as holotype; $1 \sigma^{\star}$, Barahona Prov., La Cienaga, 3. Aug. 1991; 4 o $\sigma^{*}$, Pedernales Prov., Las Abejas, 26.-27. Nov. 1992, all leg. Grimaldi \& Stark.

Depository: Holotype and 4 paratypes in AMNH, 5 paratypes in CWMP. 


\section{Scatopsciara (Xenopygina) destituta MoHrig \& Röschmann spec. nov.}

(Fig. 39)

Diagnosis: This new species belongs to the genus Scatopsciara by the unequal spurs of mid and hind tibiae and a small comb of bristles at the inner apex of fore tibiae. A closely related species is unknown so at present it is placed in the Subgenus Xenopygina.

Description: $\sigma$. Head: Eye bridge 3 facets wide; antennae uniform brown, necks rather long, uniform brown; flagellomere 4 about 2.0 x longer than wide, setae of flagellomeres as long as the diameter of the basal part; palpi short, three-segmented, basal segment with 1 bristle and a patch of sensillae.

Thorax: Yellow-brown; katepisternum, lateral parts of the mesonotum, the scutellum and the mediotergite as well as the base of wings yellow; mesonotum with short, brown setae, longer lateral and two scutellar setae; postpronotum bare, antepronotum and prethoracic episternum with sparse, fine setae; wings slightly browned; wide; $R_{1}$ very short, = $1 / 3$ $\mathrm{R}$; $\mathrm{R}_{5}$ with only dorsal macrotrichia; $\mathrm{C}$ slightly longer $1 / 2 \mathrm{w} ; \mathrm{y}=\mathrm{x}$; bare; posterior veins distinct and without macrotrichia; halteres short, with darkened heads; legs yellow; tarsi darkened; fore tibiae at the inner apex with an almost comb-like row of bristles, spurs of mid and hind tibiae long and distinctly unequal; outer side of hind tibiae with a row of strong bristles. Claws untoothed.

Abdomen: Tergite brown, 1. and 2. sternite yellowish, with rather sparse, short setae; base of hypopygium and the inner ventral margin of gonocoxites with sparse, short setae; gonostyles narrow, apex with setae, with 3 strong, short widely subapical spines in a ????cross-row; tegmen rounded, with a small area of teeth; aedeagus rather short. Body length: $1.5 \mathrm{~mm}$. 9 : unknown.

Locus typicus: Hispaniola (Dominican Republic): La Romana.

Holotype: $1 \mathrm{o}^{\mathrm{T}}$, sea level, forest along coastal inlet, 30. Sept. 1992, leg. D. Grimaldi \& J. Stark.

Depository: Holotypus in CWMP.

\section{Scatopsciara (Xenopygina) terribilis MoHrug \& Röschmann spec. nov.}

(Fig. 40)

Diagnosis: This new species belongs to the genus Scatopsciara by the unequal spurs of mid and hind tibiae. It is characterised by the 3 long and strong spines on the inner side of gonostyles. It shows distinct similarities to the East Palaearctic species Sc. camptospina Mohrig \& Mamaev, 1990 of the subgenus Xenopygina.

Description: 0 . Head: Eye bridge 3 facets wide; antennae uniform brown, necks uniform colour; flagellomere 4 about $2.4 \times$ longer than wide, setae of flagellomeres shorter than the diameter of the basal part; palpi three-segmented, basal segment with 1-2 bristles and a patch of sensillae.

Thorax: Brown, mesonotum with short, brown setae, lateral and scutellar setae scarcely longer; postpronotum bare, antepronotum and prethoracic episternum with sparse, fine setae; wings pale; wide; $R_{1}$ very short, $=1 / 3 R ; R_{5}$ with only dorsal macrotrichia; $C=2 /$ $3 \mathrm{w} ; \mathrm{y}=\mathrm{x}$; bare; posterior veins weak and without macrotrichia; halteres rather long with 
darkened heads; legs brownish; tarsi darkened; fore tibiae at inner apex with a comb-like row of rather long bristles; one spur of mid tibiae very short; spurs of hind tibiae distinctly unequal. Claws untoothed.

Abdomen: Brown, with rather sparse, short setae; base of hypopygium and the inner ventral margin of gonocoxites with short setae; gonostyles excavated on dorsal side, with 3 strong spines, 2 near apex, 1 in the middle of the inner side, a few long setae between; tegmen obtuse cone-shape; aedeagus reduced with exception of the basal sclerite. Body length: $1.2 \mathrm{~mm}$. ㅇ: : unknown.

Locus typicus: Hispaniola (Dominican Republic): Pedernales Prov., $20 \mathrm{~km}$ NE Pedernales, Las Abejas.

Holotype: $1 \%$, alt. $1.500 \mathrm{~m}$, broadleaf cloud forest, 26.-27. Nov. 1992, leg. Grimaldi \& Stark.

Paratypes: $2 \sigma^{\star}$, same data as holotype, $2 \sigma^{\star}$, same locality, 1. Oct. 1992.

Depository: Holotype and 2 paratypes in AMNH, 2 paratypes in CWMP.

\section{Genus Corynoptera WINNERTZ, 1867}

We follow the genus concept of Tuomikoski (1960) with exception of species of the Corynoptera fulvicollis group and the Corynoptera clausa group which were excluded by Hrppa \& VilixamaA (1994) and Hippa et al. (2003) and placed in the new genera Camptochaeta Hippa \& VilamaA and Claustropyga. Hippa, VilkamaA \& Mohrig. The species-rich genus Corynoptera is mainly distributed within the Northern hemisphere, Micronesia (Steffan 1969) and New Zealand (Mohrig \& Jaschhof 1999). Within the Palaearctic Region about 140 species belonging to 15 quite well characterised species groups (MENZEL \& MOHRIg 2000) are known. 13 species of Corynoptera are known from the Baltic and Saxonian amber (MOHRIg \& RöschMANN 1994, RösCHMANN \& Mohrig 1994a, b; 1995a, b, c).

The genus is well characterised by the single bristle on the basal segment of palpi (rarely there are two), only two longer bristles on the posterior margin of the scutellum and the hind tibiae with a well developed row of short posterodorsale spine-like bristles. The posterior wing veins are without macrotrichia, the tibiae of the mid and hind legs have two subequal spurs and the tarsal claws are untoothed (in Holarctic species). All other Diagnosis may be very different, especially the shape of gonostyles, the tegmen and the bristle-patch on the apex of fore tibiae.

\section{Corynoptera turbata MoHRIg \& RöschmanN spec. nov.}

(Fig. 41)

Diagnosis: This new species is placed into the genus Corynoptera by the single bristle on the basal segment of palpi, the two long scutellar bristles and the shape of flagellomeres. The shape of the tegmen is also typical in the Palaearctic species of the Corynoptera parvula group. It is undoubtedly related to the following species (differences see below).

Description: 0 . Head: Eye bridge 3 facets wide; antennae short, uniform brown, necks rather short, uniform brown; flagellomere 4 about $1.2 \times$ longer than wide, setae of flagel- 
lomeres shorter than the diameter of the basal part; palpi three-segmented, basal segment with 1 bristle and a patch of sensillae.

Thorax: Brown; mesonotum with short, brown setae, lateral and 2 scutellar setae longer; postpronotum bare, antepronotum and prethoracic episternum with sparse, fine setae; wings pale; $R_{1}=2 / 3 R ; R_{5}$ only distally with ventral macrotrichia; $C$ slightly longer $1 / 2 \mathrm{w} ; y=x$; with $1-2$ macrotrichia; posterior veins without macrotrichia; halteres short, with darkened heads; legs brownish; tarsi darkened; fore tibiae at inner apex without a distinct patch of bristles, with only a few longer bristles; spurs of mid and hind tibiae long and equal. Claws untoothed.

Abdomen: Brown, with rather sparse, short setae; base of hypopygium and the inner ventral margin of gonocoxites with sparse, short setae; gonostyles long-ovoid, with 2 stronger spines; tegmen distinctly wide, laterally angled, with a small area of teeth; aedeagus short. Body length: $2 \mathrm{~mm}$. q : unknown.

Locus typicus: Hispaniola (Dominican Republic): Pedernales Prov., $20 \mathrm{~km}$ NE Pedernales, Las Abejas.

Holotype: $1 \sigma^{*}$, alt. $1.500 \mathrm{~m}$, broadleaf cloud forest, 26.-27. Nov. 1992, leg. Grimaldi \& Stark.

Paratypes: $4 \sigma^{\circ}$, same data as holotype.

Depository: Holotype and 1 paratype in AMNH, 3 paratypes in CWMP.

\section{Corynoptera sicca Mohrig \& Röschmann spec. nov.}

(Fig. 42)

Diagnosis: This new species is placed into the genus Corynoptera by the two strong scutellar bristles and the untoothed claws. The wide and angled tegmen and the gonostyles, dorsally excavated on the inner side, are similar to species of the Holarctic distributed Corynoptera parvula group.

Description: $\sigma^{*}$. Head: Eye bridge 3 facets wide; antennae rather short, uniform brown, necks rather long, uniform brown; flagellomere 4 about $2.0 \times$ longer than wide, setae of flagellomeres shorter than the diameter of the basal part; palpi three-segmented, basal segment with 1-2 bristles and a patch of sensillae.

Thorax: Brown; mesonotum with short, brown setae, lateral and 2 scutellar setae longer; postpronotum bare, antepronotum and prethoracic episternum with sparse, fine setae; wings pale; $R_{1}=2 / 3 R ; R_{5}$ only distally with ventral macrotrichia; $C 2 / 3 \mathrm{w} ; y=x$; bare; posterior veins without macrotrichia; halteres short, with darkened heads; legs yellow; tarsi darkened; fore tibiae at inner apex without a distinct patch of bristles, with only a few longer bristles; spurs of mid and hind tibiae long and subequal. Claws untoothed.

Abdomen: Brown, with rather sparse, short setae; base of hypopygium and the inner ventral margin of gonocoxites with sparse, short setae; gonostyles curved; apex narrowed, distinctly excavated at inner dorsal side, with 2 stronger spines and few bristles apically; tegmen distinctly wide, laterally angled, with a small area of teeth; aedeagus rather short. Body length: $1.8 \mathrm{~mm}$. $\%$ : unknown.

Locus typicus: Hispaniola (Dominican Republic): Pedernales Prov., $20 \mathrm{~km}$ NE Pedernales, Las Abejas. 
Holotype: $1 \sigma^{*}$, alt. $1.500 \mathrm{~m}$, broadleaf cloud forest, 26.-27. Nov. 1992, leg. Grimaldi \& Stark.

Paratypes: $30^{*} o^{*}$, same data as holotype, $20^{*}$, same locality, 1. Oct. 1992.

Depository: Holotype and 2 paratypes in AMNH, 3 paratypes in CWMP.

\section{Genus Keilbachia MoHrig, 1987}

Approximately 10 described species of the genus Keilbachia are distributed in the eastern Palaearctic Region, chiefly from Nepal (Mohrig \& Martens 1987, Menzel \& Martens 1995, Mohrig et al. 1999). Two species are known from Japan and northern Europe (Hippa \& Vilkamaa 1994, Mohrig \& Menzel 1992). Only one species is known from the Nearctic Region (Sciara neglecta JoHANnsen, 1912). It is assumed that the evolutionary centre of this genus is found in the Eastern Palaearctic and perhaps in the Central Oriental Region.

The genus is characterised by the rather simple gonostyles, narrowed to the apex, with one tooth or few short apical spines or only setae. The gonostyles are excavated on the inner dorsal side and have a long curved spine on a (usually) large protuberance in the middle or lower (often near the base). In many species, this spine is a long, strong, curved whip lash spine but in a few species is separated into two or more long, thin flagellar-like spines. In all known species, the basal segment of palpi has only one single bristle, as is usual in Corynoptera species. The bristle patch at the apex of the fore tibiae usually has a semicircular margin, rarely it is indistinct and without any margin.

\section{Keilbachia paucipalpa MoHrug \& Röschmann spec. nov.}

(Fig. 43)

Diagnosis: The new species is a typical Keilbachia by the long curved whip lash spine on the inner side of the gonostyles and one bristle at the basal segment of palpi. It is similar to the one known species of the Nearctic Region, Sciara neglecta JoHannsen. $K$. paucipalpa differs by the three subapical spines, a longer whip lash spine and the simple row of bristles, without semicircular margin.

Description. $\sigma$. Head. Eye bridge 3 facets wide; antennae uniform brown; palpi three segmented, very short, basal segment wide, short club-shape, with 1 bristle; segments 2 and 3 short, roundish.

Thorax: Brown; mesonotum with rather long, brownish setae, with some stronger dorsocentral and lateral bristles; scutellum with 2 strong, posterior bristles and few short setae. Postpronotum bare; antepronotum and prethoracic episternum with sparse, rather long setae; wings pale; $R_{1}=1 / 2 R ; R_{5}$ with only dorsal macrotrichia; $C=2 / 3$ w; $y$ shorter $x$, bare; $\mathrm{M}$ and $\mathrm{CU}$ without macrotrichia. Halteres short, with darkened heads; legs brown; apex of fore tibia with an indistinct row of dark bristles, without semicircular margin; spurs of the mid and hind tibia equal and longer than the diameter of the apex; tarsal claws untoothed.

Abdomen: Brown, with rather long setae; hypopygium ventrally on the inner margin of gonocoxites indistinct and with rather long setae; gonostyles slightly curved, apically 
narrowly rounded and with 3 subapical spines; inner side flatly excavated with a long, strong, curved whip lash spine in the middle; tegmen with lateral corners, wide; aedeagus rather long. Body length: $2 \mathrm{~mm}$. \% . unknown.

Locus typicus: Hispaniola (Dominican Republic): Duarte Prov., $13 \mathrm{~km}$ N San Francisco de Macoris.

Holotype: $1 \sigma^{\star}$, alt. $800 \mathrm{ft}$., Malaise trap in cloud forest, Jul. 1991, leg. V. Almanzar.

Paratype: 10 , same data as holotype.

Depository: Holotype in AMNH, paratype in CWMP.

\section{Genus Epidapus HaLIDAY in WalKer, 1851}

The description of the genus was based on the well known Palaearctic species E. atomarius (De GEer), E. gracilis (WALKER) and E. microthorax (BöRNER). In recent years more than 20 species were described as new ot new combined (MOHRIG et al. 1990, MoHrig \& Dimitrova 1993, Mohrig \& Kauschke 1994, Mohrig \& Menzel 1992, Rulik et al. 1999) and the investigation of this genus has been completed in nearly all diagnosis. Usually, males of most Holarctic species are easily recognized by the long flagellomeres, long halteres, long legs, narrow base of wings and one-segmented palpi. Few species from the Mediterranean Europe show differences in one to three of these diagnosis. Species found in New Zealand (Mohrig \& JASChHof 1999) and Central America (Mohrig 2003) demonstrate quite new and unusual diagnosis so that we are a long way from a complete picture of this difficult genus.

Diagnosis are a globular head; antennae usually long, flagellomere 4 about 3-5 x longer than wide with distinct and long necks; palpi with tendency toward reduction, usually 1 or 2-segmented, basal segment usually without a sensory pit; scutellum usually with two strong posterior and two weaker latero-posterior setae; wings usually with a reduced anal angle and bare and evanescent posterior veins; halteres in most species unusually long; legs rather long, many species with elongated coxae, femora and tibiae; fore tibia usually without a distinct patch of bristles at apex; mid and hind tibial spurs slightly shorter than diameter of the tibial apex; male genitalia within the typical species of Epidapus s. str. with rather short gonostyles with a moderately strong tooth at the apex and some spinelike bristles, in other species without an apical tooth, but with spines of different size and arrangement. The females differ from the male in shorter flagellomeres and the absent or strongly reduced wings and halteres in most Palaearctic species.

Up to now the species of Epidapus have been seen as a young evolutionary group of sciarids (FrEY 1942) because of their tendency toward reduction of constitutive morphologic structures in connection with the unusual specialisation of long halteres. New data presented from investigations of the sciarid fauna of tertiary wood formations and by analysis of inclusions in Baltic amber demonstrated that typical Epidapus species were living in the Oligocene with an age of at least 35 million years (MOHRIG \& RösCHMANN 1994, Röschmann \& MOHRIg 1993). The genus has a global distribution and is divided in four subgenera (MENZEL \& MOHRIG 2000). 


\section{Epidapus (Clandestina) conciliatus MoHrug, 2003}

Literature: Mohrig 2003. Beitr. Ent. 53: 63-64, fig. 45.

This small species is characterized through the long, narrow gonostyles, densely covered with microtrichia, and with a short tooth below the short setose apex. The palpi are onesegmented, the coxae and legs long and the wings relatively narrow. It was described from Costa Rica.

\section{Material:}

5 o $\sigma^{*}$, Hispaniola (Dominican Republic), Pedernales Prov., $20 \mathrm{~km}$ NE Pedernales, Las Abejas, alt. $1.500 \mathrm{~m}$, broadleaf cloud forest, 26.-27. Nov. 1992, leg. Grimaldi \& Stark; $9 \sigma^{\star}$, Duarte Prov., $13 \mathrm{~km}$ N San Francisco de Macoris, Jul. 1991, leg. V. Almanzar.

Depository: 9 specimens in AMNH, 5 specimens in CWMP.

\section{Epidapus (Epidapus) flavothoracicus MoHRIG \& RösCHMANn spec. nov.}

(Fig. 44)

Diagnosis: The new species is in most Diagnosis (short gonostyles with a strong apical tooth, one-segmented palpi, wide tegmen, lack of distinct bristle patch at the inner apex of the fore tibiae, short and thin tibial spurs) a typical Epidapus in the sense of the Holarctic species. Short halteres and wider wings seems to be a normal picture of a reinstallation of apomorphic Diagnosis.

Description: ${ }^{*}$. Head: Roundish; eye bridge wide, 3-4 facets wide above the ocellae; antennae rather long; necks half as long as the basal part; flagellomere 2 about $2 \times$ longer than wide; setae of flagellomeres bristle-like, dense and longer than the diameter of the basal part, palpi one-segmented; sensillae at the apex.

Thorax: Yellow-ochreous, mesonotum with moderately long setae, 2-3 stronger lateral and 2 stronger scutellar setae; postpronotum bare; antepronotum and prethoracic episternum with sparse, fine setae; wings pale, wide and with a well developed anal angle; $R_{1}=1 / 2 R ; R_{5}$ in the distal half with ventral macrotrichia; $C=2 / 3 ; y=2 x$, with macrotrichia; $\mathrm{M}$-fork short and rather wide, CuA-stem short; posterior veins weak and without macrotrichia; halteres short, darkened; coxae somewhat elongated; legs of normal size; apex of fore tibia without a distinct patch of bristles; spurs of mid and hind tibiae short, fine and subequal, tarsal claws untoothed.

Abdomen: Yellow-ochreous, tergal and sternal setae sparse and moderately short; genitalia ventrally with sparse, short setae, also inner margin of gonocoxites; gonocoxites rather short and strong; gonostyles rather short, with only a strong apical tooth; tegmen wider than high, with very fine teeth, aedeagus very short. Body length: $2.4 \mathrm{~mm}$. $f$ : unknown.

Locus typicus: Hispaniola (Dominican Republic): Duarte Prov., 13 km N San Francisco de Macoris.

Holotype: 1 ot, alt. $800 \mathrm{ft} .$, Malaise trap in cloud forest, Jul. 1991, leg. V. Almanzar.

Paratypes: $1 \sigma^{x}$, same data as holotype.

Depository: Holotype in AMNH, paratype in CWMP. 
Epidapus (Pseudoaptanogyna) obstinatus MoHrig \& Röschmann spec. nov. (Fig. 45)

Diagnosis: The new species is in most Diagnosis typical of Epidapus from the Holarctic region. It belongs to the subgenus Pseudoaptanogyna by the absence of an apical tooth and is characterised by two subequal apical spines.

Description: $\sigma$. Head: Roundish; eye bridge wide, 3 facets wide above the ocellae, 2 facets wide laterally; antennae long; necks shorter than half of the basal part; flagellomere 4 abour $2.4 \times$ longer than wide; setae of flagellomeres sparse and bristle-like, longer than the diameter of the basal part, palpi short rounded, one-segmented, with sensillae at the apex.

Thorax: Brown, mesonotum with short, sparse setae, 1-2 stronger lateral and 2 scutellar stronger setae; postpronotum bare; antepronotum and prethoracic episternum with sparse, fine setae; wings pale; $R_{1}$ short, $=1 / 3 R_{5} R_{5}$ rather short, with sparse macrotrichia; $\mathrm{C}=4 / 5 \mathrm{w} ; \mathrm{y}$ short, $=1 / 3 \mathrm{x}$, without macrotrichia; posterior veins weak and without macrotrichia; halteres slightly elongated, darkened; coxae somewhat elongated; legs of normal size; apex of fore tibia without a distinct patch of bristles, only with some longer setae; spurs of mid and hind tibiae short, fine and subequal, tarsal claws untoothed.

Abdomen: Brown, tergal and sternal setae sparse and moderately short; genitalia ventrally and inner margin of gonocoxites with sparse, short setae; gonostyles short and strongly narrowed with two subequal apical spines; tegmen wider than high, rounded, and sclerotised in basal part. Body length: $1 \mathrm{~mm}$. $q$ : unknown.

Locus typicus: Hispaniola (Dominican Republic): Pedernales Prov., $20 \mathrm{~km}$ NE Pedernales, Las Abejas.

Holotype: $1 \sigma^{\pi}$, alt. $1.500 \mathrm{~m}$, in broadleaf cloud forest, 1. Oct. 1992, leg. D. Grimaldi \& J. Stark.

Depository: Holotype in CWMP.

Discussion

This paper is the first comprehensive study of sciarids within the Caribbean faunistic area. Earlier reports on Caribbean sciarid flies were of only minor significance, including the description of 7 species by WILLISTON (1896) from St. Vincent, some species of Pseudosciara and Bradysia by Lane (1959a, b; 1960) from Trinidad, a few species from Puerto Rico (RüBsaAMen 1894, LANe 1959a) and one species by MeNzel (1997) from Cuba. In our study we have found 50 species in 11 genera, 44 of them new to science. 45 species derived from the Dominican Republic, 5 from Puerto Rico.

In the Late Cretaceous and early Cenozoic periods the island arc between North and South America was stretched and fragmented to form the Antillean island chain nearly into their present positions. This geological history accounts for the relationships of the Caribbean biota with the South, Central and North American mainland (DonNelly 1988, LIEBHERr 1988). Assessing the biogeography situation of the sciarid fauna in the Dominican Republic in relation to the Central Caribbean area (Cuba, Jamaica, Puerto Rico and Greater Antilles) is nearly impossible, because the sciarid fauna is largely unknown in these neighboring areas. But also very little of the sciarid fauna of the northern 
South American countries is known. From Central America only a few species are described (Coquillett 1904; RüBSAAMEN 1894; ENDERLEIN 1911; LENGERSDORF 1930, 1940, 1944; Mohrig 2003). The sciarid fauna of the USA has been studied in accordance with centers of taxonomic activity, mainly from northeastern states and Canada (Johannsen 1912; Pettey 1918; Shaw 1934, 1941, 1953a, b; Hippa \& Vilikamaa 1994). Owen's studies in southern California, in Arizona and Texas demonstrated, in comparison to extensive material from Costa Rica and Honduras, that the deserts in North Mexico are a strong barrier between the two faunas and only few Central American species reach the southwestern region of the USA. A great handicap in assessing the Caribbean fauna is the fact that absolutely nothing is known of the sciarids of tropical and subtropical Florida.

Nevertheless, based on the well known sciarid fauna of the Palaearctic Region, and the partly known Nearctic Region, the Carribbean sciarid fauna is surprisingly Holarctic in most Diagnosis. This is particulary true for Leptosciarella, Chaetosciara, Keilbachia, Scatopsciara, most species of Bradysia, Corynoptera and Epidapus and at least partly so for Pseudolycoriella. The only endemic Neotropical groups found thus far in the Carribean is the genus Pseudosciara, the subgenus Protosciarella of the genus Leptosciarella and the species of the Bradysia pararufescens group.

The Caribbean species of Leptosciarellas. str. and Chaetosciara are very similar to their Holarctic counterparts. The single species of Cratyma belongs to the subgenus Cratyna s. str. and is more similar to South American species [c.f. Plastosciara, in LANE (1960)] than to Holarctic species of this cosmopolitan subgenus.

The genus Pseudosciara was revised by LANE (1959b), but the taxonomy is not yet certain concerning the synonomy of many species which have very uniform male hypopygia. The genus is of South American origin and includes only a few species in Mesoamerica and in the southern parts of the USA (e.g. Sciara forceps Petrey, 1918).

Nearly all species of Bradysia from Hispaniola and Puerto Rico display to the generic features of Holarctic species. Six of the 15 species belong to the $B$. hilaris group. This group has a few species in the Nearctic Region and Europe, but they are very species rich in the eastern parts of the Palaearctic Region, Papua New Guinea and eastern parts of southern Africa (unpublished data). Three species belong to the $B$. amoena group known also from the Holarctic. One of the species, B. ocellaris (Comstock, 1882) has been reported from the USA, Europe and Africa. It is often associated with greenhouses and is perhaps spread by humans. One species belongs to the $B$. brunnipes group and is similar to B. forcipulata (LundBeck, 1898) or B. subamoena Mohrig \& Krivosheina, 1989.

A new species group ( $B$. pararufescens group) is proposed here for the two closly related species $B$. pararufescens and $B$. mellea. They are characterised by a membranous basal lobe on the hypopygium and in the case of $B$. pararufescens, also by long convergent setae on the ventral inner margin of the gonocoxites. Both Diagnosis are suggestive of species of the Holarctic $B$. rufescens group. Species of the pararufescens group differ by lacking an apical tooth, the membranous basal lobe (not sclerotized and without long bristles as in B. rufescens group species) and bicoloured necks of the flagellomeres. Similar species from Costa Rica are known, so these appear to be endemic to the Neotropics.

The five species of Scatopsciara show similarities with species of the Holarctic subgenus Xenopygina. The two closely related species $S_{c}$. caribiana and Sc. abiecta are related to European species around Sc. fritzi MoHrig \& MENzel, 1992. Scatopsciara terribilis 
is similar to Sc. camptospina Mohrig \& Mamaev, 1990, described from the eastern Palaearctic near Vladivostok.

The two species of Corynoptera have similarities to the mainly Palaearctic C. parvula group, based on the wide tegmen and the excavated or flattened inner side of the gonostyles.

This genus Keilbachia was described from Nepal (MoHrig 1987). Out of Nepal this genus shows a dispersed distribution - one species in northern Europe, one in Japan, one in North America. The Dominican species is similar to the American and Palaearctic species and represents a Holarctic origin.

Little is known of the taxonomic situation within the genus Pseudolycoriella, so that comparison with Old World species is presently impossible. The 13 Caribbean species represent three groups of closely related species. Pseudolycoriella fuscivenosa, Psl. indocera and Psl. florentissima have narrow and elongate gonostyles and two rather short subapical spines like the Palaearctic Psl. bruckii group (Menzel \& MoHrig 2000). The four species Psl. torva, Psl. bicornis, Psl. pulla and Psl. barbata represent the new proposed Psl. torva group, characterised by longer curved and apically narrowed gonostyles (sometimes somewhat excavated on the inner side) with two long apical spines and a more or less weakly developed patch of specialized bristles at the apex of the fore tibiae. In this group also belongs Psl. bicornis (Menzel, 1997) from Cuba. Psl. zealandica (Edwards, 1927) from New Zealand shows some similarities with this new species group.

The five species $P_{s l}$. aculeacea, Psl. ovistyla, $P_{s} l$. subovistyla, Psl. rotundostyla, Psl. virgata belong to the newly proposed $P s l$. aculeacera group. The group is characterised by large gonostyles that are widely rounded at apex with more than one or two apical/subapical spines on the gonostyles, and a lack of a semicircular or ovoid structure on the apical margin of the tegmen. They show no similarities with Old World species and may be of South American origin.

\section{Acknowledgement}

We are very grateful to Dr. D. A. GRIMALDI and the American Museum of Natural History, New York, for discussions and help during this successful investigation, We thank Dr. Frank Menzel (DEI, Eberswalde) for taxonomic and zoogeographic remarks and Jane E. SMrru (Warwick HRI, Wellesbourne, UK) for improving the English of that manuscript. Frank Röschmann was supported by grants of the Alexander von Humboldt-Stiftung and the Deutsche Forschungsgemeinschaft (DFG, Ro 1250/1-1).

\section{References}

Amorim, D. S. 1992: A Catalogue of the family Sciaridae (Diptera) of the Americas South of the United States. - Revista Brasileira de Entomologia, Rio de Janeiro 36 (1): 55-77.

Breuer, M. E. 1969: Revision of the Genus Rhynchosciara RÜBSAAMEN (Diptera: Sciaridae) in the Neotropical region. - Arquivos do Zooligia, Sao Paulo 17 (4): 167-198.

Coquillett, D. W. 1904: New Diptera from Central America. - Proceedings of the Entomological Society of Washington, Washington D.C. 6: 90-98.

Donelly, T. W. 1988: Geologic constraints on Caribbean biogeography. - In: Liebherr, J. K. [ed.]: Zoogeography of Caribbean insects. - Cornell University Press, Ithaca: 15-37.

Enderlern, G. 1911: Die phyletischen Beziehungen der Lycoriiden (Sciariden) zu den Fungivoriden (Mycetophiliden) und Itonididen (Cecidomyiiden) und ihre systematische Gliederung. - Archiv für Naturgeschichte, Berlin 77 (1) Supplement 3: 116-201.

FREY, R. 1942: Entwurf einer neuen Klassifikation der Mückenfamilie Sciaridae (Lycoriidae). - Notulae Entomologicae, Helsingfors 22: 5-44. 
Johannsen, O. A. 1912: The fungus gnats of North America, Part IV. - Bulletin of the Maine Agricultural Experimental Station, Orono 200: 57-146.

Hippa, H. \& VilkamaA, P. 1994: The genus Camptochaeta gen. nov. (Diptera, Sciaridae). - Acta Zoologica Fennica, Helsinki 194: 1-85.

Hippa, H.; VilkamaA, P. \& Mohrig, W. 2003: Phylogeny of Corynoptera Winnertz and related genera, with the description of Claustropyga gen. nov. (Diptera, Sciaridae). - Studia dipterologica, Halle (Saale) 9 (2002) 2: 469-511.

LANE, J. 1959a: On Neotropical Neosciara (Diptera: Sciaridae). - Studia Entomologica, Rio de Janeiro 2 $(1-4): 69-104$.

Lane, J. 1959b: On Neotropical „Pseudosciara" (Diptera: Sciaridae). - Revista Brasiliera de Biologia, Rio de Janeiro 19 (3): 287-298.

Lane, J. 1960: New Neotropical Plastosciara (Diptera: Sciaridae). - Revista Brasiliera de Entomologia, Sao Paulo 9: 119-126.

Lengersdorf, F. 1930: Neue Sciara (Lycoria)-Arten des Zoologischen Museums in Hamburg aus Borneo und Kostarika. - Zoologischer Anzeiger, Leipzig 92 (5-6): 123-130.

Lengersdorf, F. 1940: Beitrag zur Kenntnis der Lycoriiden (Sciariden) in Mexiko. (Diptera). - Arbeiten über morphologische und taxonomische Entomologie aus Berlin-Dahlem, Berlin-Dahlem 7 (3): 245-251.

Lengersdorf, F. 1944: Beitrag zur Kenntnis der Lycoriiden (Sciariden) in Mexiko. (Diptera: Lycoriidae). 2. Teil. - Arbeiten über morphologische und taxonomische Entomologie aus Berlin-Dahlem, BerlinDahlem 11 (2-4): 123-130.

LiebHerr, J. K. 1988: General patterns in West Indian insects, and graphical biogeographic analysis of some Circum-Caribbean Platynus beetles (Carabidae). - Systematic Zoology, Washington D.C. 37 (4): $385-409$.

Menzel, F. 1997: Merianina bicornis spec. nov. - eine neue Trauermücken-Art aus Kuba, nebst einigen Bemerkungen zur Gattung Merianina FreY, 1942 (Insecta: Diptera: Sciaridae). - Reichenbachia, Dresden 32 (19): 107-111.

Menzel, F. \& Martens, J. 1995: Die Sciaridae (Diptera, Nematocera) des Nepal-Himalaya. Teil I. Die blütenbesuchenden Trauermücken an Aronstabgewächsen der Gattung Arisaema (Araceae Juss.). - Studia dipterologica, Halle (Saale) 2 (1): 97-129.

Menzel, F. \& Mohrig, W. 1997: 2.6. Family Sciaridae. - In: Papp, L. \& Darvas, B. [eds]: Contributions to a Manual of Palaearctic Diptera (with special reference to flies of economic importance). Nematocera and Lower Brachycera. - Science Herald, Budapest 2: 51-69.

Menzet, F. \& Mohrig, W. 1998: Beiträge zur Taxonomic und Faunistik der paläarktischen Trauermücken (Diptera, Sciaridae). Teil. VI. - Neue Ergebnisse aus Typenuntersuchungen und die daraus resultierenden taxonomisch-nomenklatorischen Konsequenzen. - Studia dipterologica, Halle (Saale) 5 (2): 351-378.

Menzel, F. \& Mohrig, W. 2000: Revision der paläarktischen Trauermücken (Diptera: Sciaridae). - Studia dipterologica Supplement, Halle (Saale) 6 (1999): 1-761.

Mohrig W. 1999: Die Trauermücken (Diptera: Sciaridae) von Papua-Neuguinea. Teil I. - Gattungen Sciara, Schwenckfeldina, Aerumnosa gen. nov., Cratyna, Phytosciara und Chaetosciara. - Studia dipterologica, Halle (Saale) 6 (1): 153-203.

Moнrig, W. 2003: Black fungus gnats (Diptera, Sciaridae) of Central America. Part I. - Beiträge zur Entomologie, Keltern 53 (1): 1-69.

Mohrig, W. \& Dimitrova, B. 1993: Zwei neue Arten der Gattung Epidapus Hal. aus Bulgarien. (Insecta: Diptera: Sciaridae). - Reichenbachia, Dresden 30 (15): 99-102.

Mohrig, W. \& JAschror, M. 1999: Sciarid flies (Diptera, Sciaridac) from New Zealand. - Studia dipterologica Supplement, Halle (Saale) 7: 1-101.

Mohrig, W. \& Kauschike, E. 1994: New sciarid flies from the Italian Province of Apulia (Diptera, Sciaridae). - Bolletino della Societa Entomologica Italiana, Genova 126 (2): 175-185.

Mohrig, W.; Krivosheina, N. \& Mamaev, B. 1989a: Beiträge zur Kenntnis der Trauermücken (Diptera, Sciaridae) der Sowjetunion. Teil XII: Gattung Bradysia, Serie 1. - Zoologische Jahrbücher, Abteilung für Systematik, Ökologie und Geographie der Tiere, Jena 116 (4): 411-425.

Mohrig, W.; Krivosheina, N. \& Mamaev, B. 1989b: Beiträge zur Kenntnis der Trauermücken (Diptera, Sciaridae) der Sowjetunion. Teil XIII: Gattung Bradysia, Serie 2. - Zoologische Jahrbücher, Abteilung für Systematik, Ökologie und Geographie der Tiere, Jena 116 (4): 427-445.

Mohrig, W.; Krtvosheina, N. \& Mamaev, B. 1990: Beiträge zur Kenntnis der Trauermücken (Diptera, Sciaridae) der Sowjetunion. Teil XV: Gattungen: Sciara, Trichosia, Chaetosciara, Pharetratula, Parapnyxia, Epidapus und Caenosciara. - Zoologische Jahrbücher, Abteilung für Systematik, Ökologie und Geographie der Tiere, Jena 117 (2): 219-236. 
Mohrig, W. \& MARtens, J. 1987: Sciaridae aus dem Nepal-Himalaya (Insecta: Diptera). - Courier Forschungsinstitut Senckenberg, Frankfurt am Main 93: 481-490.

Mohrig, W. \& MENzel, F. 1992: Neue Arten europäischer Trauermücken (Diptera: Sciaridae). - Dipterological Research, St. Petersburg 3: 1-16.

Mohrig, W. \& Menzel, F. 1997: Revision der paläarktischen Arten von Trichosia WInNerTz sensu Tuomiкоskт, 1960 (Diptera: Sciaridae). - Teil II. Gattungen Leptosciarella Tuomikoski, 1960 und Trichodapus gen. nov. - Studia dipterologica, Halle (Saale) 4 (1): 41-98.

Mohrig, W. \& Röschmann, F. 1994: Revision der Trauermücken-Typen von LoEw und Meunier aus dem Baltischen Bernstein (Diptera, Sciaridae). - Deutsche Entomologische Zeitschrift (Neue Folge), Berlin 41 (1): 79-136.

Mohrig, W.; Röschmann, F. \& Rulrk, B. 1999: New Sciarid Flies (Diptera: Sciaridae) from Nepal. Deutsche Entomologische Zeitschrift (Neue Folge), Berlin 46 (2): 189-201.

Pettey, F. W. 1918: A revesion of the genus Sciara of the family Mycetophilidae (Diptera). - Annals of the Entomological Society of America, Columbus 11 (4): 319-343.

Poole, R. W. \& Gentili, P. [eds] 1996: Nomina Insecta Nearctica. A Check List of the Insects of North America. - Entomological Information Services, Rockville: 238-240.

Röschmann, F. \& Mohrig, W. 1993: Beiträge zur Kenntnis fossiler Trauermücken (Diptera, Sciaridae) aus dem Sächsischen Bernstein. Teil I. Erster fossiler Nachweis der Gattung Epidapus Haliday. Veröffentlichungen des Naturhistorischen Museums Schleusingen, Hildburghausen 7-8: 77-81.

Röschmann, F. \& Mohrig, W. 1994a: Einschlüsse fossiler Trauermücken (Diptera, Sciaridae) in Baltischem Bernstein aus Kollektionen des Deutschen Entomologischen Institutes Eberswalde. - Beiträge zur Entomologie, Berlin 44 (2): 403-408.

Röschmann, F. \& Mohrig, W. 1994b: Checklist of fossil sciarids from Baltic amber (Diptera, Sciaridae). - Studia dipterologica, Halle (Saale) 1 (1): 126-138.

Röschmann, F. \& MoHrig, W. 1995a: Die Trauermücken des Sächsischen Bernsteins aus dem Untermiozän von Bitterfeld / Deutschland (Diptera, Sciaridae). - Deutsche Entomologische Zeitschrift (Neue Folge), Berlin 42: 17-54.

Röschmann, F. \& Mohrig, W. 1995b: Beiträge zur Kenntnis fossiler Trauermücken aus Sächsischem Bernstein. Teil II. Drei neue Sciariden aus Tertiär-Harzen des Bitterfelder Braunkohlenreviers (Insecta, Diptera: Sciaridae). - Paläontologische Zeitschrift, Stuttgart 69 (1-2): 153-166.

Röschmann, F. \& Mohrig, W. 1995c: Die Trauermückenfauna des Baltischen und Sächsischem Bernsteins (Diptera: Sciaridae). - Mitteilungen der Deutschen Gesellschaft für allgemeine und angewandte Entomologie, Giessen 10 (1-6): 637-340.

RÜBSAAMEN, E. H. 1894: Die aussereuropäischen Trauermücken des Königlichen Museums für Naturkunde zu Berlin. - Berliner Entomologische Zeitschrift, Betlin 39 (1): 17-42.

Rurtk, B.; Röschmann, F. \& Mohrig, W. 1999: New Species of Sciarid fies (Diptera, Sciaridae) from Greece and Turkey. - Journal of the Entomological Research Society, Ankara 1 (3): 21-50.

SHAW, F. R. 1934: A new species of Sciara (Diptera). - Canadian Entomologist, Orillia 66 (10): 233.

SHAw, F. R. 1953a: Some new Diptera with remarks on the affinities of the genus Pnyxia JoH. - Psyche, Cambridge 60 (2): 62-68.

SHAw, F. R. 1953b: A review of some of the more important contributions to our knowledge of the systematic relationships of the Sciaridae (Diptera). - Proceedings of the Hawaiian Entomological Society, Honolulu 15 (1): 25-32.

SöLI, G. E. E. 1997: The adult morphology of Mycetophilidae (s. str.), with a tentative phylogeny of the family (Diptera, Sciaroidea). - Entomologica Scandinavika Supplement, Kopenhagen 50: 6-55.

Steffan, W. A. 1966: A generic revision of the family Sciaridae (Diptera) of America North of Mexico. - University of California Publications in Entomology, Berkeley 44: 1-77.

Steffan, W. A. 1969: Insects of Micronesia. Diptera: Sciaridae. - Insects of Micronesia, Honululu 12 (7): $669-732$.

Steffan, W. A. 1972: Family Sciaridae. - In: Delfinado, M. D. \& Hardx, D. E. [eds]: A Catalog of the Diptera of the Oriental Region. - University Press of Hawaii, Honolulu 1: 464-476.

StefFan, W. A. 1981: 15. Sciaridae. - In: McAlpine, J. F. et al. [eds]: Manual of Nearctic Diptera, Vol. 1. - Monograph, Ottawa 27: 247-255.

Tuomrкoski, R. 1960: Zur Kenntnis der Sciariden (Diptera) Finnlands. - Annales Zoologici Societatis Zoologicae Botanicae Fennicae 'Vanamo', Helsinki 21 (4): 1-164. 


\section{Authors' addresses:}

Prof. Dr. Werner Mohrig

Puddemin 6

18574 Poseritz, Germany
Dr. Frank Röschmann

Gustaf-Adolf-Strasse 4

18435 Stralsund, Germany

Björn Rulik

Ernst-Moritz-Arndt-Universität Greifswald

Institut für Geologische Wissenschaften

AG Paläontologie und Historische Geologie

Friedrich-Ludwig-Jahn-Straße 17 a

17487 Greifswald, Germany
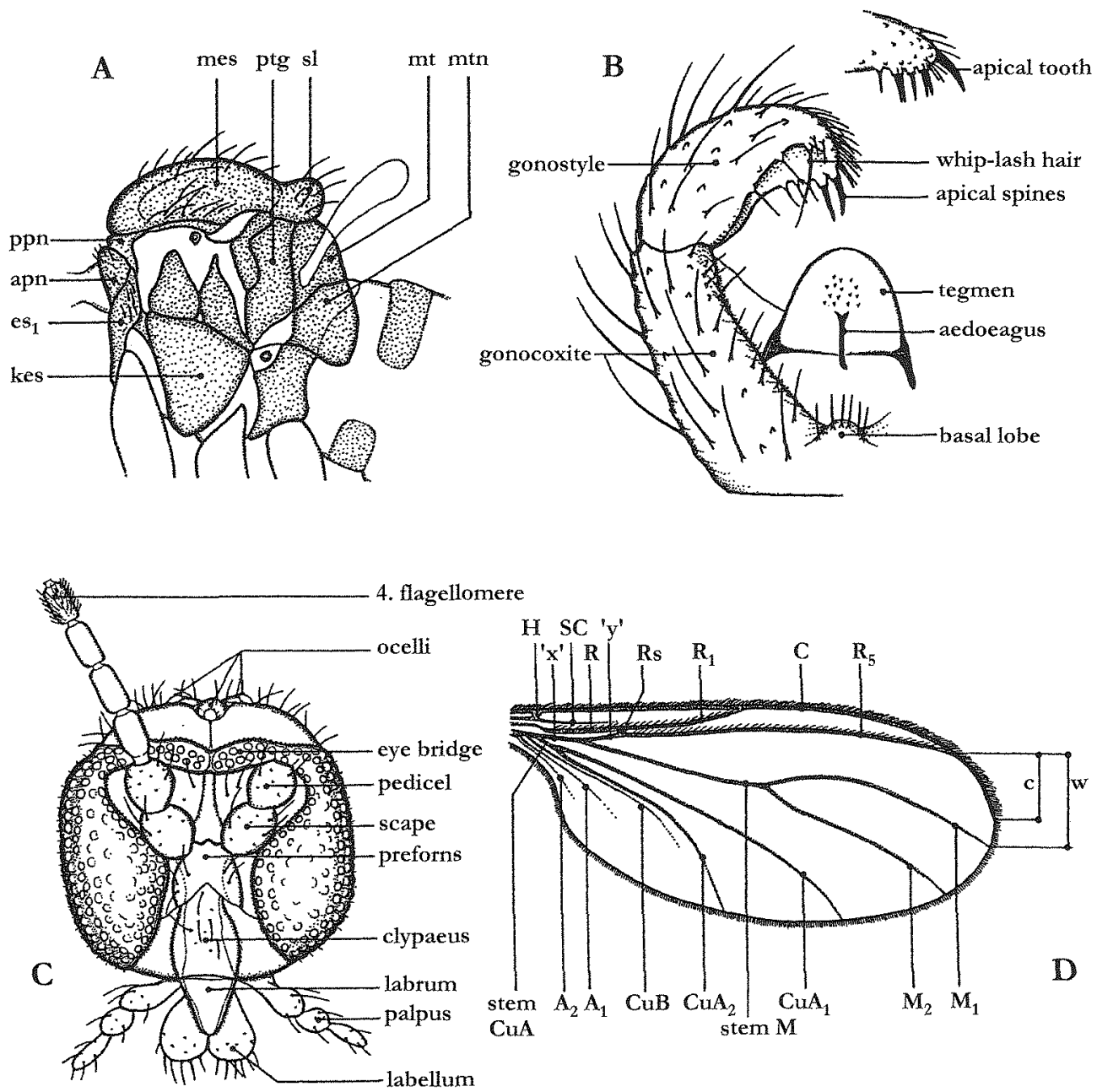

Fig. 1: Morphologic structures and abbreviations. - A. Thorax: apn - anterior pronotum; es 1 - prothorical episternum; kes - katepisternum; mes - mesonotum; $\mathrm{mt}$ - mediotergit; mtn - metanotum; ppn - posterior pronotum; ptg - pleurotergite; sl - scutellum. - B. Ventral view of male genitalia. C. Head, frontal view. D. Wing venation. 

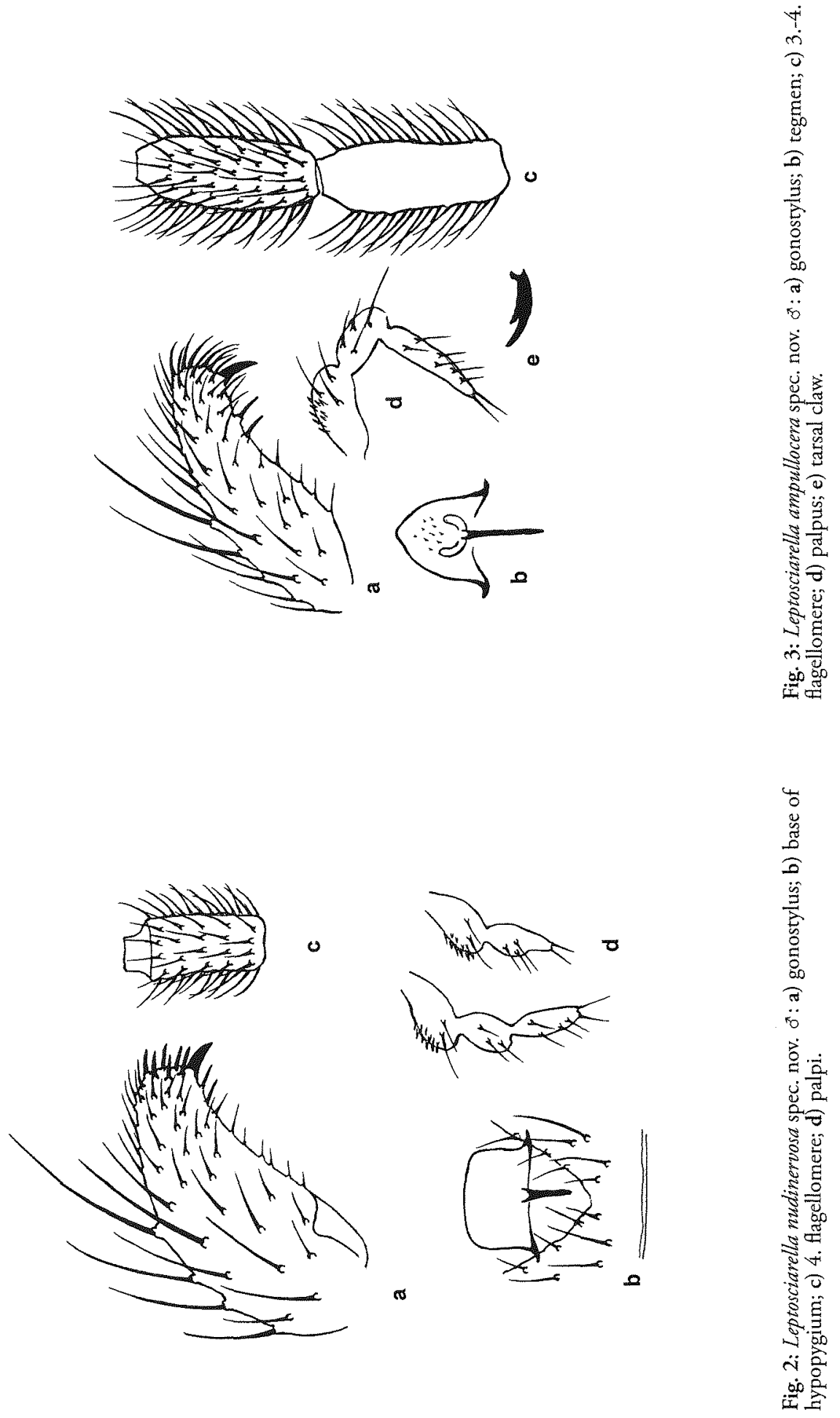

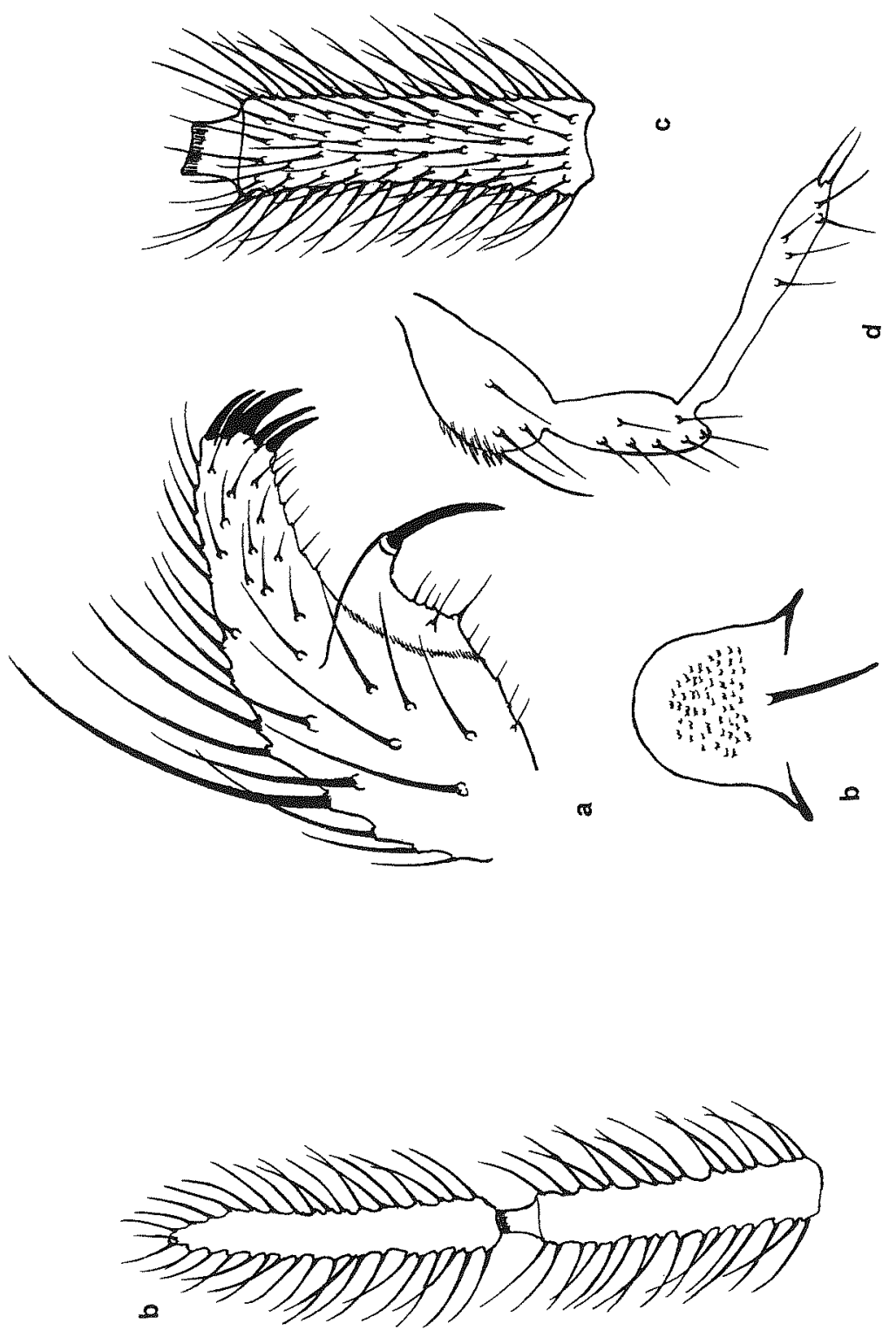

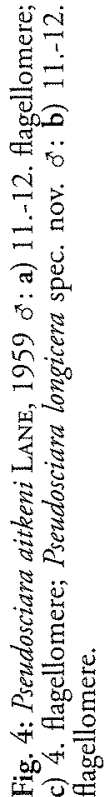



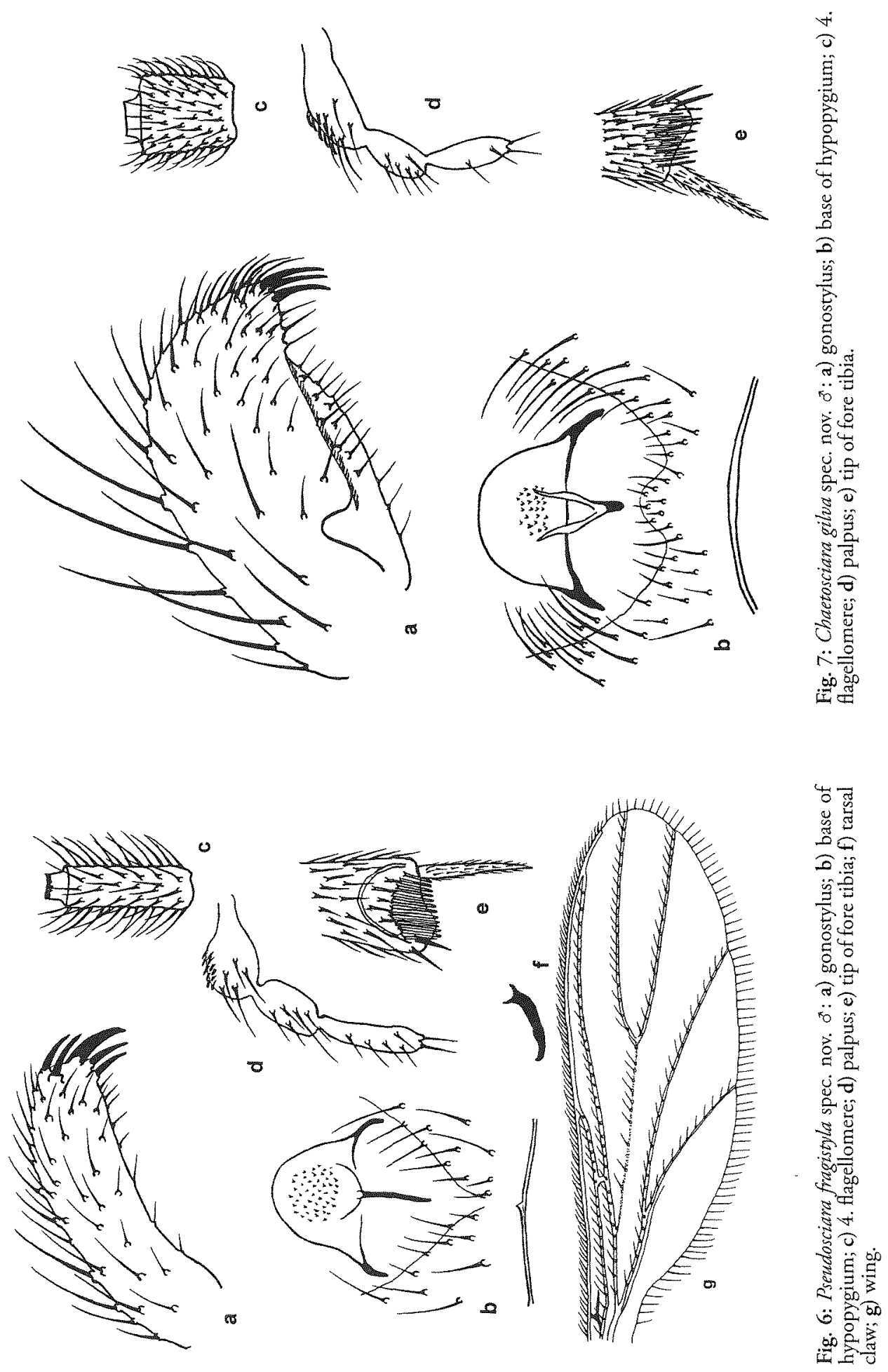

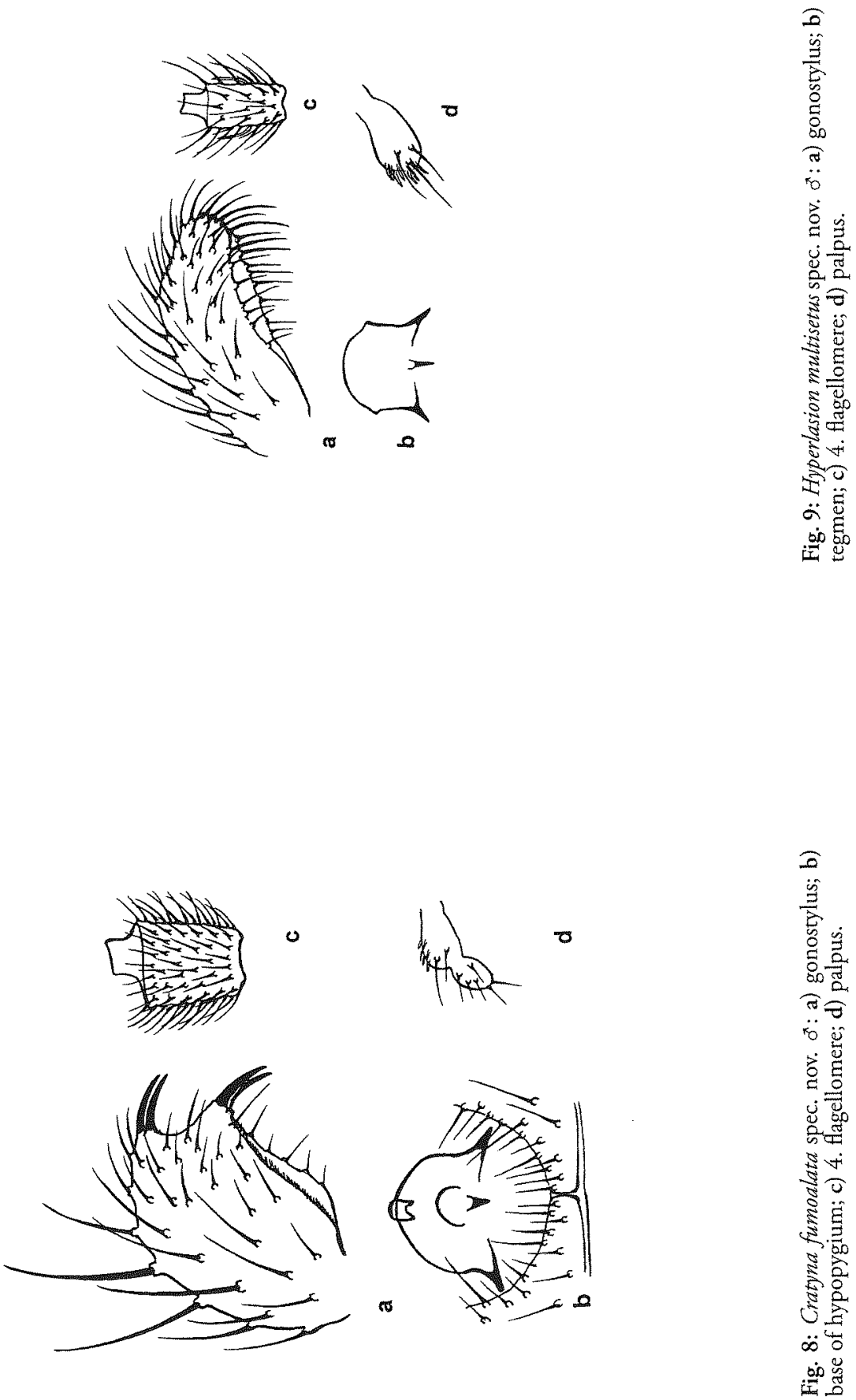

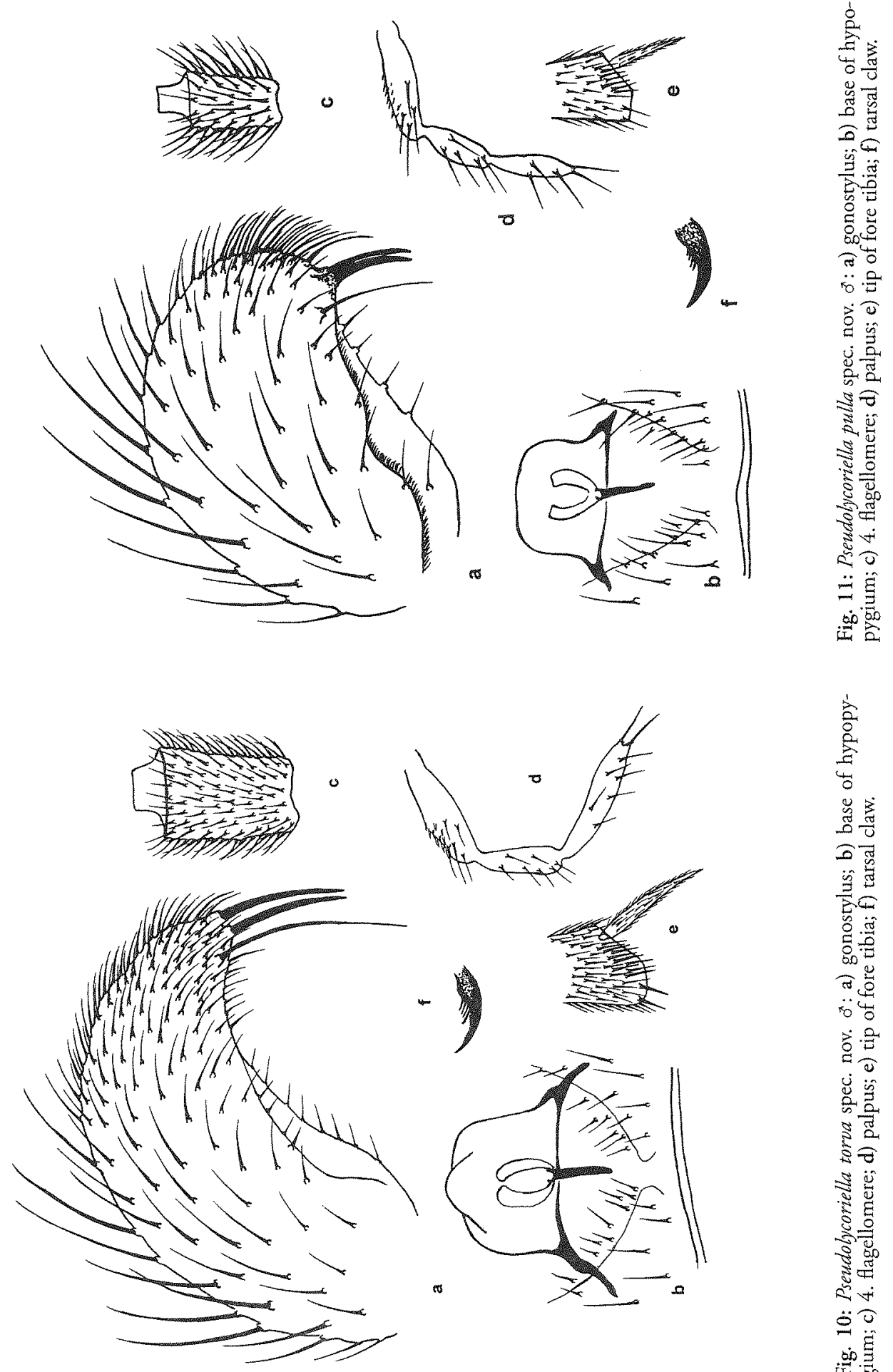

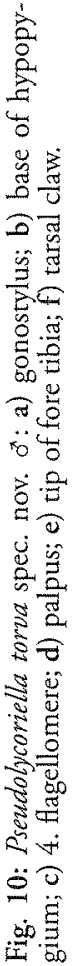



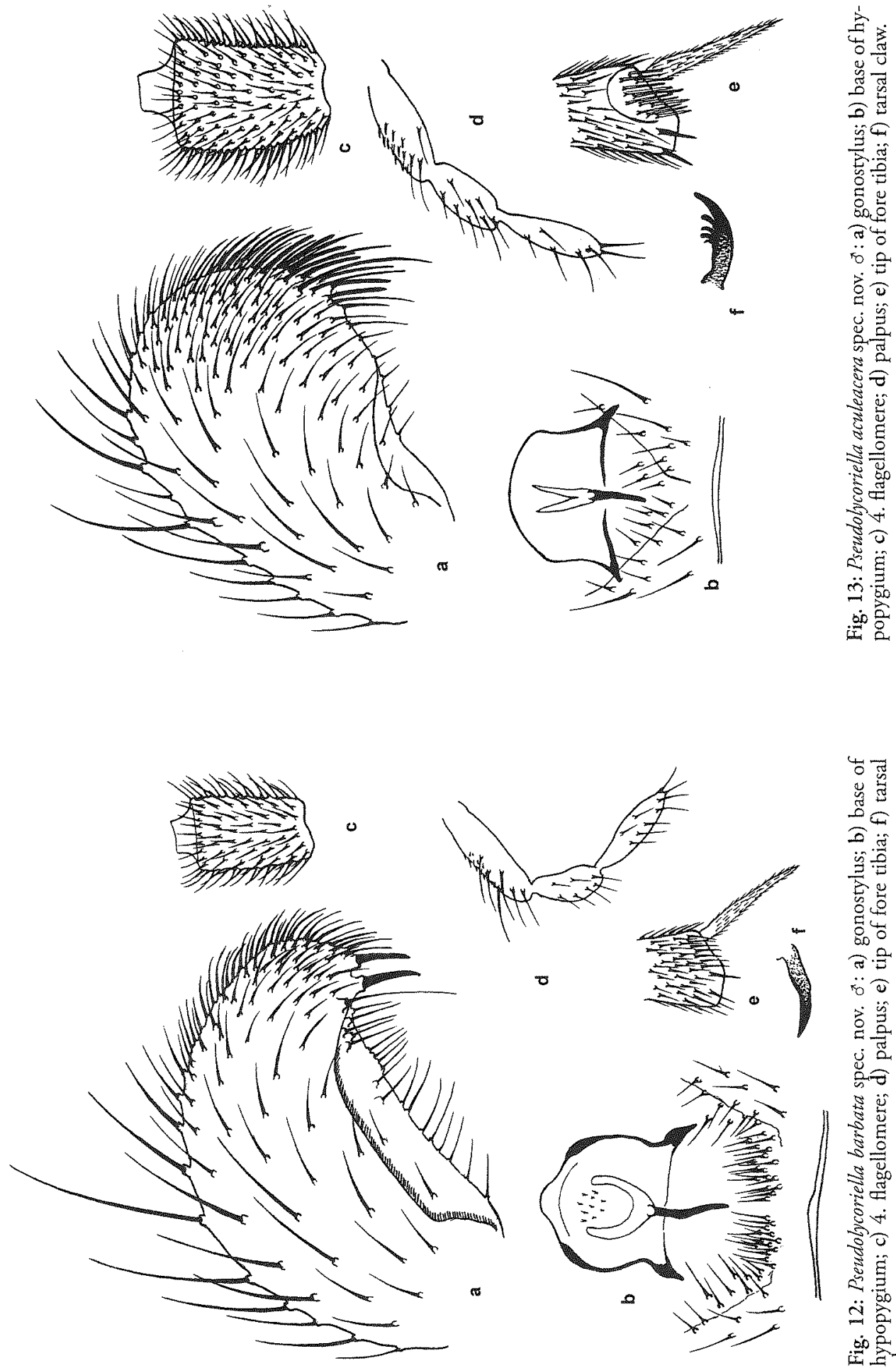

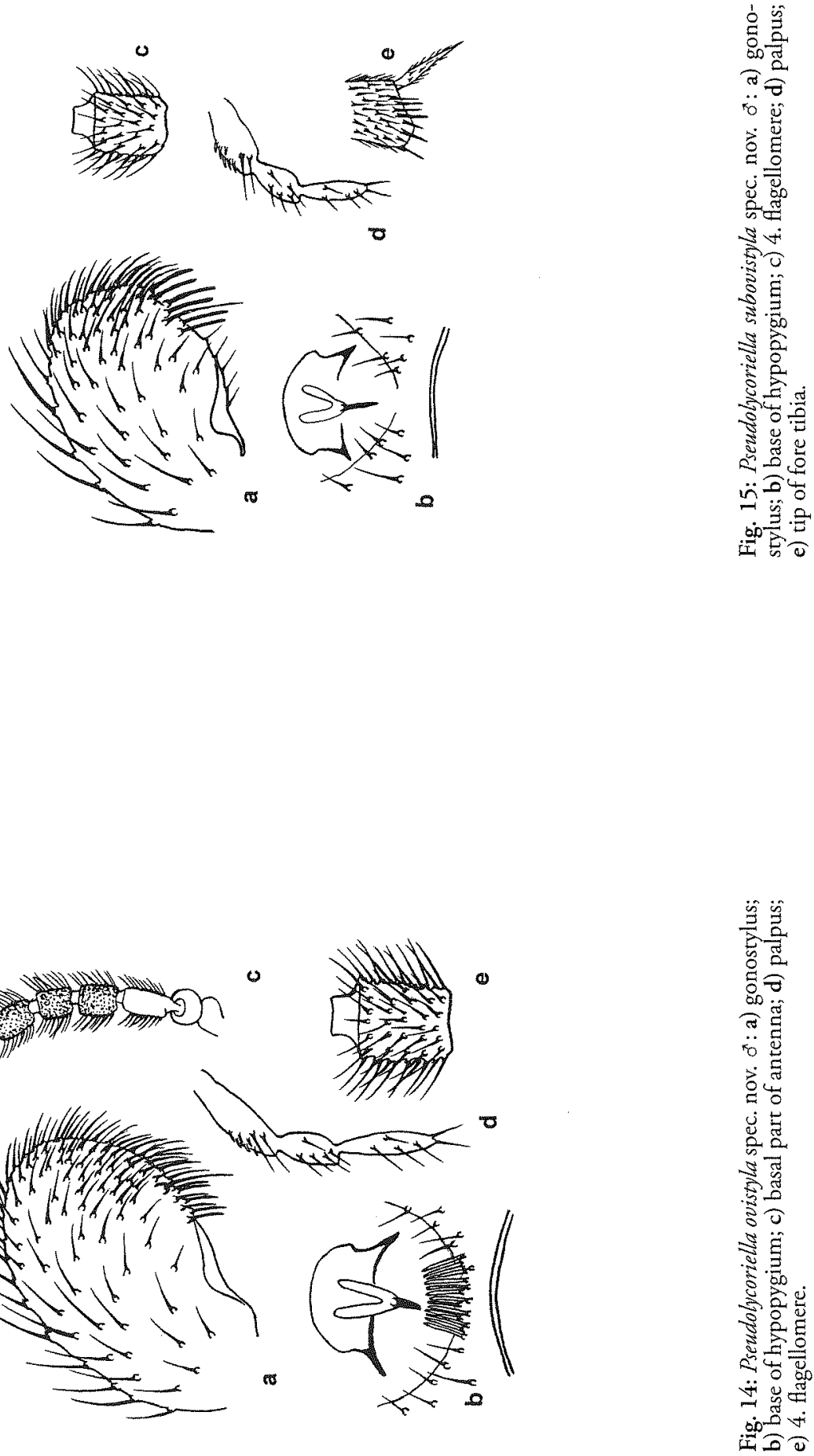

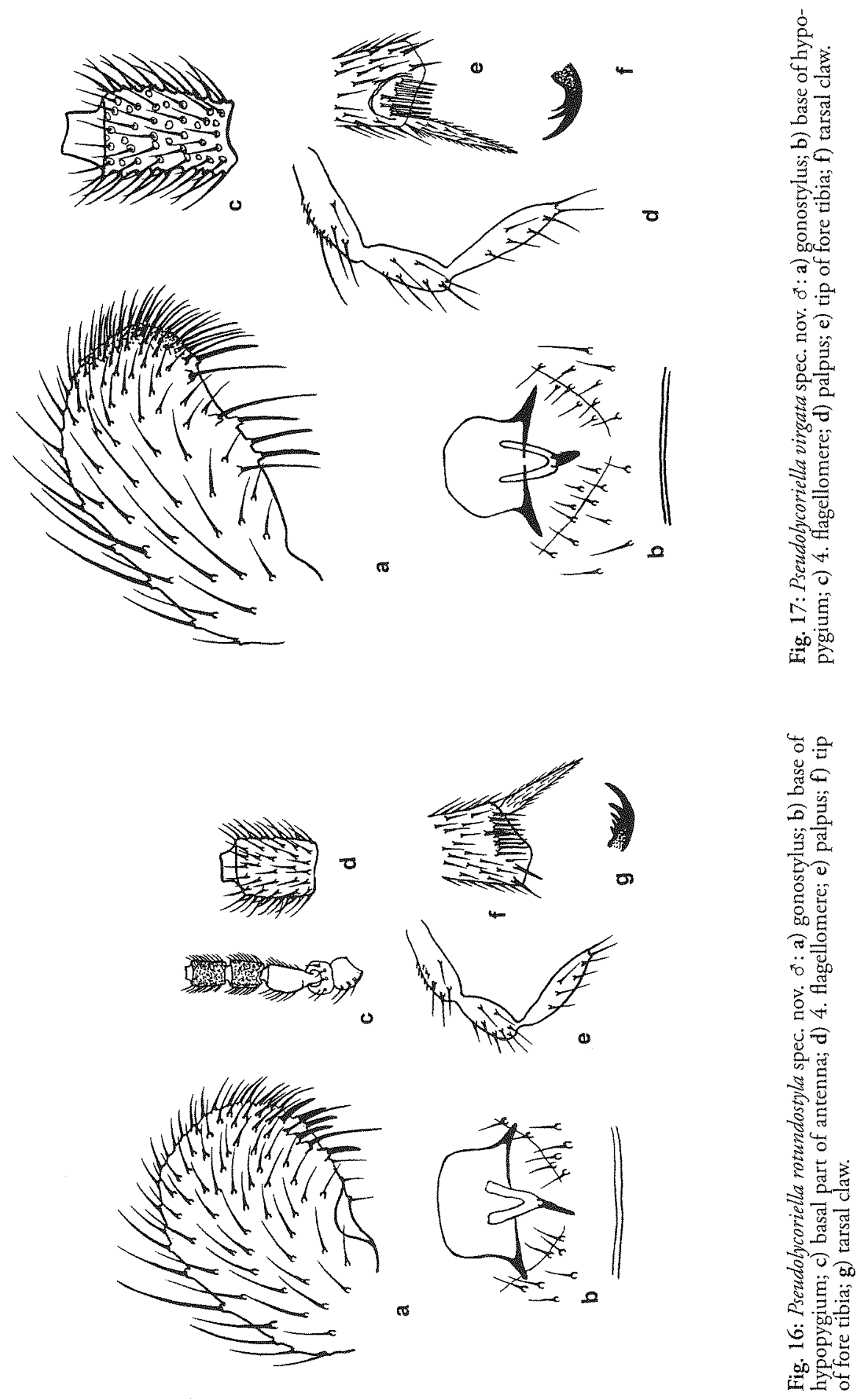

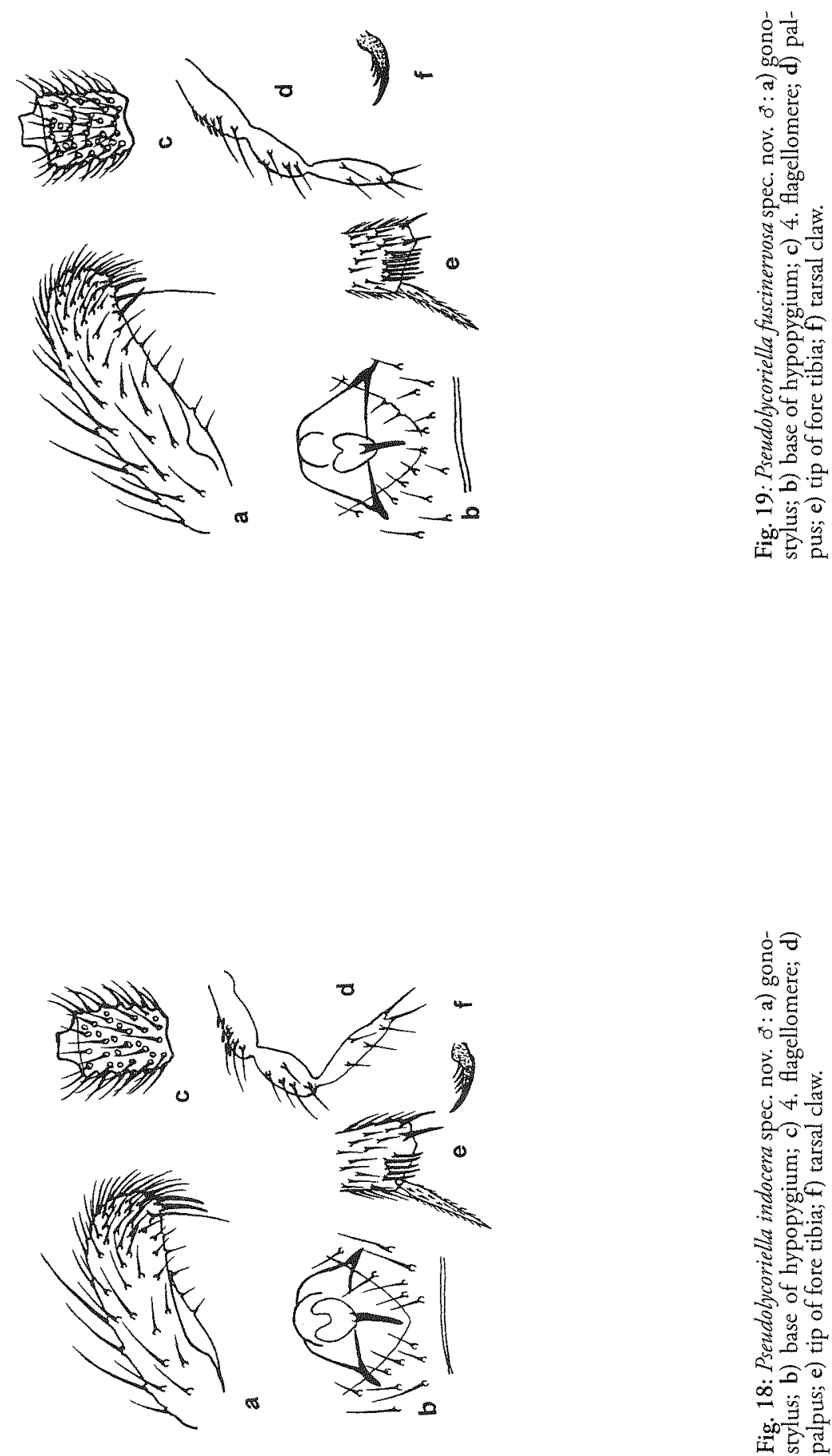

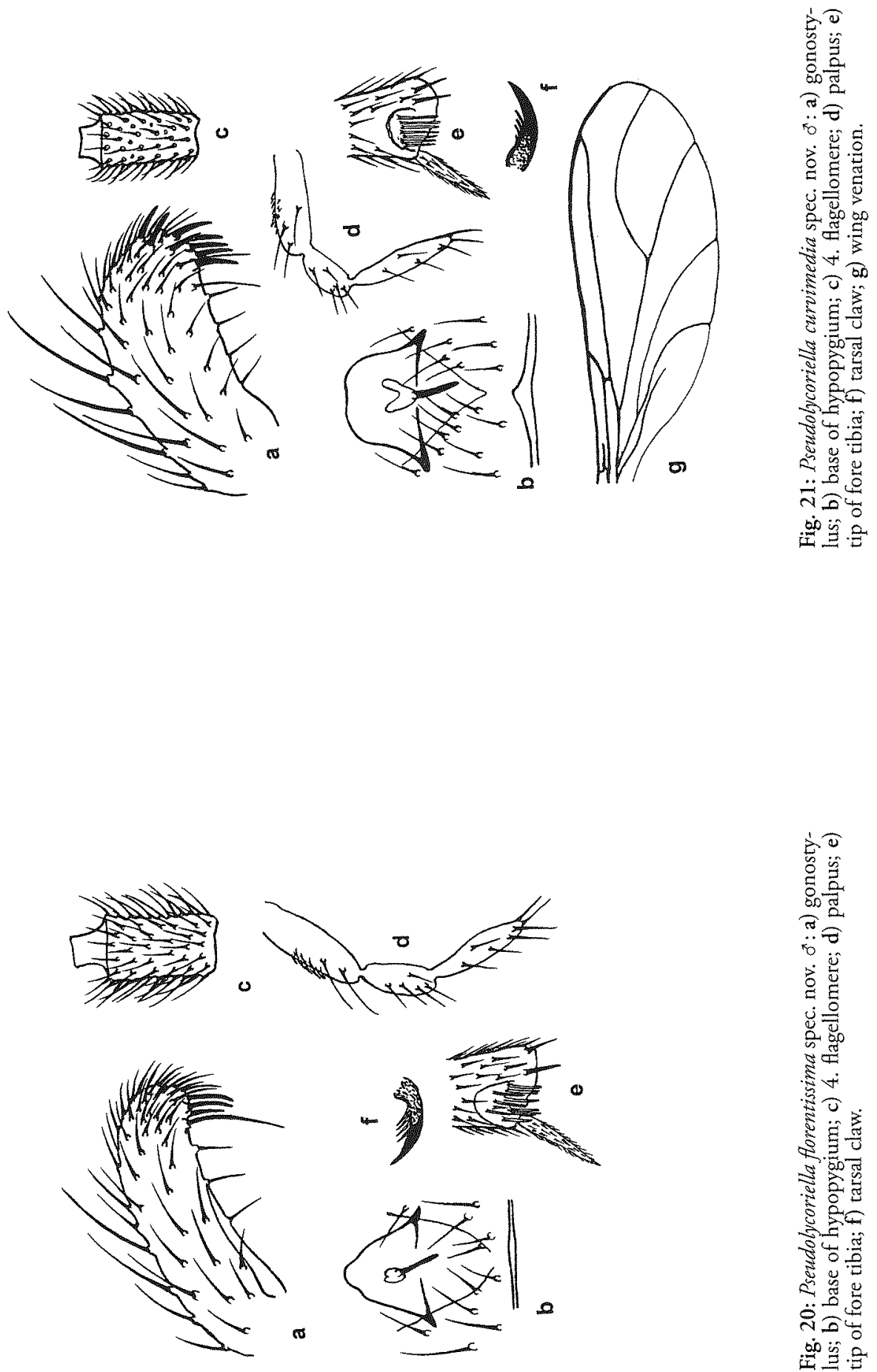

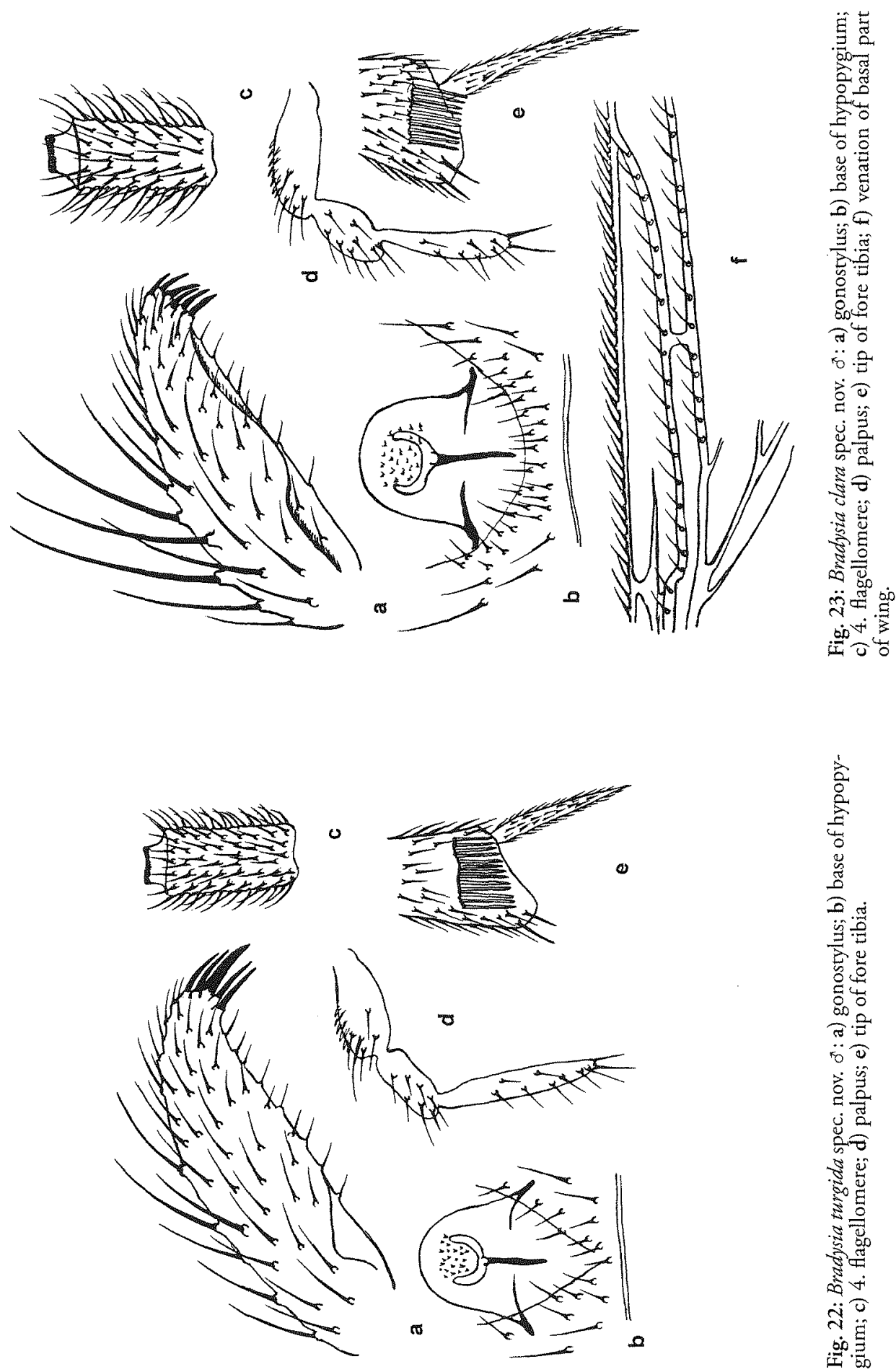

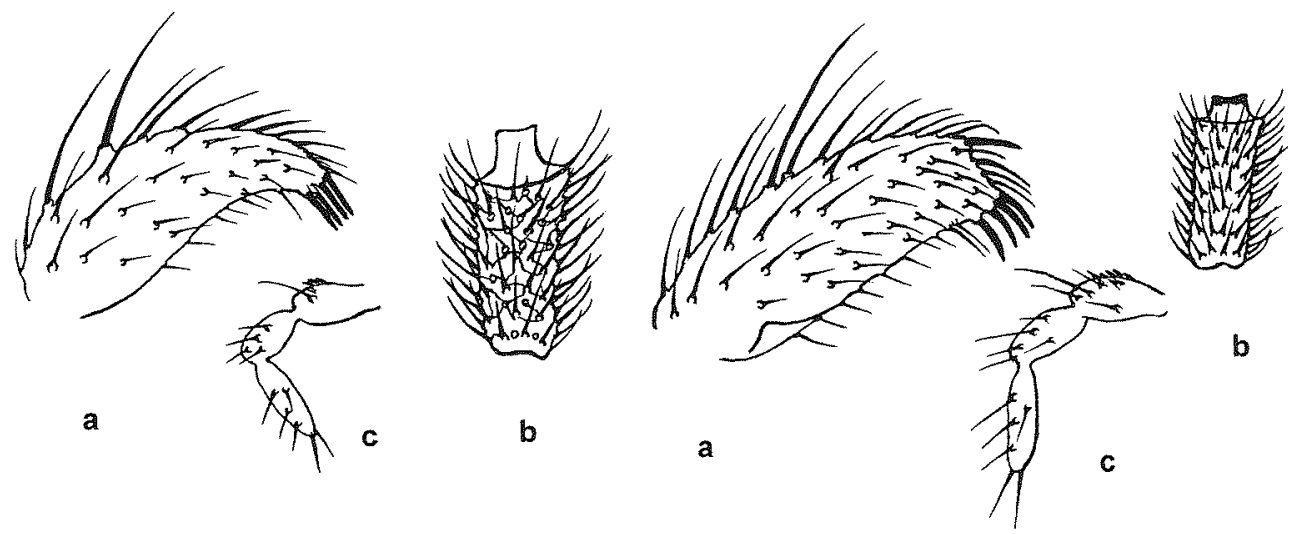

b

Fig. 24: Bradysia reticulata spec. nov. a) gonostylus; b) 4. flagellomere; c) palpus.

Fig. 25: Bradysia spinea spec. nov. ot: a) gonostylus; b) 4. flagellomere; c) palpus.
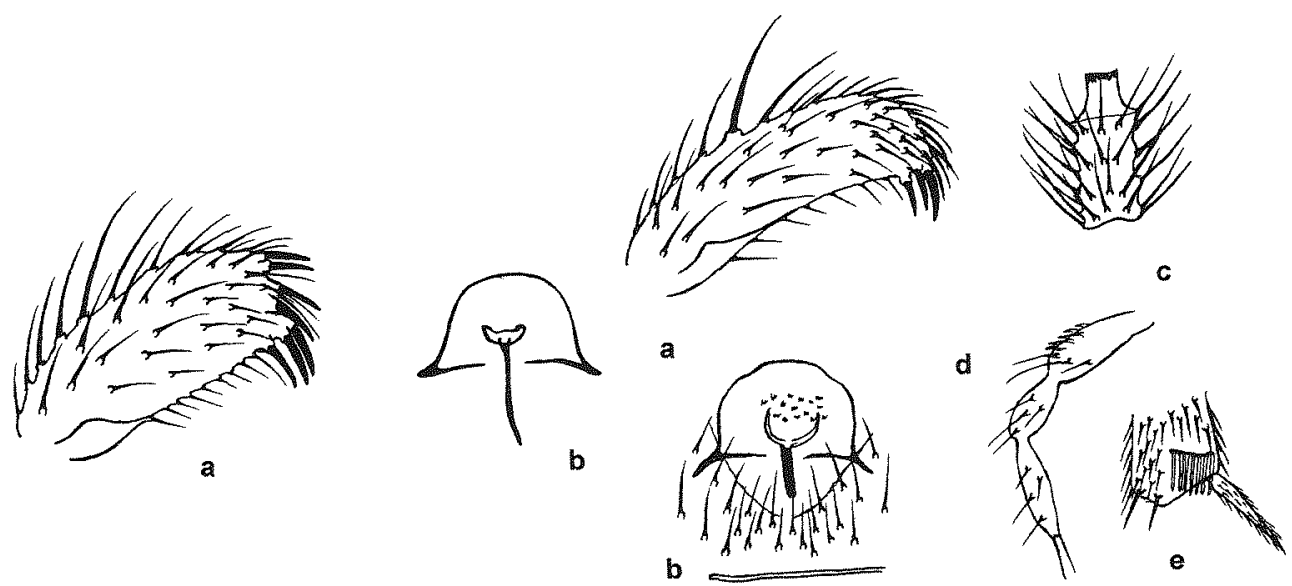

Fig. 26: Bradysia subspinea spec. nov. ot: a) gonostylus; b) tegmen.

Fig, 27: Bradysia ciliocera spec. nov. ot: a) gonostylus; b) base of hypopygium; c) 4. flagellomere; d) palpus; e) tip of fore tibia. 

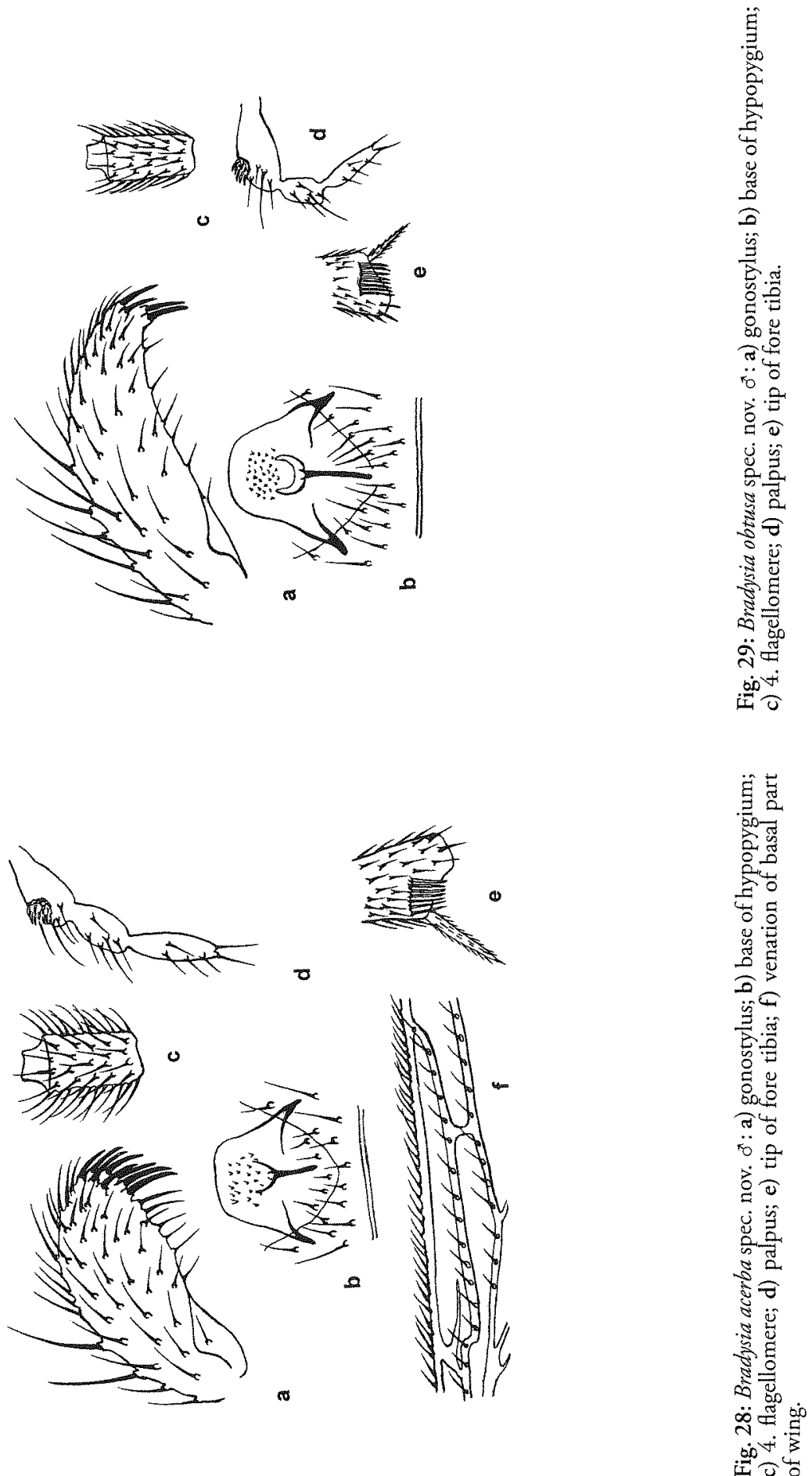

0 

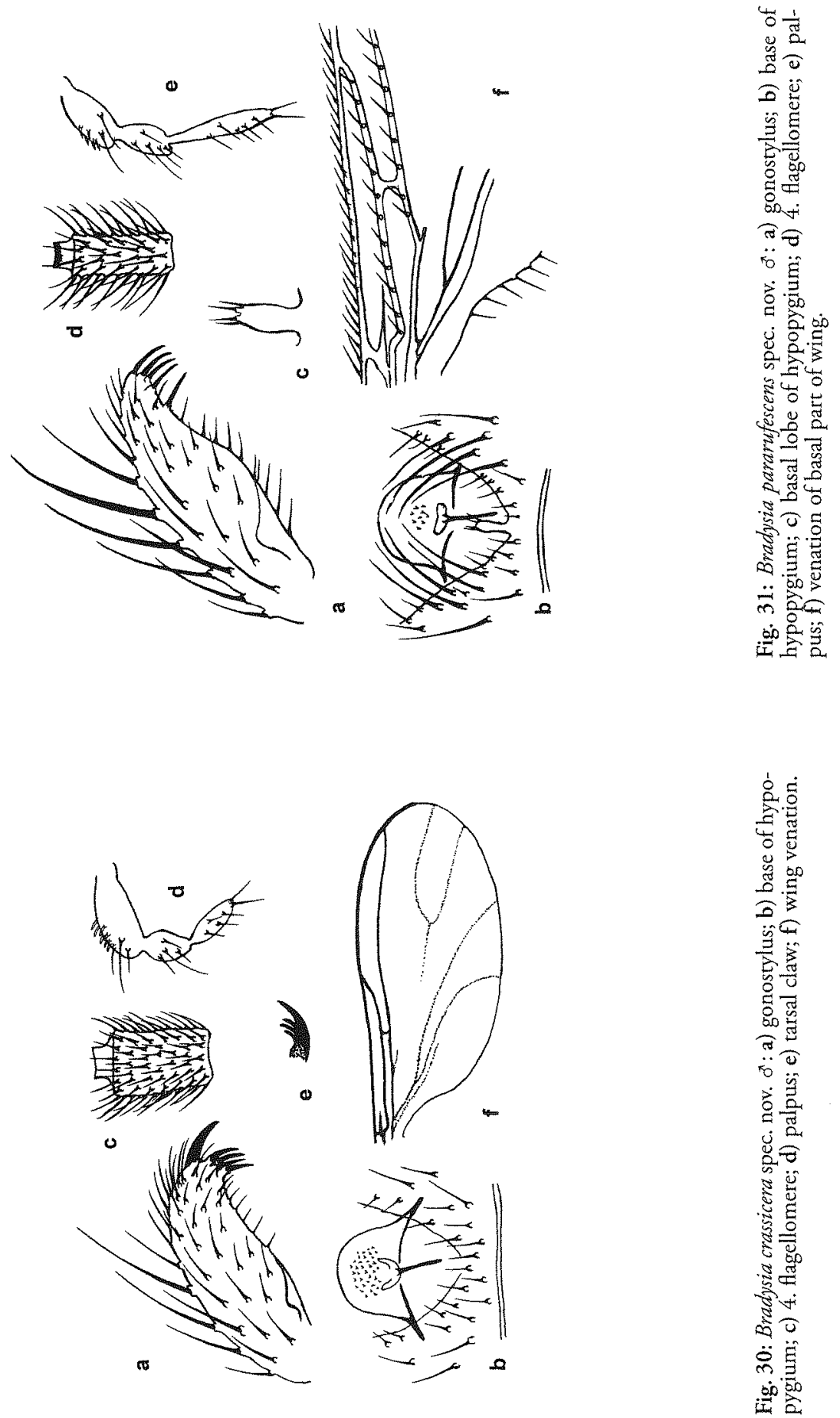

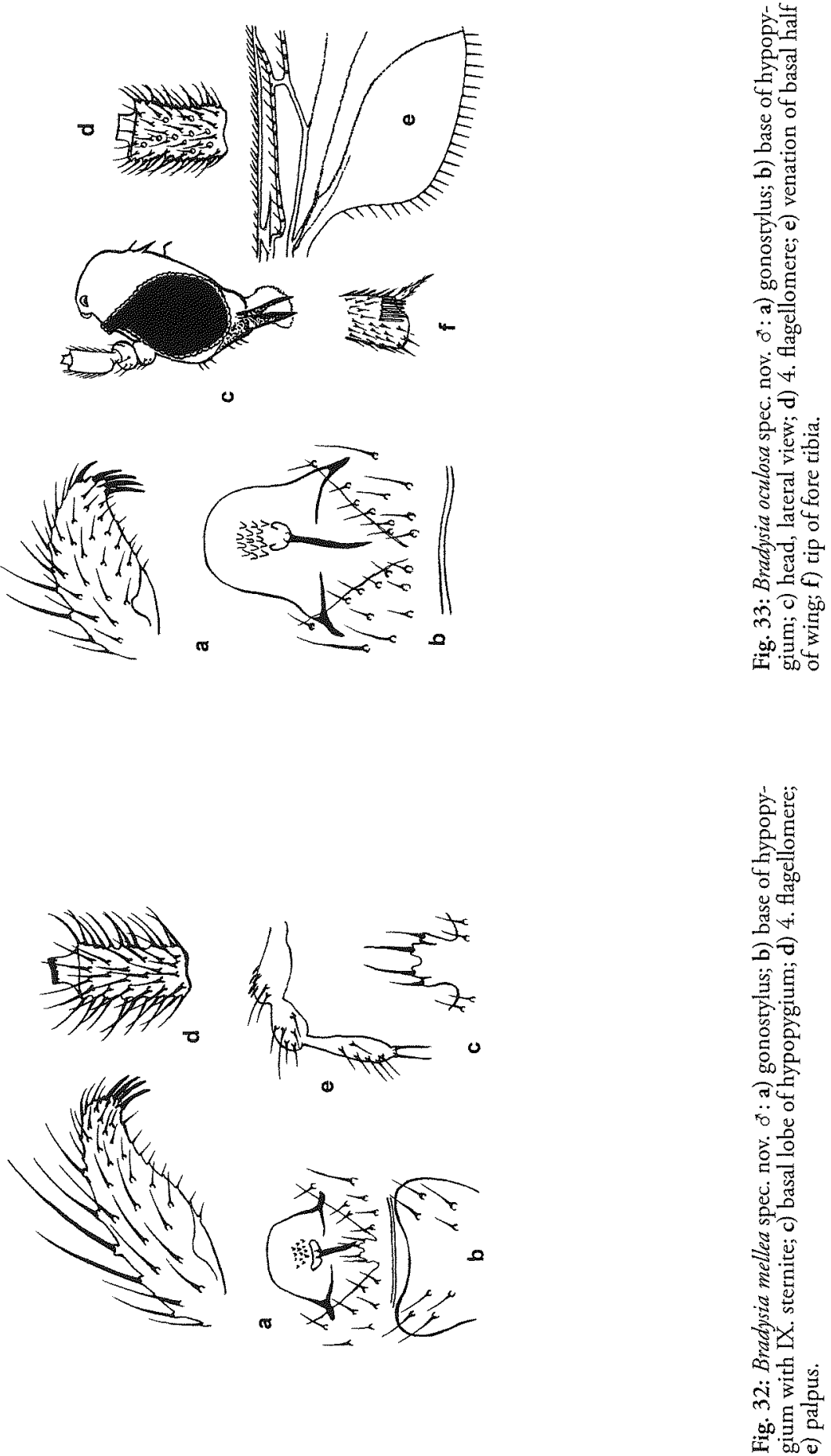

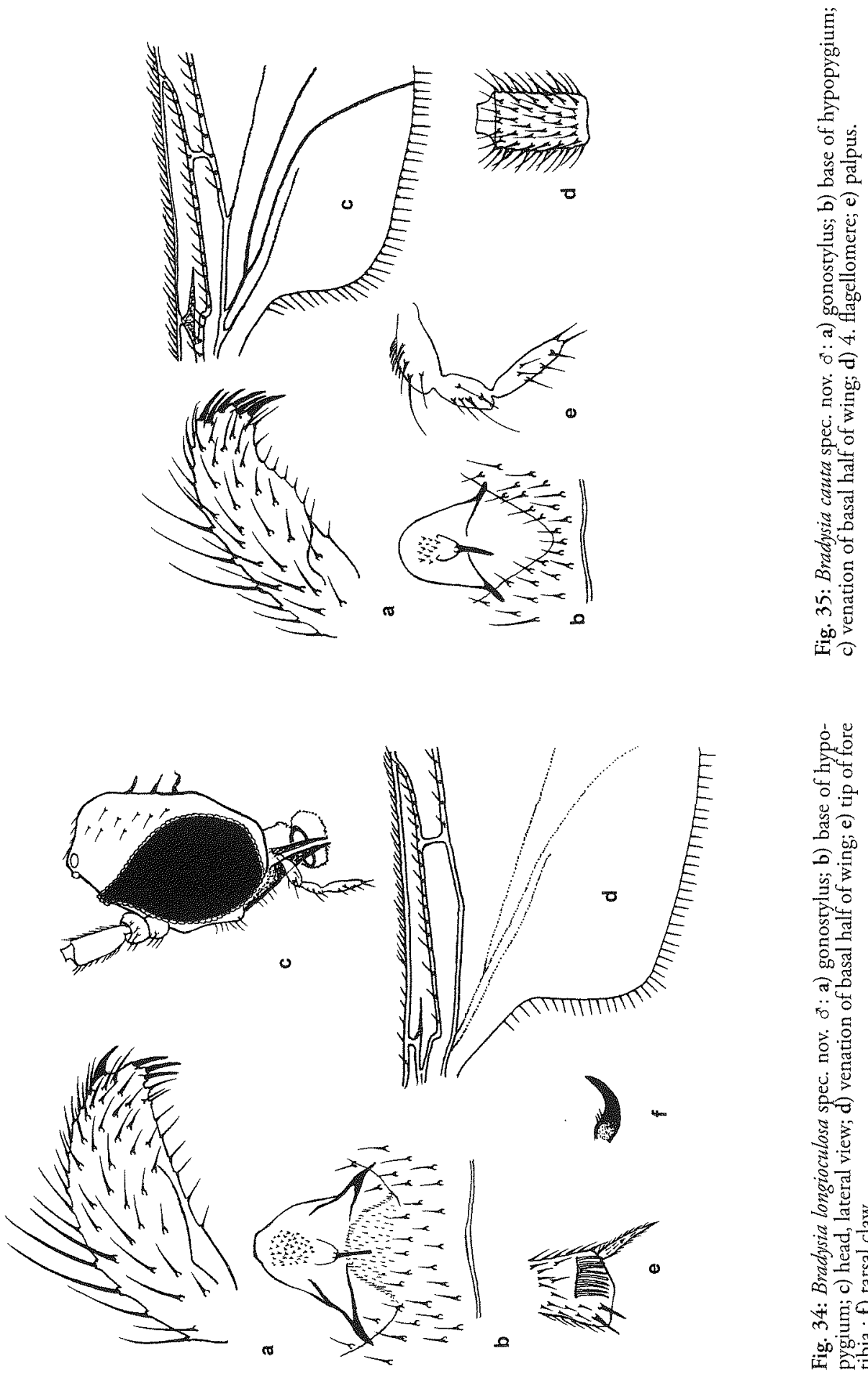

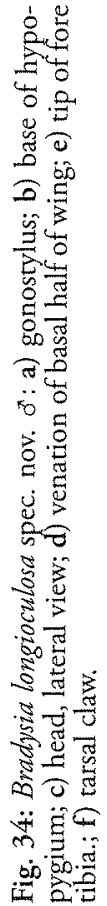

DOI: 10.21248/contrib.entomol.54.2.267-331 


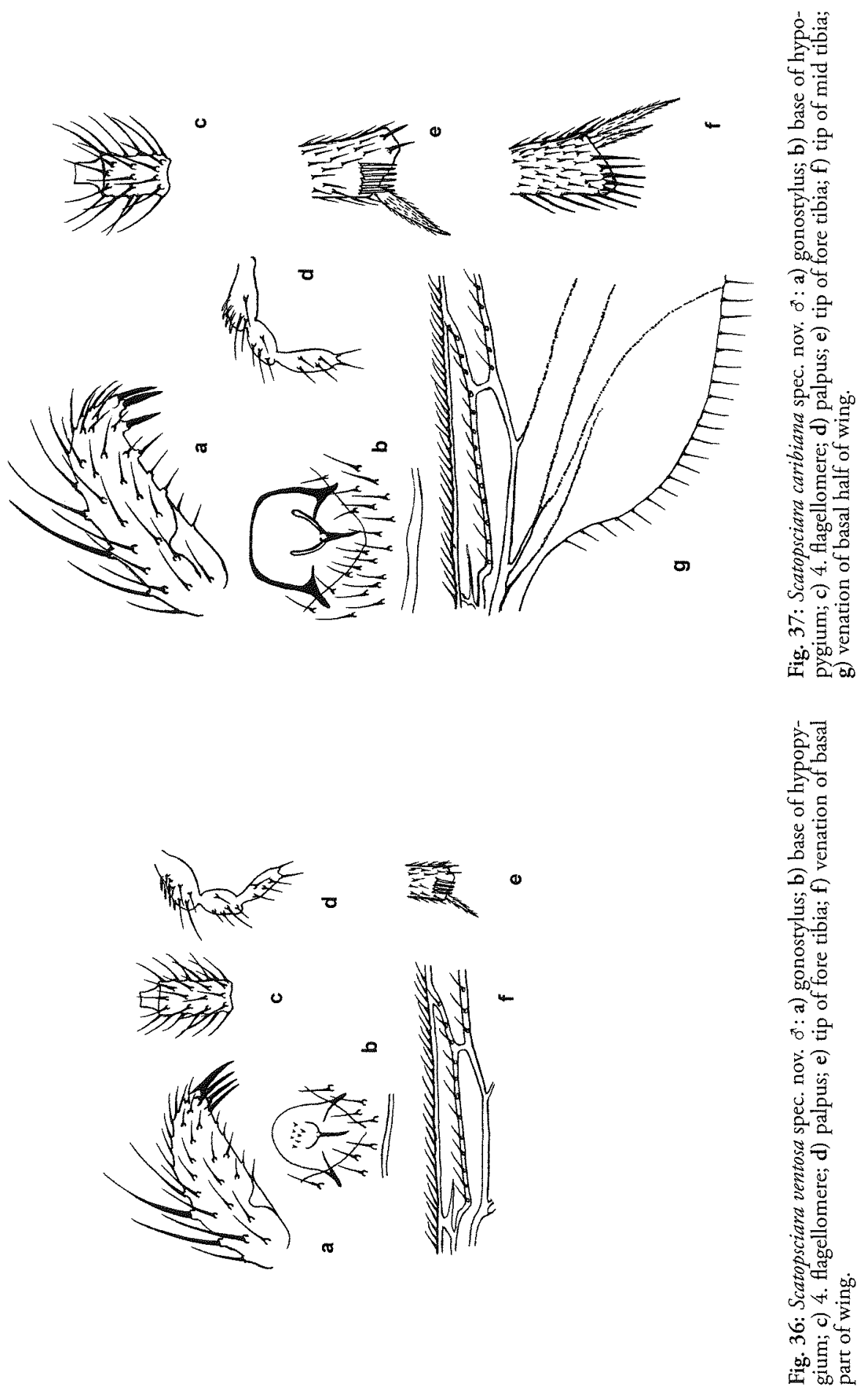



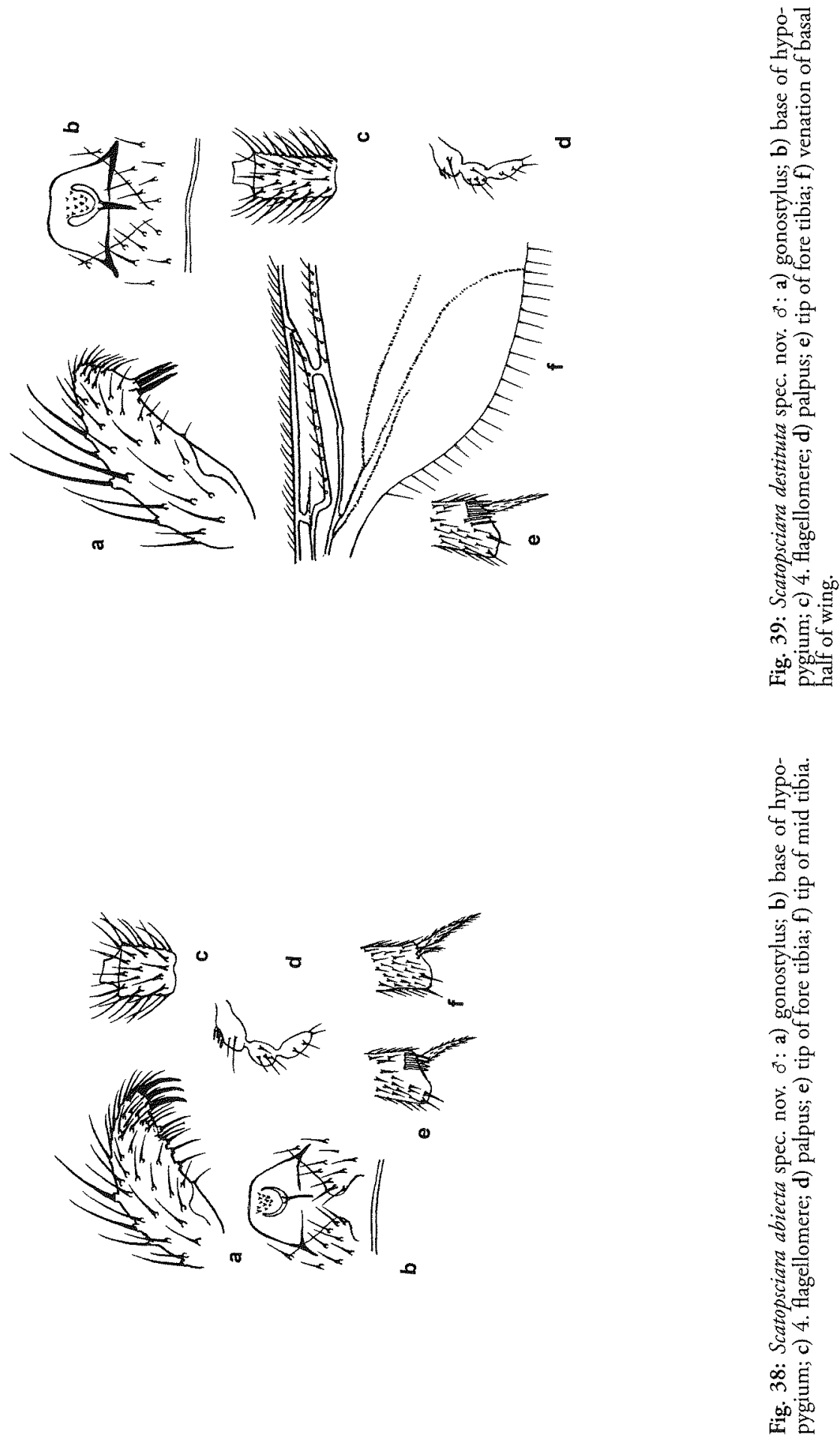

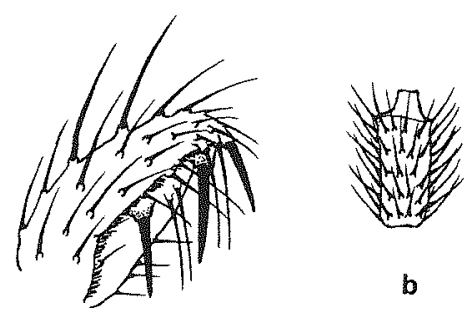

b

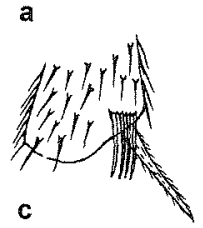

c

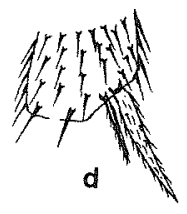

Fig. 40: Scatopsciara terribilis spec. nov. o : a) gonostylus; b) 4. flagellomere; c) tip of fore tibia; d) tip of mid tibia.
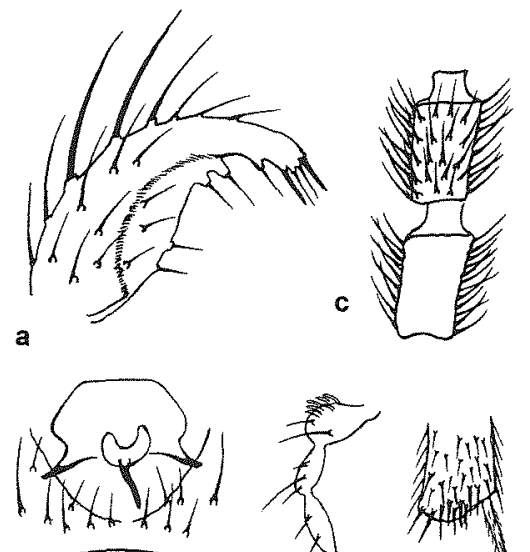

b
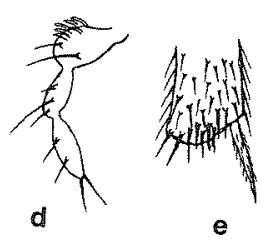

Fig. 42: Corynoptera sicca spec. nov. $\sigma^{t}$ : a) gonostylus; b) base of hypopygium; c) 3.-4. flagellomere; d) palpus; e) tip of fore tibia.
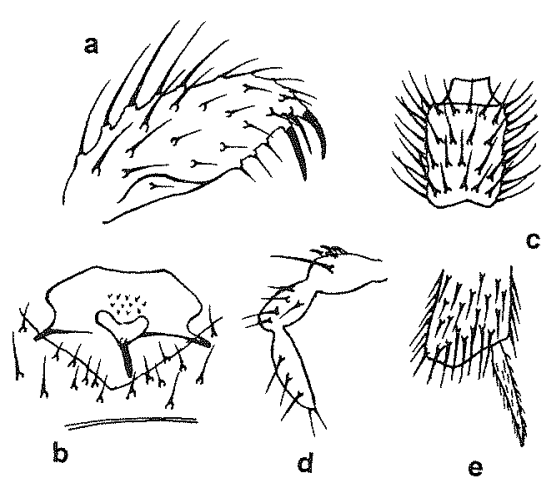

Fig. 41: Corynoptera turbata spec. nov. o: a) gonostylus; b) base of hypopygium; c) 4 . flagellomere; d) palpus; e) tip of fore tibia.
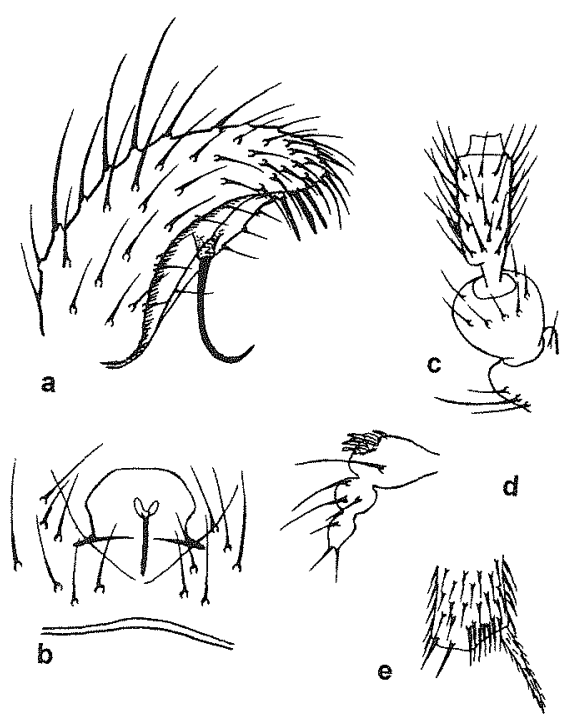

Fig. 43: Keilbachia paucipalpa spec. nov. ot: a) gonostylus; b) base of hypopygium; c) basal segments of antenna; d) palpus; e) tip of fore tibia. 
Beitr. Ent. 54 (2004) 2
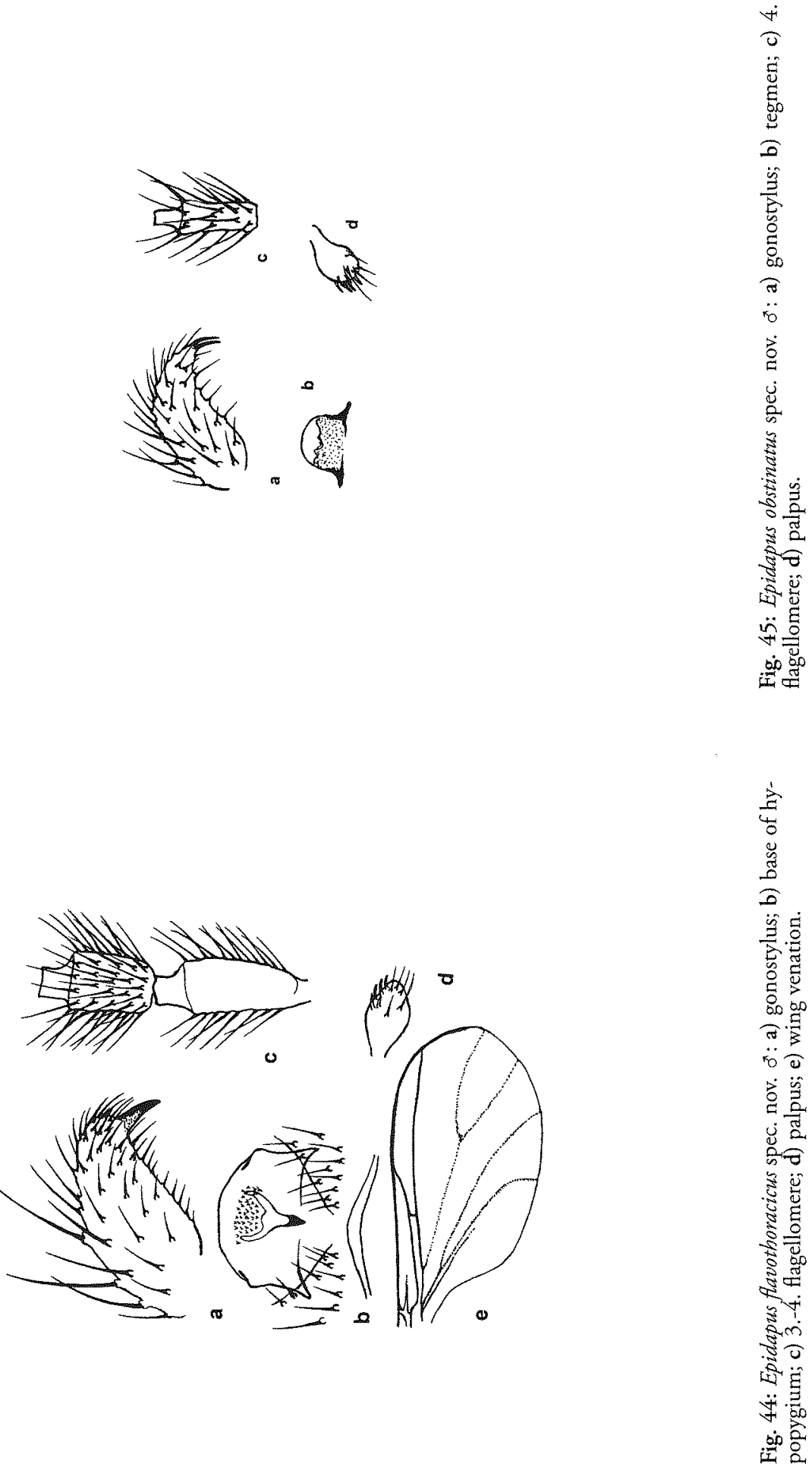